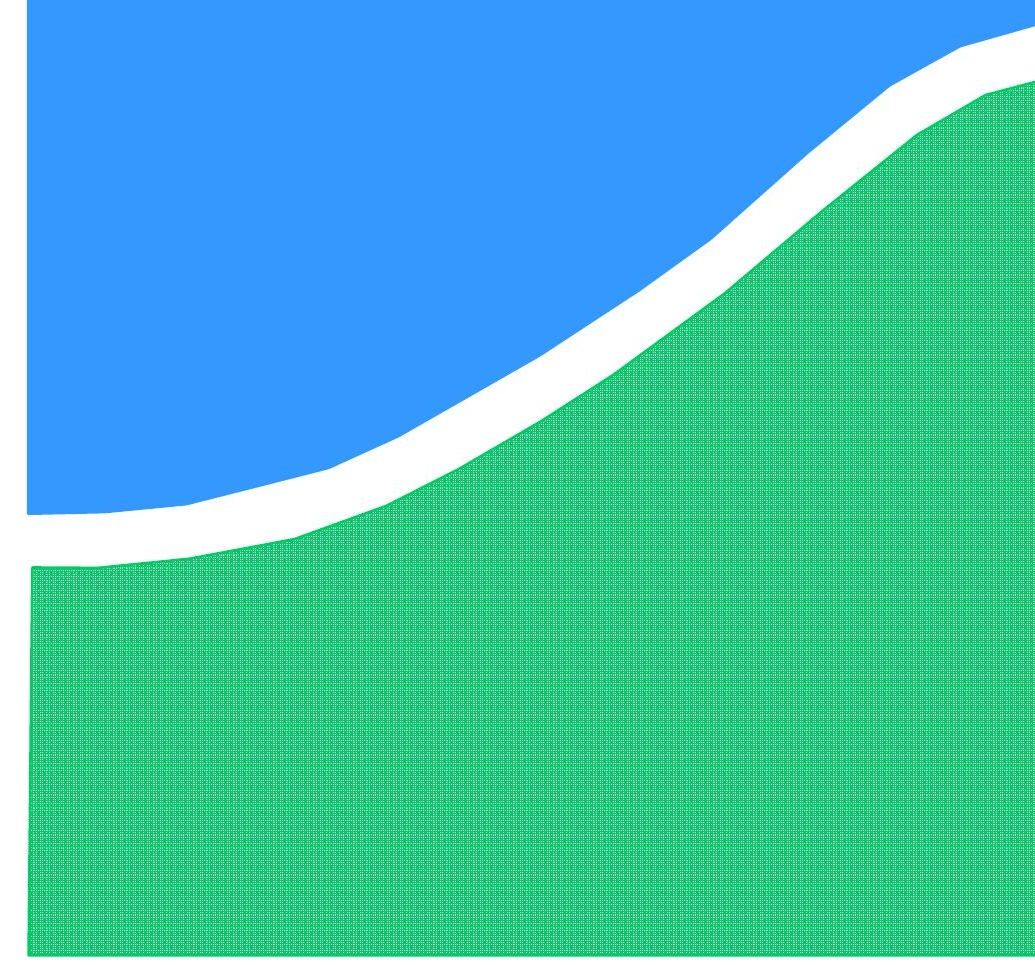

PROJETO FINAL DE GRADUAÇÃO

\title{
FERRAMENTA COMPUTACIONAL PARA ANÁLISE DE SITUAÇÕES DE DESEQUILÍBRIO DE TENSÃO
}

Carlos Eduardo Simões Martins

\section{UNIVERSIDADE DE BRASILIA}

FACULDADE DE TECNOLOGIA 


\title{
PROJETO FINAL DE GRADUAÇÃO
}

\section{FERRAMENTA COMPUTACIONAL PARA ANÁLISE DE SITUAÇÕES DE DESEQUILÍBRIO DE TENSÃO}

\author{
Carlos Eduardo Simões Martins \\ Relatório submetido como requisito parcial para obtenção \\ do grau de Engenheiro Eletricista
}

\section{Banca Examinadora}

Prof. Anésio de Leles Ferreira Filho,(ENE-UnB)

(Orientador)

Prof. Francisco Damasceno Freitas,(ENE-UnB)

(Examinador Interno)

Prof. Mauro Moura Severino,(ENE-UnB)

(Examinador Interno) 


\section{FICHA CATALOGRÁFICA}

MARTINS, CARLOS EDUARDO SIMÕES

Ferramenta Computacional para Análise de Situações de Desequilíbrio de Tensão

Publicação ENE-2/07, Departamento de Engenharia Elétrica, Universidade de Brasília, Brasília, DF, 93p.

\section{REFERÊNCIA BIBLIOGRÁFICA}

MARTINS, C. E. S.; Ferramenta Computacional par Análise das Situações de Desequilíbrio de Tensão. Trabalho de Graduação, Publicação ENE-2/07, Departamento de Engenharia Elétrica, Universidade de Brasília, Brasília, DF, 93p.

\section{CESSÃO DE DIREITOS}

AUTOR:

Carlos Eduardo Simões Martins

ORIENTADOR: Anésio de Leles Ferreira Filho

TÍTULO: Ferramenta Computacional para Análise das Situações de Desequilíbrio de Tensão.

ANO: 2007

É concedida à Universidade de Brasília permissão para reproduzir cópias deste trabalho de graduação e para emprestar ou vender tais cópias somente para propósitos acadêmicos e científicos. O autor reserva outros direitos de publicação e nenhuma parte deste projeto de graduação pode ser reproduzida sem autorização por escrito do autor. 


\section{Dedicatória}

Dedico esse trabalho à minha famíla, que me possibilitou alcançar essa conquista.

Carlos Eduardo Simões Martins 


\section{Agradecimentos}

Agradeço a Deus, por me conceder a capacitacão necessária para a realizacão desse trabalho.

À minha mãe Helenilza (in memorian), pelos ensinamentos, por todo amor dedicado à família e pelas saudades de ótimas recordações.

Ao meu pai, por sua competência, atenção, sabedoria e por todo seu esforço e apoio fornecido durante minha trajetória.

Aos amigos Marcos Garcia e Thompson Rolim pela ajuda e compreensão dedicada durante a elaboração desse projeto.

Ao Professor Anésio, por sua excelente orientação no desenvolvimento desse trabalho.

Agradeço á Eletornorte, pelo apoio oferecido.

Agradeço aos funcionários da UnB, pelo suporte fornecido a vencer este desafio.

Carlos Eduardo Simões Martins 


\section{RESUMO}

\section{FERRAMENTA COMPUTACIONAL PARA ANÁLISE DE SITUAÇÕES DE DESEQUILÍBRIO DE TENSÃO}

Autor:

Carlos Eduardo Simões Martins

Orientador: Anésio de Leles Ferreira Filho

Brasília, dezembro de 2007

Este trabalho aborda uma ferramenta computacional acerca de um dos fenômenos que causam a perda da qualidade de energia elétrica: o desequilíbrio de tensão. Para tanto, foi considerada uma relação de condições de desequilíbrio que, a partir de suas possíveis combinações, compõem diferentes situações que podem se encontrar os fasores de tensão, quando estes estão desequilibrados.

Todos os procedimentos e funcionalidades da ferramenta são minuciosamente descritos. Seu desenvolvimento deu-se a partir do Matlab 6.5, que forenece um ambiente de programação simples e compreensível, além de possuir numerosas funções previamente definidas. Em seguida, a ferramenta foi conduzida à análise de oito pontos do sistema ELETRONORTE, a partir de medições coletadas com o aparelho ION 8500, durante o período de seis semanas, com o objetivo de qualificar as situações de desequilíbrio apresentadas nestes pontos.

A metodologia empregada consistiu na análise do banco de dados de cada local para obtenção de informações gráficas e estatísticas a partir dos dados colhidos. Foram realizadas avaliações quantitativas, de distribuição no tempo e da similaridade para as tensões de seqüência positiva, negativa e zero, para a quantificação do fator de desequilíbrio e para análise de fasores. Com isso, efetuou-se a comparação dos valores obtidos com as situações de desequilíbrio em análise.

A importância deste projeto consiste na efetivação da primeira etapa de um estudo sobre os efeitos em motores de indução quando submetidos a um suprimento desequilibrado. 


\section{S UMÁR IO}

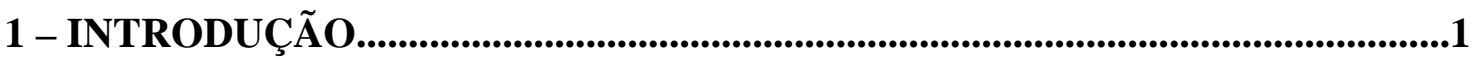

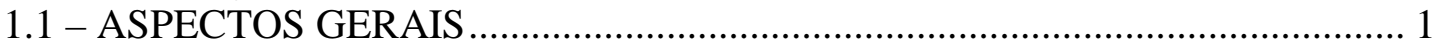

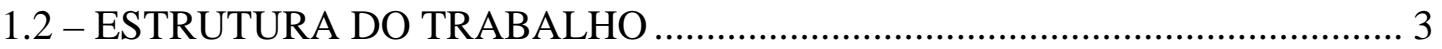

2 - DESEQUILÍBRIO DE TENSÃO..................................................................4

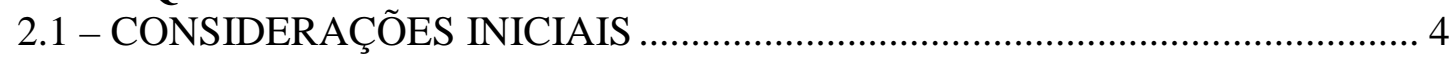

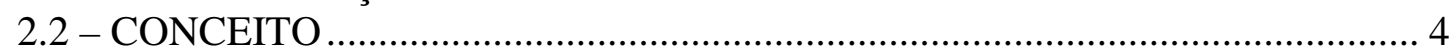

2.3 - MÉTODOS DE CÁLCULO DO DESEQUILÍBRIO DE TENSÃO …………..... 5

2.4 - CAUSAS DOS DESEQUILÍBRIOS DE TENSÃO........................................... 8

2.5 - EFEITOS DOS DESEQUILÍBRIOS DE TENSÃO EM MOTORES DE

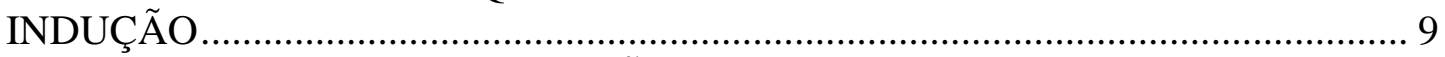

2.6 - NORMAS E RECOMENDAÇÕES …………………............................... 11

3 - DESCRIÇÃO DA FERRAMENTA COMPUTACIONAL PARA ANÁLISE

DAS SITUAÇÕES DE DESEQUILÍBRIO.................................................................. 14

3.1 - CONSIDERAÇÕES INICIAS …………………………………………..... 14

3.2 - CLASSIFICAÇÃO DO DESEQUILÍBRIO................................................... 14

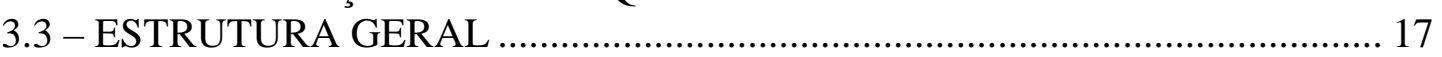

3.4 - PROCEDIMENTOS E MÓDULOS DA FERRAMENTA COMPUTACIONAL

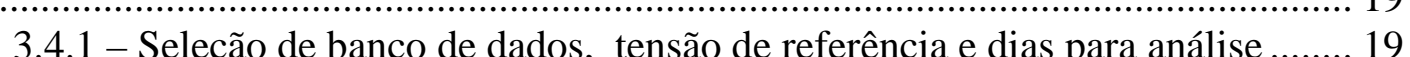

3.4.2 - Apresentação das situações de desequilíbrio presentes ............................... 20

3.4.3 - Análise de uma Situação de Desequilíbrio .................................................. 21

3.4.4 - Análise de Distribuição no Tempo ......................................................... 23

3.4.5 - Análise de Similaridade entre Situações ................................................. 25

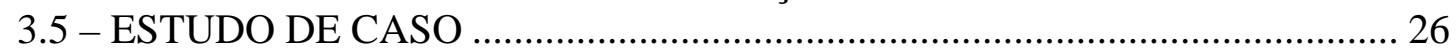

3.5.1 - Ocorrências das Situações de Desequilíbrio............................................... 27

3.5.2 - Análise dos métodos de cálculo de K\% ................................................... 28

3.5.2.1 - Quantificação do desequilíbrio abrangendo todas situações presentes 30

3.5.3 - Análise das Componentes Simétricas ........................................................ 31

3.5.4 - Análise de Distribuição no Tempo .......................................................... 35

3.5.4.1 - Análise utilizando a média quadrática como limite superior .............. 37

3.5.4.2 - Análise utilizando P95\% como limite superior ................................... 40

3.5.4.3 - Análise utilizando P99\% como limite superior .................................. 43

3.5.5 - Análise de Distribuição de Probabilidade e Distribuição Acumulativa .... 45

3.5.6 - Análise de Similaridades entre Situações de Desequilíbrio ....................... 46

3.5.6.1 - Análise das Componentes Simétricas................................................. 47

3.5.6.2 - Análise do fator K de desequilíbrio ................................................ 50

3.5.6.3 - Análise dos Fasores ......................................................................... 51

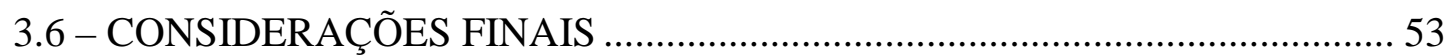

4 - ANÁLISE ESTATÍSTICA DAS SITUAÇÕES DE DESEQUILÍBRIO DE TENSÃO PRESENTES NO SISTEMA ELÉTRICO BRASILEIRO........................54

4.1 - CONSIDERAÇÕES INICIAIS ………………………………………...... 54

4.2 - APRESENTAÇÃO DOS LOCAIS EM ESTUDO …………………………... 54

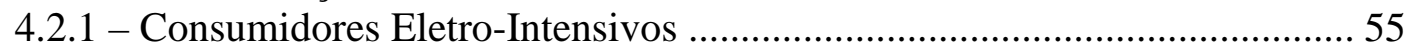

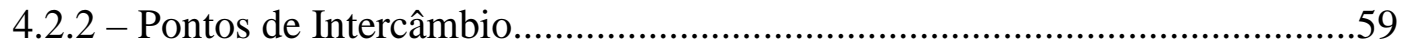

4.3 - IDENTIFICAÇÃO DOS NÍVEIS DE DESEQUILÍBRIO ............................... 60 
4.4 - DISTRIBUIÇÃO DE PROBABILIDADE DE OCORRÊNCIAS DAS

SITUAÇÕES DE DESEQUILÍBRIO

4.5 - AVALIAÇÃO DOS NÍVEIS DE DESEQUILÍBRIO DAS SITUAÇÕES DE DESEQUILÍBRIO

4.6 - AVALIAÇÃO DA DISTRIBUIÇÃO NO TEMPO DAS OCORRÊNCIAS DE

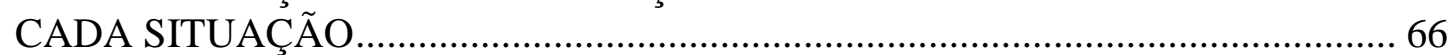

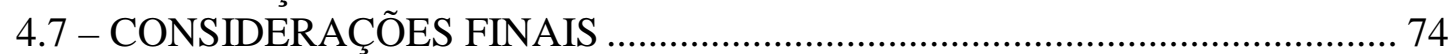

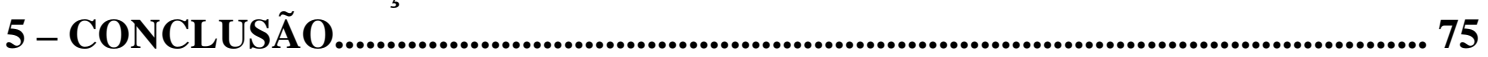

REFERÊNCIAS BIBLIOGRÁFICAS.................................................................... 78

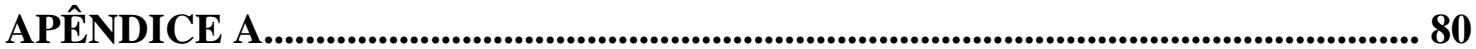

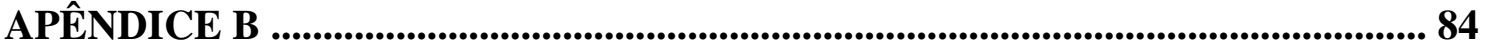




\section{LISTA DE FIGURAS}

Figura 2.1 - Desequilíbrio de Tensão

Figura 2.2 - Diagrama fasorial das componentes simétricas (ALMEIDA \& FREITAS, 1995).

Figura 3.1 - Estrutura geral da ferramenta computacional ........................................ 18

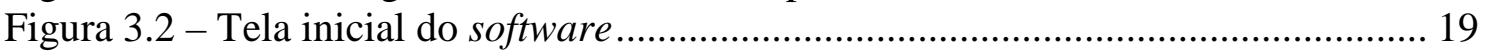

Figura 3.3 - Apresentação das situações de desequilíbrio ............................................ 20

Figura 3.4 - Análise de uma Situação de Desequilíbrio................................................... 21

Figura 3.5 - Análise das Componentes Simétricas .................................................... 22

Figura 3.6 - Análise de Distribuição no Tempo........................................................... 23

Figura 3.7 - Análise de Similaridade entre Situações de Desequilíbrio ........................ 25

Figura 3.8 - Situações de Desequilíbrio e probabilidade de suas ocorrências ............... 28

Figura 3.9 - Gráfico comparativo dos métodos de K\% para a situação 3D-OV ............ 29

Figura 3.10 - Ângulo do fator K para a situação 3D-OV ............................................... 30

Figura 3.11 - Gráfico de barras das Estatísticas de Módulo da Componente de

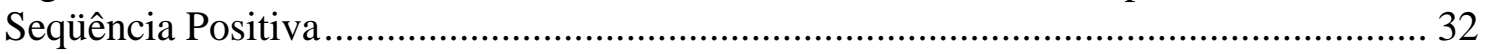

Figura 3.12 - Gráfico de barras das Estatísticas de ângulo da Componente de Sequiência

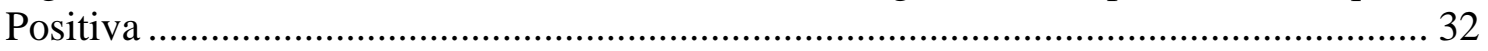

Figura 3.13 - Gráfico de barras das Estatísticas de Módulo da Componente de

Seqüência Negativa

Figura 3.14 - Gráfico de barras das Estatísticas de ângulo da Componente de Sequiência

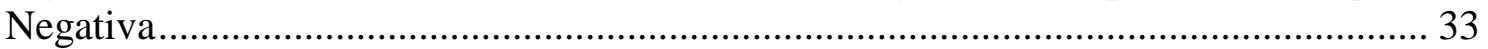

Figura 3.15 - Gráfico de barras das Estatísticas de Módulo da Componente de

Seqüência Zero

Figura 3.16 - Gráfico de barras das Estatísticas de ângulo da Componente de Sequiência

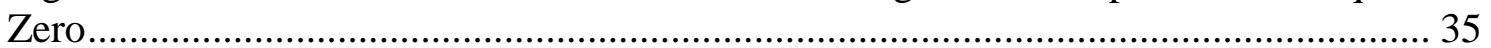

Figura 3.17 - Distribuição no tempo da situação 3D-OV ............................................ 35

Figura 3.18 - Gráfico dos valores de $\mathrm{K} \%$ dentro da faixa mínimo $\leq \mathrm{K} \% \leq$ média

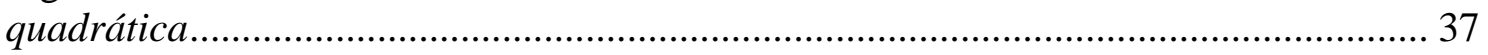

Figura 3.19 - Gráfico dos valores de $\mathrm{K} \%$ fora da faixa mínimo $\leq \mathrm{K} \% \leq$ média

quadrática.

Figura 3.20 - Intervalos ininterruptos com $\mathrm{K} \%$ dentro da faixa mínimo $\leq \mathrm{K} \% \leq$ média

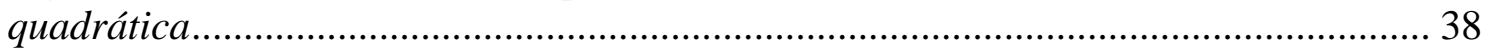

Figura 3.21 - Intervalos ininterruptos com $\mathrm{K} \%$ fora da faixa mínimo $\leq \mathrm{K} \% \leq$ média

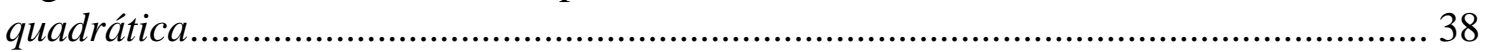

Figura 3.22 - Probabilidade das ocorrências dos intervalos de tempo ininterruptos com

valores dentro da faixa mínimo $\leq \mathrm{K} \% \leq$ média quadrática .......................................... 39

Figura 3.23 - Probabilidade das ocorrências dos intervalos de tempo ininterruptos com

valores fora da faixa mínimo $\leq \mathrm{K} \% \leq$ média quadrática ............................................. 39

Figura 3.24 - Gráfico dos valores de K\% dentro da faixa mínimo $\leq \mathrm{K} \% \leq P 95 \%$ versus

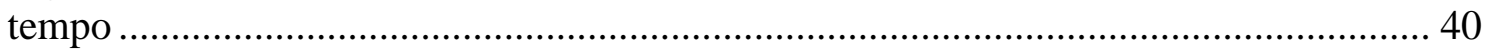

Figura 3.25 - Gráfico dos valores de $\mathrm{K} \%$ fora da faixa mínimo $\leq \mathrm{K} \% \leq P 95 \%$ versus

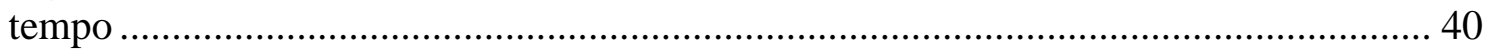

Figura 3.26 - Intervalos ininterruptos com $\mathrm{K} \%$ dentro da faixa mínimo $\leq \mathrm{K} \% \leq P 95 \% 41$

Figura 3.27 - Intervalos ininterruptos com K\% fora da faixa mínimo $\leq \mathrm{K} \% \leq P 95 \% \ldots 41$

Figura 3.28 - Probabilidade das ocorrências dos intervalos de tempo ininterruptos com

valores dentro da faixa mínimo $\leq \mathrm{K} \% \leq P 95 \%$........................................................ 42 
Figura 3.29 - Probabilidade das ocorrências dos intervalos de tempo ininterruptos com valores dentro da faixa mínimo $\leq \mathrm{K} \% \leq P 95 \%$

Figura 3.30 - Gráfico dos valores de $\mathrm{K} \%$ dentro da faixa mínimo $\leq \mathrm{K} \% \leq P 99 \%$ versus tempo

Figura 3.31 - Gráfico dos valores de $\mathrm{K} \%$ fora da faixa mínimo $\leq \mathrm{K} \% \leq P 99 \%$ versus tempo

Figura 3.32- Intervalos ininterruptos com K\% dentro da faixa mínimo $\leq \mathrm{K} \% \leq P 99 \% 44$

Figura 3.33- Intervalos ininterruptos com K\% fora da faixa mínimo $\leq \mathrm{K} \% \leq P 99 \%$.... 44

Figura 3.34 - Probabilidade das ocorrências dos intervalos de tempo ininterruptos com

valores dentro da faixa mínimo $\leq \mathrm{K} \% \leq P 99 \%$

Figura 3.35 - Probabilidade das ocorrências dos intervalos de tempo ininterruptos com

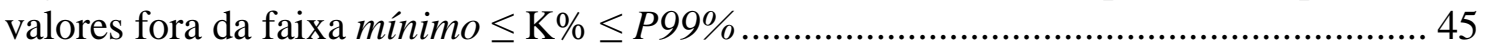

Figura 3.36 - Distribuição de Probabilidade ……....................................................... 45

Figura 3.37 - Distribuição Acumulativa de Probabilidade ............................................ 46

Figura 3.38 - Dados comparativos de sequiência positiva para quatro situações ............ 47

Figura 3.39 - Dados comparativos de sequiência negativa para quatro situações .......... 48

Figura 3.40 - Dados comparativos de seqüência zero para quatro situações ................. 49

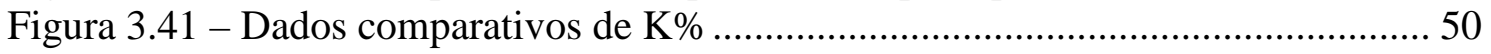

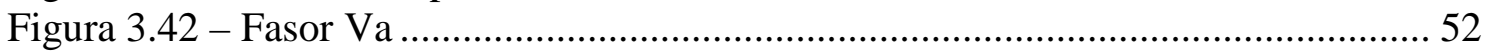

Figura 4.1 - Consumidores eletro-intensivos da Eletronorte.........................................54

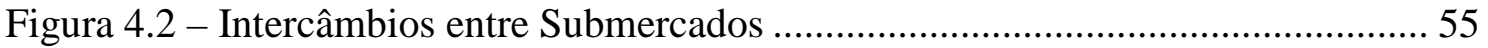

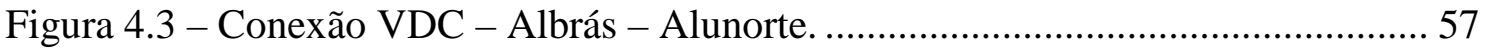

Figura 4.4 - Conexão LD - Alumar refinaria - Alumar redução. ................................ 58

Figura 4.5 - Distribuição no tempo de 3D-OV na Albrás de 29/08 a 04/09 de 2007 .... 67

Figura 4.6 - Distribuição no tempo em Alumar de 01 a 07/08 de 2007 ....................... 68

Figura 4.7 - Distribuição no tempo em Alumar de 08 a 14/08 de 2007 ......................... 68

Figura 4.8 - Distribuição no tempo em Alumar de 05 a 11/09 de 2007 ........................ 69

Figura 4.9 - Distribuição no tempo de 3D-OV em Alunorte ......................................... 70

Figura 4.10 - Distribuição no tempo de 3D-UV em CCM de 01 a 07/08 de 2007 ........ 70

Figura 4.11 - Intervalos ininterruptos de tempo da situação 3D-UV em CCM de 5 a

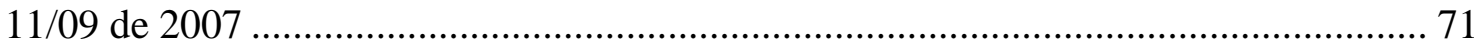

Figura 4.12 - Distribuição no tempo de 3D-OV em CVRD São Luís de 01 a 07/08 de

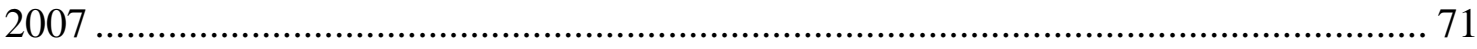

Figura 4.13 - Distribuição no tempo em Marabá de 22 a 28 de agosto ........................ 72

Figura 4.14 - Distribuição no tempo em Marabá de 5 a 11/09 de 2007 ........................ 73 


\section{LISTA DE TABELAS}

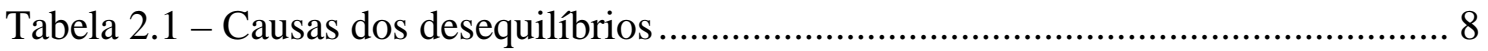

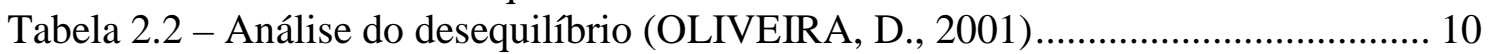

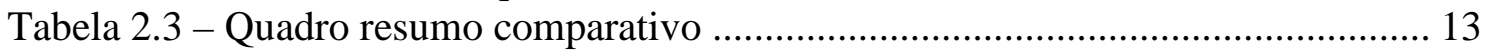

Tabela 3.1 - Classificação das Situações de Desequilíbrio possíveis ............................. 16

Tabela 3.2 - Ocorrências e Probabilidades das situações de desequilíbrio..................... 27

Tabela 3.3 - Estatísticas de K\% pelos quatro métodos de cálculo para a situação 3D-OV

Tabela 3.4 - Estatísticas de K\% pelos quatro métodos de cálculo considerando tadas

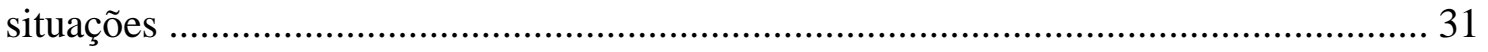

Tabela 3.5 - Estatísticas das Componentes Simétricas para a situação 3D-OV ............ 31

Tabela 3.6 - Resultados com relação aos índices P95\%, P99\% e Média Quadrática .... 36

Tabela 3.7 - Resultados de cálculos de componentes de seqüência positiva.................. 47

Tabela 3.8 - Resultados de cálculos de componentes de seqüência negativa.................. 48

Tabela 3.9 - Resultados de cálculos de componentes de seqüência zero ...................... 49

Tabela 3.10 - Resultados de cálculos de fator K ....................................................... 50

Tabela 3.11 - Estatísticas dos fasores Va, Vb e Vc da situação 3D-OV......................... 51

Tabela 3.12 - Estatísticas dos fasores Va, Vb e Vc das situações (3D-UV), (3D-UV,

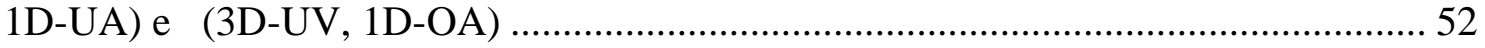

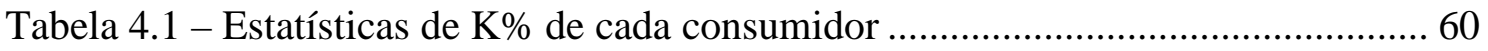

Tabela 4.2 - Probabilidade de Ocorrência de cada Situação de Desequilíbrio ............... 62

Tabela 4.3 - Níveis de K\% para cada situação de desequilíbrio ..................................... 65 


\section{CAPÍTULO 1}

\section{INTRODUÇÃO}

\section{1 - ASPECTOS GERAIS}

Desde a produção até o consumo da energia elétrica, especial atenção deve ser dada ao controle dos fenômenos que contribuem para a perda de qualidade de um suprimento elétrico. Um desses fenômenos que caracteriza a perda da qualidade de energia elétrica (QEE) é o desequilíbrio de tensão.

Atualmente, há disponíveis algumas metodologias para a quantificação do desequilíbrio em recomendações e normas que tratam dele ao redor do mundo e trazem limites para o índice que o quantifica. Contudo, tais metodologias não consideram, conforme Lee (1997), Wang (2001), Siddique (2004), Faiz (2004) e Kersting (2001) demonstram em seus estudos que abordam as condições de desequilíbrio, que diversas características relacionadas ao desempenho e à vida útil de elementos do sistema podem dar-se de maneira distinta em razão das circunstâncias que se encontram os fasores de tensão.

Este trabalho caracteriza-se como a primeira etapa de um estudo para a compreensão da relação entre cada condição de desequilíbrio e os efeitos por ele causados em motores de indução trifásicos (MIT). Objetiva-se, nesta fase, o desenvolvimento de uma ferramenta computacional para alcançar resultados acerca desta relação. A ferramenta visa possibilitar que se trabalhe com uma grande quantidade de dados para a obtenção de resultados fidedignos. Deve-se permitir ainda a realização de uma análise contendo gráficos e valores estatísticos que possibilitem traçar diagnósticos da disposição e do comportamento dos desequilíbrios para cada situação identificada a fim de retirar maiores informações dos dados tratados.

Assim, análises dos respectivos níveis de desequilíbrio das situações, bem como a avaliação de sua distribuição no tempo, tornam-se possíveis partindo-se da utilização de dados 
obtidos em medições reais de diversos locais e levantando-se algumas situações que mais ocorrem em determinados locais do sistema elétrico brasileiro.

Compreende-se, nesse mesmo estudo, a realização de simulações computacionais por meio da implementação de modelos elétricos e térmicos, para adquirir as temperaturas mais elevadas num MIT, quando suprido por tensões desequilibradas que caracterizam as diversas situações de desequilíbrio. Com a obtenção destas temperaturas, torna-se possível estimar a redução da vida útil do motor por meio da metodologia de cálculo que toma por base a teoria de "Arrhenius-Darkin" (SOUTO, 2001).

As citadas simulações podem ser validadas com a realização de ensaios correspondentes sobre um MIT. Com os resultados destes testes, almeja-se gerar grupos de situações de desequilíbrio das quais se possa afirmar que os efeitos causados são semelhantes. As simulações computacionais e os testes em laboratório são previstos para as próximas etapas desta investigação.

Antes que essas simulações e ensaios sejam empregados, portanto, a ferramenta computacional se justifica pela necessidade de um prévio tratamento das situações de desequilíbrio. 


\section{2 - ESTRUTURA DO TRABALHO}

Este trabalho apresenta-se desenvolvido da seguinte forma:

O Capítulo 2 destina-se à conceituação dos desequilíbrios de tensão, evidenciando-os com maior propriedade, sobretudo quanto às principais normas referentes a este fenômeno, causas, efeitos e as metodologias para cálculo da quantificação de $\mathrm{K} \%$.

No Capítulo 3 é apresentada a ferramenta computacional, ilustrando suas funcionalidades. É explicado como se dá sua utilização e, ao final do capítulo, um estudo de caso é desenvolvido.

Análises estatísticas das situações de desequilíbrios de tensão são realizadas no Capítulo 4, avaliando diversos consumidores e identificando os níveis de desequilíbrio de cada situação. Efetuam-se ainda análises comparativas entre distrubuições de probabilidades de ocorrências e suas distribuições no tempo.

As conclusões finais alcançadas com este trabalho são abordadas no Capítulo 5. 


\section{CAPÍTULO 2}

\section{DESEQUILÍBRIO DE TENSÃO}

\section{1 - CONSIDERAÇÕES INICIAIS}

Neste capítulo serão abordados tópicos referentes à compreensão dos desequilíbrios de tensão. A princípio, serão apresentados conceitos e formas de cálculo da quantificação do desequilíbrio. Em seguida, serão tratadas as principais causas do desequilíbrio e efeitos no motor de indução. Depois será exibida uma lista com as principais normas e recomendações que abordam o tema em questão.

\section{2 - CONCEITO}

O desequilíbrio de tensão é uma condição na qual as fases, em um sistema elétrico trifásico, apresentam discrepâncias aos padrões trifásicos, das quais se têm tensões com módulos diferentes entre si, ou defasagem angular entre as fases diferentes de $120^{\circ}$ elétricos ou, ainda, as duas condições simultaneamente.

Como ilustração, na Figura 2.1 (XAVIER, 2005) observa-se, em certo instante, um desequilíbrio na magnitude da fase (a). Posteriormente verifica-se uma ocorrência de assimetria do ângulo da fase (b):

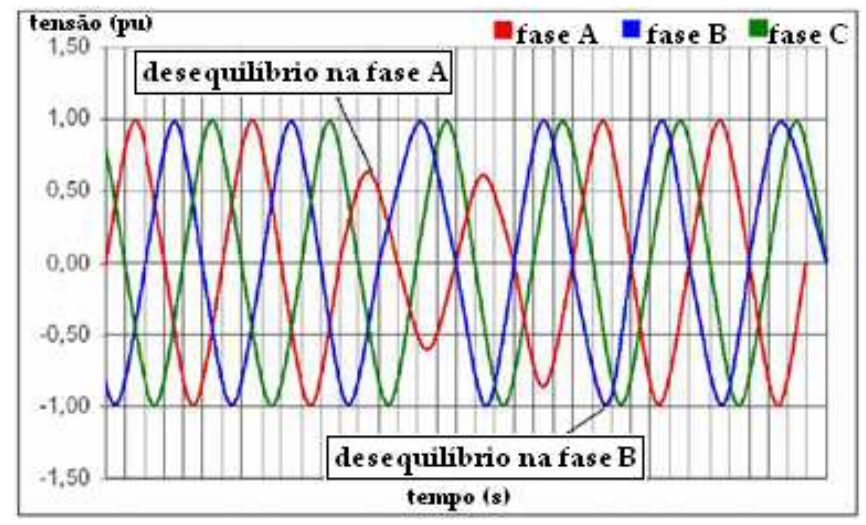

Figura 2.1 - Desequilíbrio de Tensão 


\section{3 - MÉTODOS DE CÁLCULO DO DESEQUILÍBRIO DE TENSÃO}

Na literatura atual podem ser encontrados vários métodos de cálculo para obtenção do fator de desequilíbrio de tensão. Diversas alternativas foram desenvolvidas para sua medição. Porém, diante do fato de muitos medidores não registrarem informações quanto às defasagens angulares dos fasores, ocorre, em alguns casos, o incentivo ao uso de métodos que utilizam apenas a magnitude dos fasores.

Serão descritos quatro métodos para a quantificação do desequilíbrio. Contudo, apenas o primeiro utiliza as magnitudes e os ângulos das tensões. Os outros três baseiam-se somente nos valores de magnitude das tensões de linha.

\section{- Método 1: Componentes Simétricas}

Afirma o Teorema de Fortescue que "Qualquer grupo desequilibrado de $n$ fasores associados, do mesmo tipo, pode ser resolvido em $\mathrm{n}$ grupos de fasores equilibrados, denominados componentes simétricas dos fasores originais".

Assim, para um sistema trifásico, o sistema desequilibrado é composto de três sistemas trifásicos, sendo eles:

Sistema de seqüência positiva ou direta, equilibrado, em que a seqüência das fases é a mesma do sistema original;

Sistema de seqüência negativa ou inversa, equilibrado, na qual a seqüência das fases é inversa da do sistema desequilibrado;

Sistema de seqüência zero, composta por três fasores paralelos, de mesma magnitude.

O diagrama dessas componentes é mostrado na Figura 2.2 a seguir: 

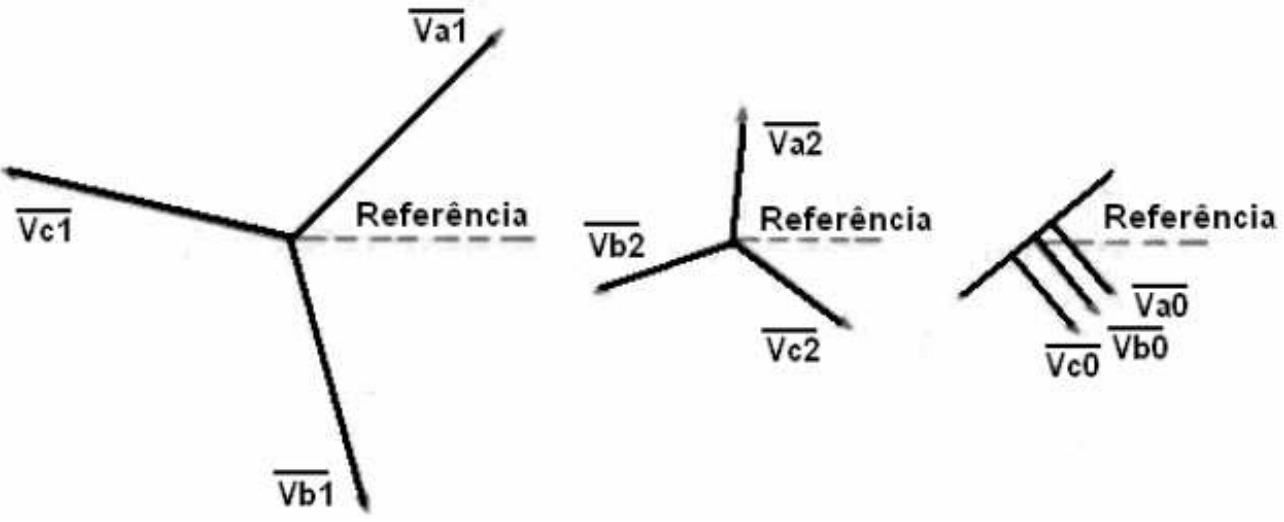

Figura 2.2 - Diagrama fasorial das componentes simétricas (ALMEIDA \& FREITAS, 1995)

A partir da chamada equaçào matricial de Fortescue, mostrada na Eq.(2.1), pode-se analiticamente encontrar as componentes simétricas.

$$
\left[\begin{array}{l}
\bar{V}_{a} \\
\bar{V}_{b} \\
\bar{V}_{c}
\end{array}\right]=\left[\begin{array}{ccc}
1 & 1 & 1 \\
1 & a^{2} & a \\
1 & a & a^{2}
\end{array}\right]\left[\begin{array}{l}
\bar{V}_{0} \\
\bar{V}_{1} \\
\bar{V}_{2}
\end{array}\right]
$$

Em que $V_{o}, V_{1}$, e $V_{2}$ são os módulos das tensões de seqüência zero, positiva e negativa, respectivamente, referenciados à fase "a". Nesta metodologia, define-se o fator $\mathrm{K}$ na equação (2.2) como sendo a razão entre os módulos das tensões de seqüência negativa e positiva, percentualmente. Contudo, pode-se considerar ainda o ângulo do fator K como sendo a diferença entre os ângulos das tensões de seqüência positiva e negativa.

$$
K \%=\frac{V_{2}}{V_{1}} \times 100
$$

A metodologia abordada pelas componentes simétricas é a única que se utiliza tanto das magnitudes como dos ângulos das tensões para o cálculo do fator K. Esta metodologia é adotada, no Brasil, pelo Operador Nacional do Sistema Elétrico - ONS. Neste trabalho, as componentes simétricas constituem a metodologia aplicada no cálculo do fator $\mathrm{K}$. 
- Método 2: CIGRÉ - Congress Internationale des Grand Réseaux Életriques a Haute Tension

É uma metodologia que se utiliza da expressão mostrada na equação 2.3 para o fator de desequilíbrio, ou fator $\mathrm{K}$, partindo-se de uma grandeza adimensionao dada pela equação 2.4 que faz uma correlação das tensões de linha.

$$
K \%=\sqrt{\frac{1-\sqrt{3-6 \beta}}{1+\sqrt{3-6 \beta}}} \times 100
$$

Onde:

$$
\begin{gathered}
\beta=\frac{\left|V_{a b}\right|^{4}+\left|V_{b c}\right|^{4}+\left|V_{c a}\right|^{4}}{\left(\left|V_{a b}\right|^{2}+\left|V_{b c}\right|^{2}+\left|V_{c a}\right|^{2}\right)^{2}} \\
\left|V_{a b}\right|,\left|V_{b c}\right|,\left|V_{c a}\right| \rightarrow \text { Módulo das tensões trifásicas. }
\end{gathered}
$$

- Método 3: NEMA - National Electrical Manufactures Association

Uma metodologia bastante utilizada provida da norma NEMA-MG-14.34 que define na Eq.(2.5) a quantificação do fator de desequilíbrio pela relação entre o máximo desvio da tensão média e a tensão média, utilizando-se para isso das tensões de linha.

$$
K \%=\frac{\Delta V}{V_{m}} \times 100
$$

Onde:

$\Delta \mathrm{V} \rightarrow$ Máximo desvio das tensões de linha em relação ao valor médio;

$\mathrm{V}_{\mathrm{m}} \rightarrow$ Média aritmética dos módulos das tensões trifásicas. 
- Método 4: IEEE - Institute of Electrical and Electronics Engineers

No procedimento adotado pelo IEEE, sugere-se obter o K por meio da relação Eq.(2.6) que exprime a maior diferença entre as tensões de linha medidas e o somatório das mesmas tensões.

$$
K \%=\frac{3(V m a ́ x-V \min )}{V_{a b}+V_{b c}+V_{c a}} \times 100
$$

Onde:

$V_{\text {máx }} \rightarrow$ Maior valor dentre os módulos das tensões trifásicas;

$V_{\min } \rightarrow$ Menor valor dentre os módulos das tensões trifásicas;

$V_{a b}, V_{b c}, V_{c a} \rightarrow$ Módulo das tensões trifásicas.

\section{4 - CAUSAS DOS DESEQUILÍBRIOS DE TENSÃO}

Os causadores mais comuns de desequilíbrios são as más distribuições de cargas entre as fases e anomalias em bancos de capacitores, como queima de fusíveis em uma fase. Podem ser ainda citadas as fontes que provocam esse tipo de desequilíbrio destacados na Tabela 2.1, conforme (LEE et al., 1997), (WANG et al., 2000) e (JOUANNE et al, 2001):

Tabela 2.1 - Causas dos desequilíbrios

Principais Causas dos Desequilíbrios de Tensão

- Linhas de distribuição muito longas (principalmente em sistemas rurais cuja alimentação é monofásica);

- Assimetria nas impedâncias dos enrolamentos de transformadores e/ou máquinas rotativas;

- Transposição incompleta ou assimétrica das linhas de transmissão;

- Cargas trifásicas desequilibradas;

- Distribuição desigual de cargas monofásicas entre as fases;

- Afundamentos, interrupções, elevações, transitórios, etc.

- Motores com rotor desalinhado e/ou estator assimétrico;

- Distorção harmônica em níveis desiguais entre as fases;

- Sistemas de distribuição com grandes demandas monofásicas. 


\section{5 - EFEITOS DOS DESEQUILÍBRIOS DE TENSÃO EM MOTORES DE INDUÇÃO}

Efeitos danosos, causados por desequilíbrio de tensão, atingem o sistema elétrico e a uma quantidade de cargas variadas. Não é à toa que se têm intensificado consideravelmente estudos acerca destes efeitos ultimamente. Os problemas causados se associam a sobreaquecimento, falha e má operação dos dispositivos de proteção, solicitação indevida do isolamento e a diminuição da vida útil. (KERSTING, 2001)

Na condição de desequilíbrio, surge a tensão de componente de sequiência negativa, que gera a circulação de corrente de sequiência negativa, responsável por gerar um conjugado nas máquinas contrário ao desejado. Naturalmente, os resultados e impactos apresentados tanto para rendimento como para o fator de potência, devem-se, principalmente, às variações dos níveis das tensões de seqüência positiva, as quais, efetivamente são as responsáveis pela produção do conjugado de acionamento da carga. (SOUTO, 2001)

Desta forma torna-se importante investigar o comportamento dos motores de indução quando os mesmos estão sujeitos à presença do desequilíbrio de tensão, haja vista que estes dispositivos representam a maioria das cargas ligadas aos sistemas elétricos industriais.

Para manter a integridade dos motores de indução, a temperatura dos seus enrolamentos deve ser mantida dentro dos limites estabelecidos pelo fabricante por meio do controle dos níveis de desequilíbrio de acordo com índices de conformidade do sistema elétrico.

Assim, sob operação adversa da nominal, certamente haverá um sobreaquecimento dos condutores e um aumento substancial das perdas geradas internamente à máquina. Sua temperatura poderá atingir níveis mais elevados que o permitido, podendo ocorrer uma degradação térmica do isolamento das bobinas do estator e até mesmo a ruptura desse isolamento pode ser atingida. Ainda um subseqüente curto-circuito das bobinas viria a ocorrer devido a esta ruptura. 
Percebe-se que especial atenção é requerida para que a suportabilidade de cada aparelho seja mantida dentro dos limites. Outros fenômenos indesejáveis ocorrem quando o motor excede seus limites térmicos, sendo alguns deles:

Aceleração do processo de oxidação dos materiais isolantes, resultando nas perdas das propriedades do dielétrico;

Aumento da viscosidade do lubrificante dos rolamentos;

Fadiga mecânica;

Alterações na geometria da máquina devido às dilatações térmicas dos seus elementos.

À medida que este distúrbio da temperatura aumenta, ocasiona a redução na eficiência e na vida útil do motor. Por meio de resultados de simulações na Tabela 2.2 pode-se observar como a vida útil é intensamente afetada frente a certos desequilíbrios.

Tabela 2.2 - Análise do desequilíbrio (OLIVEIRA, D., 2001)

\begin{tabular}{c|c|c|c|c}
\hline \multirow{2}{*}{ Efeito Resultante } & \multicolumn{4}{|c}{ Desequilíbrio (K\%) } \\
\cline { 2 - 5 } & 2 & 5 & 10 & 15 \\
\hline $\begin{array}{c}\text { Temperatura do } \\
\text { enrolamento do estator }\left({ }^{\circ} \mathrm{C}\right)\end{array}$ & 122,7 & 127,6 & 141,0 & 161,2 \\
\hline Redução da vida útil $(\%)$ & 4 & 32,9 & 80,1 & 97,0 \\
\hline
\end{tabular}

Constata-se da Tabela 2.2 que, sob um desequilíbrio de 5\%, o motor de indução pode ter sua vida útil reduzida em quase um terço. E se este fosse submetido a $15 \%$ de desequilíbrio, seria bastante danificado podendo se tornar inutilizável.

Entretanto, exige-se um estudo mais completo nesse contexto, pois atualmente sabe-se que ao quantificar os desequilíbrios é possível acontecerem condições distintas da magnitude e do ângulo dos fasores de tensão culminando em um mesmo valor de $\mathrm{K} \%$, o que certamente produzirá distintos efeitos nos motores. 


\section{6 - NORMAS E RECOMENDAÇÕES}

São necessárias a definição e a apuração de indicadores e índices de referência capazes e refletir corretamente a degradação da QEE, cobrindo os inúmeros aspectos envolvidos no seu contexto e que tenham um bom nível de consenso entre os agentes atuantes (DECKMANN, 2000).

Tais indicadores devem ser transparentes, de fácil compreensão e implementação. Devem ter correlação com a sensibilidade das cargas estabelecendo relações de causa e efeito. Contudo precisam ser diferenciados por região de forma a atenderem às necessidades dos consumidores e dos órgãos reguladores em termos de quantificação e qualificação do desempenho do sistema. (RAMOS, 2000)

Há diversas normas e recomendações internacionais que tratam dos fenômenos da QEE. Uma síntese das principais será mostrada a seguir.

\section{IEC - International Electrotechnical Commission}

Tal órgão publica documentos para o uso internacional, tais como normas, relatórios técnicos e manuais. Os documentos IEC oferecem, apenas uma orientação quantitativa dos limites recomendados. Sugere-se um nível máximo de $2 \%$ de seqüência negativa em relação à componente de sequiência positiva para sistemas de baixa tensão. Eventualmente, como em casos de curtos-circuitos, podem-se alcançar valores maiores a esse, durante períodos limitados. A IEC não faz referência aos protocolos de medição específicos para desequilíbrios.

\section{CENELEC - European Committee for Electrotechnical Standardization}

Estabelece os procedimentos comuns a serem empregados no contexto europeu. Relacionase com características a serem analisadas no ponto de acoplamento com o consumidor. A CENELEC estabelece que, em condições normais de suprimento, durante o período de sete dias consecutivos, apenas 5\% dos valores RMS da componente de sequiência negativa podem ultrapassar $2 \%$ da componente de seqüência positiva. As medições devem possuir 
pontos a cada dez minutos. Caso os consumidores sejam monofásicos ou bifásicos, admitem-se desequilíbrios de até 3\% (OLIVEIRA, J.C. 2000).

\section{NRS 048 - National Electricity Regulator}

Elaborada por representantes da South African Electricity Supply Industry, foi fundamentada em diretrizes estabelecidas pela IEC e pela CENELEC, além de relatórios e dados locais disponíveis. Adota o método de cálculo das componentes simétricas e valor limite de desequilíbrio de $2 \%$. Permite limite de $3 \%$ onde há predominância de consumidores monofásicos ou bifásicos.

\section{ANSI - American National Standard Institute}

Estabelece valores nominais de tensão e tolerâncias operacionais para sistemas de $100 \mathrm{~V}$ a $230 \mathrm{~V}$ em $60 \mathrm{~Hz}$. Quantifica o desequilíbrio por meio da metodologia proposta pelo NEMA. Não faz abordagem quanto aos protocolos de medição, mas recomenda que o desequilíbrio não ultrapasse $3 \%$.

\section{Procedimentos de Rede - submódulo 2.2}

O ONS (Operador Nacional do Sistema), criado em agosto de 1998, possui os Procedimentos de Rede, que são documentos elaborados com a participação dos Agentes e homologados pela ANEEL, os quais estabelecem os procedimentos e os requisitos técnicos para o planejamento, a implantação e as responsabilidades do ONS e de todos os demais agentes de operação (ONS, 2006). "Requisitos Mínimos para Instalações e Gerenciamento de Indicadores de Desempenho da Rede Básica e de seus Componentes” são tratados no módulo 2. Com utilização de caráter provisório, foi autorizado o submódulo 2.2, que traz os "Padrões de Desempenho da Rede Básica", que determina que o cálculo do indicador K deve ser feito a partir do método das Componentes Simétricas e que o índice de conformidade seja de $2 \%$. Estabelece ainda que, para determinar o indicador a ser comparado com tal limite, deve-se primeiramente identificar qual é o valor com probabilidade de 95\% de não ser excedido (P95\%) calculado considerando 1 dia, para 7 dias de análise. O maior dentre os sete adquiridos em base diária corresponde ao indicador. 


\section{PRODIST - Procedimentos de Rede - Módulo 8}

Admite que tanto o método CIGRÉ quanto o das Componentes Simétricas pode ser utilizado para cálculo do K\%. Determina que o limite global nos barramentos da rede de distribuição deve ser menor ou igual a $2 \%$. O procedimento para obtenção do indicador representativo é o mesmo definido pelo submódulo 2.2. Estabelece ainda que o período de medição deve ser de uma semana, possuindo 144 amostras diárias de dados a cada 10 minutos.

A Tabela 2.3 traz um quadro comparativo das expressões utilizadas para se calcular o K\% e apresenta os índices de conformidade em função das normas e recomendações supramencionadas.

Tabela 2.3 - Quadro resumo comparativo

\begin{tabular}{|c|c|c|}
\hline Recomendação/Norma & Limite & Expressões \\
\hline IEC & $2 \%$ & $K \%=\frac{V_{2}}{V_{1}} \times 100$ \\
\hline CENELEC & $2 \%$ & $K \%=\frac{V_{2}}{V_{1}} \times 100$ \\
\hline NRS-048 & $2 \%$ & $\begin{array}{c}K \%=\frac{V_{2}}{V_{1}} \times 100 \text { ou } \quad=\sqrt{\frac{1-\sqrt{3-6 \beta}}{1+\sqrt{3-6 \beta}}} \times 100 \text {, onde } \\
\beta=\frac{\left|V_{a b}\right|^{4}+\left|V_{b c}\right|^{4}+\left|V_{c a}\right|^{4}}{\left.\left.|| V_{a b}\right|^{2}+\left|V_{b c}\right|^{2}+\left|V_{c a}\right|^{2}\right)^{2}}\end{array}$ \\
\hline ANSI & $3 \%$ & $K \%=\frac{\Delta V}{V_{m}} \times 100$ \\
\hline $\begin{array}{l}\text { Procedimentos de } \\
\text { Rede }\end{array}$ & $2 \%$ & $K \%=\frac{V_{2}}{V_{1}} \times 100$ \\
\hline PRODIST & $2 \%$ & 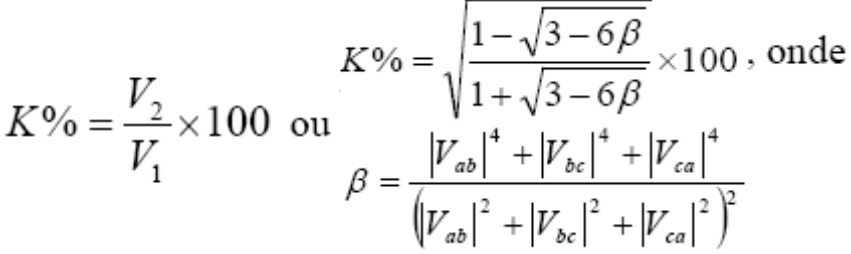 \\
\hline
\end{tabular}




\section{CAPÍTULO 3}

\section{DESCRIÇÃO DA FERRAMENTA COMPUTACIONAL PARA ANÁLISE DAS SITUAÇÕES DE DESEQUILÍBRIO}

\section{1 - CONSIDERAÇÕES INICIAS}

A princípio, expõe-se neste capítulo uma classificação do desequilíbrio que será considerada no estudo procedente. Em seguida, é apresentada a ferramenta computacional utilizada para análises das situações de desequilíbrio a fim de se compreender mais claramente o significado dos dados analisados. Posteriormente será exibida uma descrição dos módulos desta ferramenta, salientando detalhadamente o funcionamento de cada um. Por fim, realiza-se um estudo de caso.

\section{2 - CLASSIFICAÇÃO DO DESEQUILÍBRIO}

Lee (1997), em seu trabalho que aborda alguns efeitos provocados por tensões desequilibradas na performance de operação de um motor de indução, quando este é submetido a um mesmo fator $\mathrm{K}$ de quantificação de desequilíbrio, forneceu uma classificação acerca dos desequilíbrios de tensão e suas possíveis causas.

Para compreensão dos casos de desequilíbrio por ele estudados, entende-se por undervoltage a redução no valor da tensão para valores inferiores do padrão nominal, ao passo que over-voltage é a elevação acima do valor nominal. Os deslocamentos angulares se dão pela assimetria dos ângulos dos fasores de tensão dado pela disposição distinta do caso equilibrado, no qual se tem $120^{\circ}$ separando os fasores. Assim, são 8 (oito) as condições por ele sugeridas:

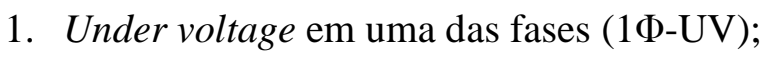

2. Under voltage em duas fases (2థ-UV);

3. Under voltage nas três fases (3Ф-UV);

4. Over voltage em uma das fases (1Ф-OV); 
5. Over voltage em duas fases $(2 \Phi-\mathrm{OV})$;

6. Over voltage nas três fases $(3 \Phi-\mathrm{OV})$;

7. Um desvio de ângulo (1Ф-A);

8. Dois desvios de ângulos (2Ф-A).

Dessa forma, Lee (1997) efetuou comparações da eficiência e do fator de potência de motores de indução para as condições de desequilíbrio sugeridas, submetendo estes motores a condições que levam a um mesmo valor de $\mathrm{K} \%$, buscando investigar o impacto dos desequilíbrios no serviço público e nos demais consumidores. Ele observou ainda que cada caso de desequilíbrio de tensão causa um diferente grau de aumento da temperatura, sendo que os desequilíbrios de under voltage constituem-se nos casos mais graves em que este fenômeno ocorre.

Com o intuito de se obter uma informação mais completa acerca do desequilíbrio angular e, conseqüentemente, uma melhor verificação da influência dos ângulos no desequilíbrio, serão consideradas novas condições, dividindo-se as condições 7 (1Ф-A) e 8 (2Ф-A) propostas por Lee (1997). Consiste em informar-se se o desvio de ângulo é superior ou inferior a $120^{\circ}$. Assim, passa-se a considerar quando há desvios de over angle (acima de $120^{\circ}$ ) e under angle (abaixo de $120^{\circ}$ ). A relação destas novas condições e das que representam desequilíbrio na magnitude, fica:

1. Under voltage em uma das fases (1D-UV);

2. Under voltage em duas fases (2D-UV);

3. Under voltage nas três fases (3D-UV);

4. Over voltage em uma das fases (1D-OV);

5. Over voltage em duas fases (2D-OV);

6. Over voltage nas três fases (3D-OV);

7. Under angle em uma das fases (1D-UA);

8. Under angle em duas fases (2D-UA); 
9. Over angle em uma das fases (1D-OA);

10. Over angle em duas fases (2D-OA).

Contudo, estas condições não compreendem todas as situações que podem ocorrer no sistema. Deve-se considerar o seu interrelacionamento, haja vista ser possível suas ocorrências simultâneas num mesmo sistema. Dessa forma, no total exitem 59 combinações possíveis diferentes destas condições, todas elas enumeradas na Tabela 3.1. Os estudos procedentes neste trabalho serão feitos baseados na classificação dada por estas situações.

Tabela 3.1 - Classificação das Situações de Desequilíbrio possíveis

\begin{tabular}{|c|c|}
\hline & SITUAÇÕ ES \\
\hline 1 & 1D-UA \\
\hline 2 & $1 \mathrm{D}-\mathrm{OA}$ \\
\hline 3 & 1D-UA / 1D-OA \\
\hline 4 & 1D-UV \\
\hline 5 & 1D-UV / 1D-UA \\
\hline 6 & 1D-UV / 1D-OA \\
\hline 7 & 1D-UV / 1D-OA / 1D-UA \\
\hline 8 & 1D-OV \\
\hline 9 & 1D-OV / 1D-UA \\
\hline 10 & 1D-OV / 1D-OA \\
\hline 11 & 1D-OV / 1D-OA / 1D-UA \\
\hline 12 & 1D-OV / 1D-UV \\
\hline 13 & 1D-OV / 1D-UV / 1D-UA \\
\hline 14 & 1D-OV / 1D-UV / 1D-OA \\
\hline 15 & 1D-OV / 1D-UV / 1D-OA / 1D-UA \\
\hline 16 & 2D-UA \\
\hline 17 & 2D-OA \\
\hline 18 & 1D-UV / 2D-UA \\
\hline 19 & 1D-UV / 2D-OA \\
\hline 20 & 1D-OV / 2D-UA \\
\hline 21 & 1D-OV / 2D-OA \\
\hline 22 & 1D-OV / 1D-UV / 2D-UA \\
\hline 23 & 1D-OV / 1D-UV / 2D-OA \\
\hline 24 & 2D-UV \\
\hline 25 & 2D-UV / 1D-UA \\
\hline 26 & 2D-UV / 1D-OA \\
\hline 27 & 2D-UV / 1D-OA / 1D-UA \\
\hline 28 & 2D-UV / 2D-UA \\
\hline 29 & 2D-UV / 2D-OA \\
\hline
\end{tabular}

\begin{tabular}{|c|c|}
\hline 30 & $1 D-O V / 2 D-U V$ \\
\hline 31 & 1D-OV / 2D-UV / 1D-UA \\
\hline 32 & 1D-OV / 2D-UV / 1D-OA \\
\hline 33 & 1D-OV / 2D-UV / 1D-OA / 1D-UA \\
\hline 34 & 1D-OV / 2D-UV / 2D-UA \\
\hline 35 & 1D-OV / 2D-UV / 2D-OA \\
\hline 36 & 2D-OV / 1D-UV \\
\hline 37 & 2D-OV / 1D-UV / 1D-UA \\
\hline 38 & 2D-OV / 1D-UV / 1D-OA \\
\hline 39 & 2D-OV / 1D-UV / 1D-OA / 1D-UA \\
\hline 40 & 2D-OV / 1D-UV / 2D-UA \\
\hline 41 & 2D-OV / 1D-UV / 2D-OA \\
\hline 42 & 2D-OV \\
\hline 43 & 2D-OV / 1D-UA \\
\hline 44 & 2D-OV / 1D-OA \\
\hline 45 & 2D-OV / 1D-OA / 1D-UA \\
\hline 46 & 2D-OV / 2D-UA \\
\hline 47 & 2D-OV / 2D-OA \\
\hline 48 & 3D-UV \\
\hline 49 & 3D-UV / 1D-UA \\
\hline 50 & 3D-UV / 1D-OA \\
\hline 51 & 3D-UV / 1D-OA / 1D-UA \\
\hline 52 & 3D-UV / 2D-UA \\
\hline 53 & 3D-UV / 2D-OA \\
\hline 54 & 3D-OV \\
\hline 55 & 3D-OV / 1D-UA \\
\hline 56 & 3D-OV / 1D-OA \\
\hline 57 & 3D-OV / 1D-OA / 1D-UA \\
\hline 58 & 3D-OV / 2D-UA \\
\hline 59 & 3D-OV / 2D-OA \\
\hline
\end{tabular}




\section{3 - ESTRUTURA GERAL}

Ao se tratar de desequilíbrios de tensão, importante atenção deve ser dada aos elementos responsáveis pela sua caracterização, como as condições em que se encontram os fasores de tensão, ou seja, a descrição da magnitude e dos ângulos dos fasores (ALMEIDA \& FREITAS, 1995).

Com o desenvolvimento desta ferramenta computacional, investiga-se o desequilíbrio com base nas situações compostas pelas condições dos fasores, tornando-se possível analisar os desequilíbrios pelas classificações relacionadas na Tabela 3.1. Parte-se ainda do uso de gráficos e levantamentos estatísticos para tornar mais simples o entendimento dos dados em estudo.

Para o desenvolvimento da ferramenta fez-se a opção do MatLab® versão 6.5, que disponibiliza numerosas funções previamente definidas, com ambiente de programação compreensível e simples.

O modo como a composição do programa está disposta é definido na Figura 3.1. Ilustra-se sua organização desde a escolha do banco de dados às análises das situações de desequilíbrio. 


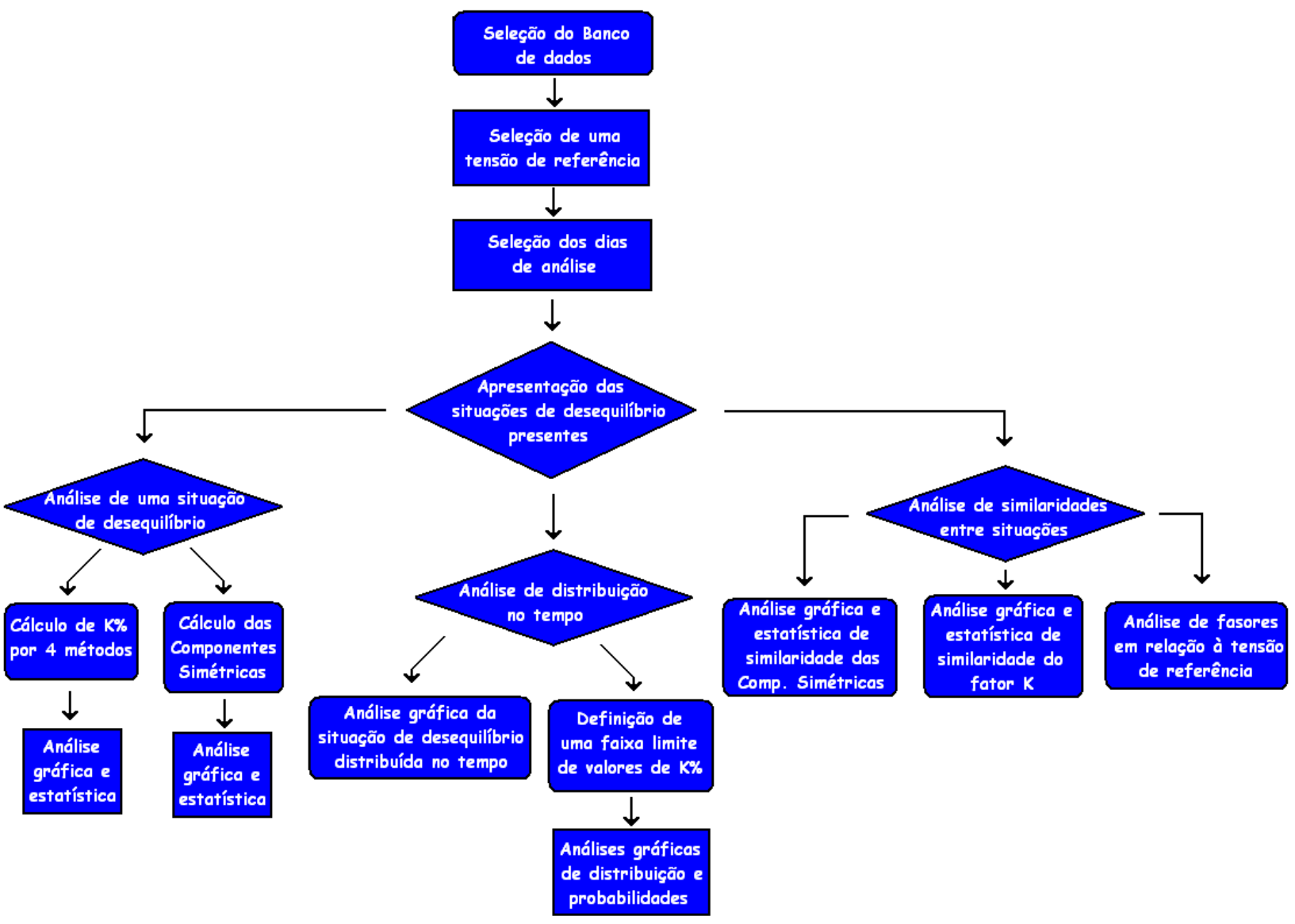

Figura 3.1 - Estrutura geral da ferramenta computacional

Inicialmente faz-se a seleção do banco de dados desejado. Após definir os dias do banco que se quer analisar, são conhecidas as situações de desequilíbrio presentes. Ao escolher uma situação para um estudo mais detalhado, é possível investigar os níveis de desequilíbrio, as componentes simétricas e a sua distribuição no tempo. Tem-se ainda uma análise comparativa entre as situações existentes para o banco escolhido, que pode ser feita para até 7 (sete) situações distintas.

Os detalhes do programa são exibidos a seguir, com a apresentação de suas funcionalidades. 


\section{4 - PROCEDIMENTOS E MÓDULOS DA FERRAMENTA COMPUTACIONAL}

\subsection{1 - Seleção do banco de dados, da tensão de referência e dos dias para análise}

A Figura 3.2 apresenta a tela inicial do software. Faz-se nesta tela, inicialmente, a opção do banco de dados que se quer analisar. À esquerda da tela, existe o botão "Carregar banco de dados". Após pressioná-lo, será aberta uma pequena janela com a relação dos bancos que podem ser escolhidos.

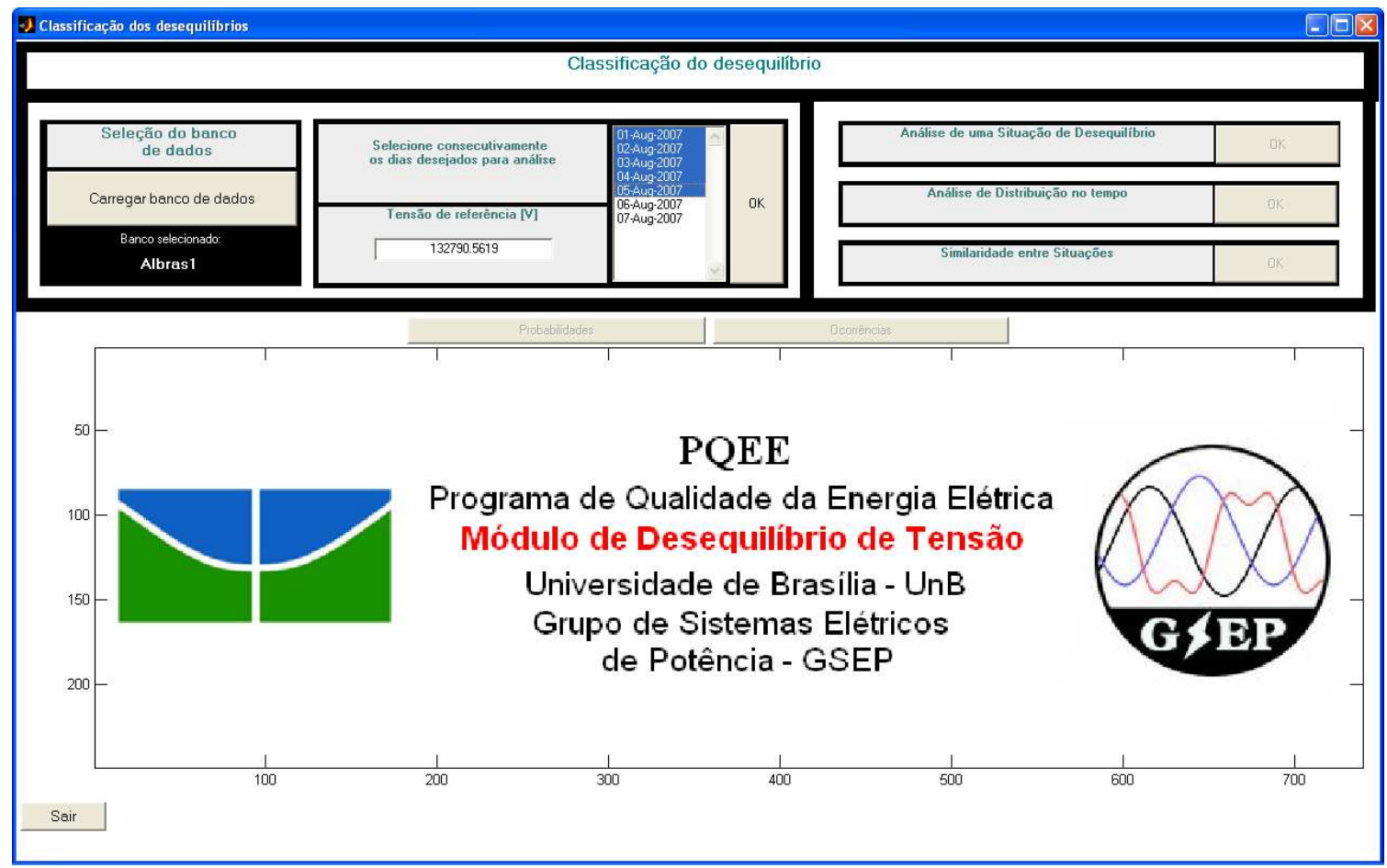

Figura 3.2 - Tela inicial do software

À direita do botão para seleção do banco, há o campo “Tensão de referência”. Nele, definese o valor em volts [V] que o programa utilizará como referência para realizar a classificação do desequilíbrio. Por padrão, a tensão nominal do banco escolhido é definida pelo software como sendo a referência. No entanto, o usuário pode entrar com outro valor que desejar. 
O passo seguinte é a escolha dos dias disponibilizados pelo banco que se deseja analisar. Basta que se faça a seleção na própria caixa de listagem. Na figura 3.2, por exemplo, vê-se a seleção de cinco dias, de $1^{\circ}$ a 5 de agosto de 2007.

\subsection{2 - Apresentação das situações de desequilíbrio presentes}

Após a escolha dos dias, deve ser pressionado o botão "OK" logo à direita da seleção dos dias. Após alguns segundos, um gráfico é gerado na mesma tela, mostrado na Figura 3.3. Este gráfico apresenta as situações de desequilíbrio que existem para o banco selecionado e o número de ocorrências de cada situação.

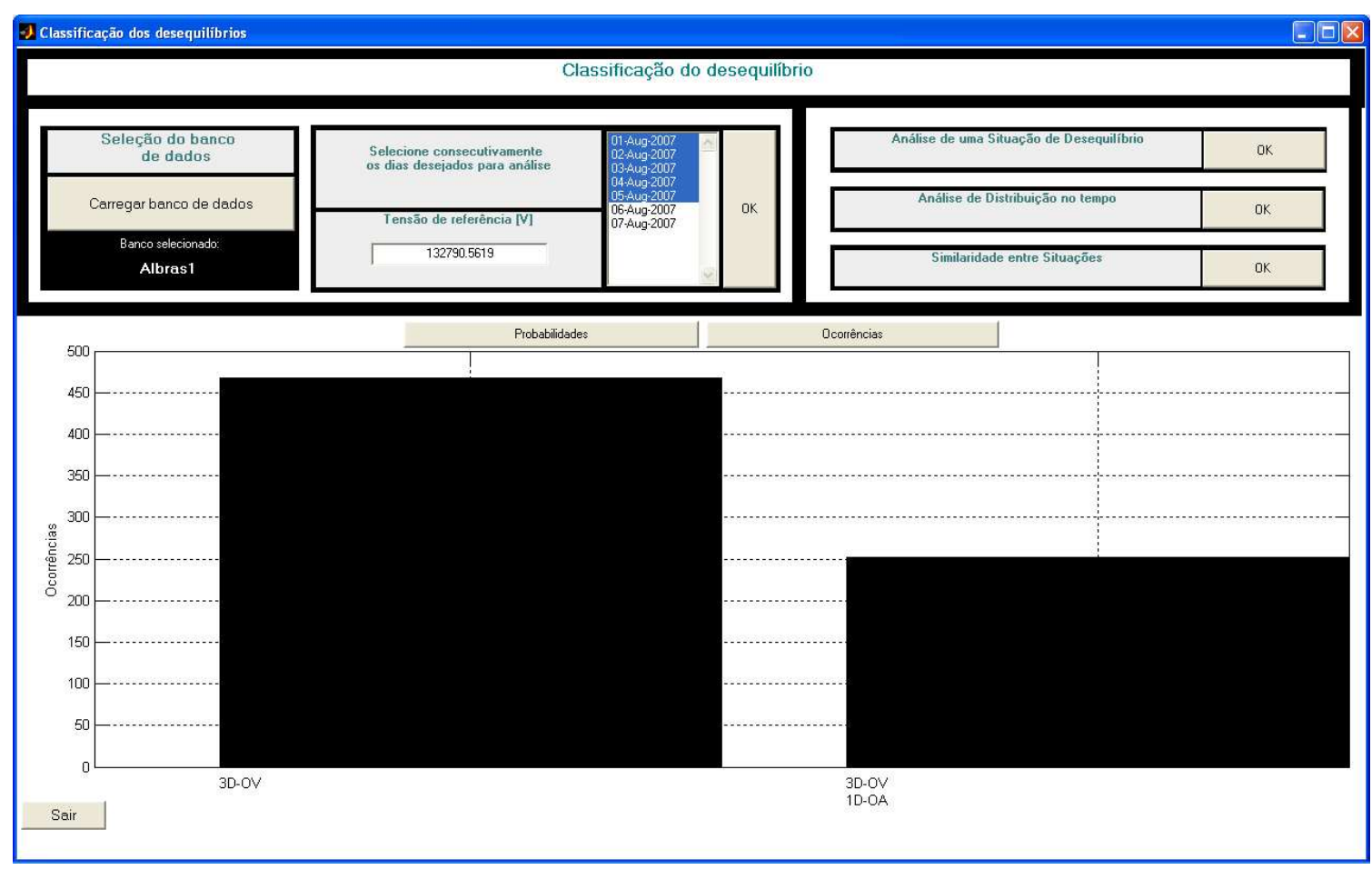

Figura 3.3 - Apresentação das situações de desequilíbrio

Este gráfico poderá registrar ainda as ocorrências dos instantes em que não houve desequilíbrio. Estas se encontrariam no gráfico marcadas por "Equi.". Ressalta-se, contudo, que o software está configurado para considerar como equilibrados os instantes nos quais ocorrem desvios de magnitude inferiores a $0,23 \%$ (ou $0,5 \div 220$ ) da tensão de referência e desvios de ângulo menores que $0,25^{\circ}$ nas fases "b" e "c". 
É possível alternar a visualização do gráfico, nesta mesma tela, para outro que também apresenta as situações presentes, contudo, representadas pelas probabilidades com que ocorrem. Para esta visualização, pressiona-se o botão "Probabilidades". E ao apertar o botão "Ocorrências", tem-se novamente o gráfico inicialmente apresentado.

\subsection{3 - Análise de uma Situação de Desequilíbrio}

A Figura 3.4 exibe a nova janela que é aberta ao ser pressionado o botão "OK" no lado direito da tela inicial indicado na Figura 3.2, referente a "Análise de uma situação de Desequilíbrio".

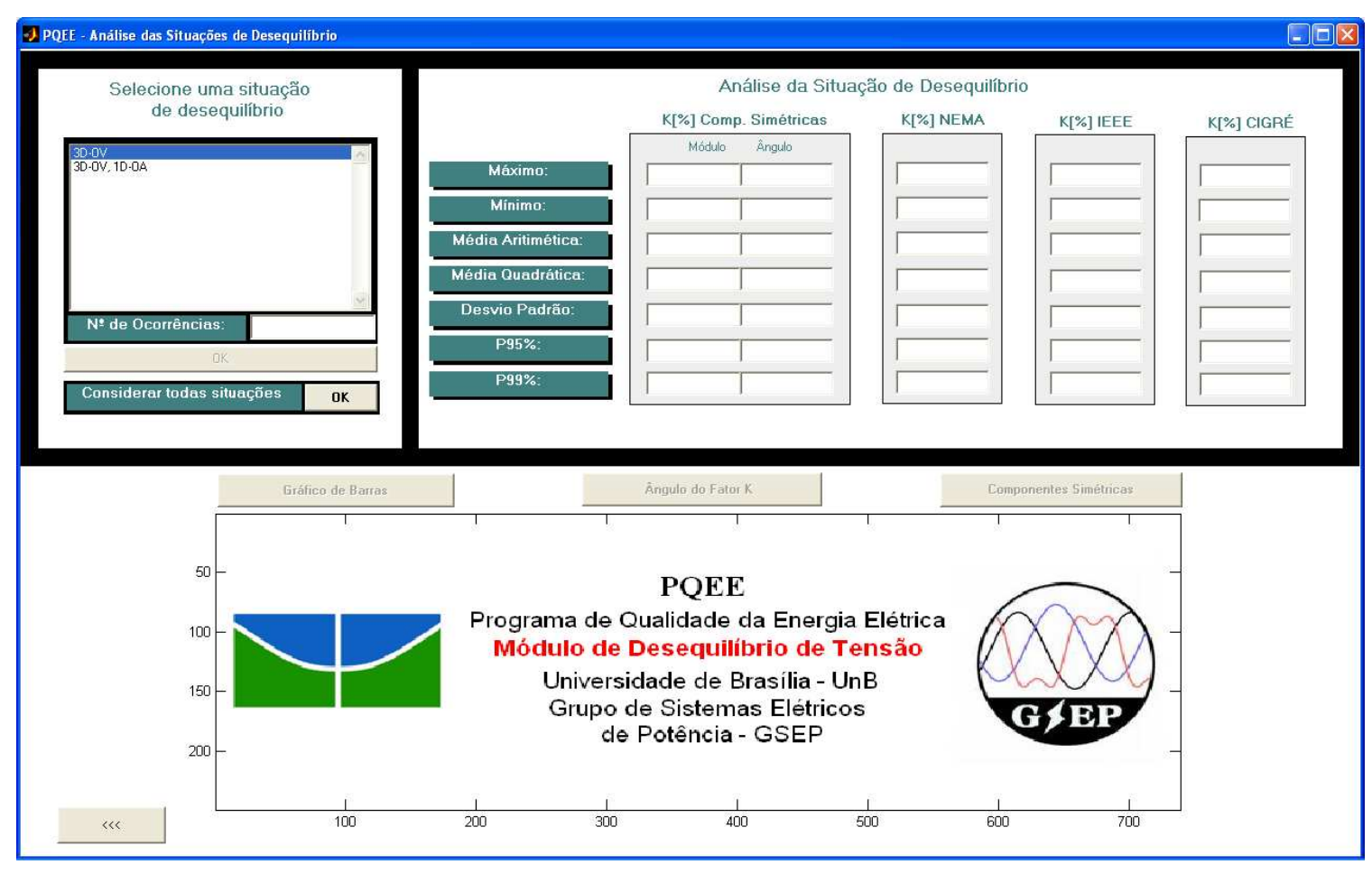

Figura 3.4 - Análise de uma Situação de Desequilíbrio

Na caixa de listagem à esquerda da tela, uma situação deve ser selecionada. Ao clicar em qualquer uma das situações listadas é indicado o número de ocorrências juntamente com a probabilidade no campo logo abaixo. Após clicar em "OK" efetuam-se os cálculos de quantificação do fator K pelos quatro métodos indicados na tela (Componentes Simétricas, 
NEMA, IEEE e CIGRÉ) e todos os campos são preenchidos com os valores estatísticos calculados.

Mais abaixo há um botão referente a "Considerar todas as situações" que, quando pressionado, efetua os cálculos de K\% considerando todas as situações simultaneamente. Essa possibilidade permite avaliar os níveis de desequilíbrio para todos os dados do banco referente ao período selecionado.

Visualiza-se ainda, nesta mesma tela, o gráfico com os valores estatísticos do fator K pelos quatro métodos anteriormente indicados e o gráfico do ângulo do fator $\mathrm{K}$, pressionando, respectivamente, os botões "Gráfico de Barras" e "Ângulo do Fator K".

Por fim, obtêm-se informações a respeito das componentes simétricas correspondentes à situação de desequilíbrio selecionada ao clicar-se no botão "Componentes Simétricas". Uma nova tela se abrirá, conforme mostrado na Figura 3.5.

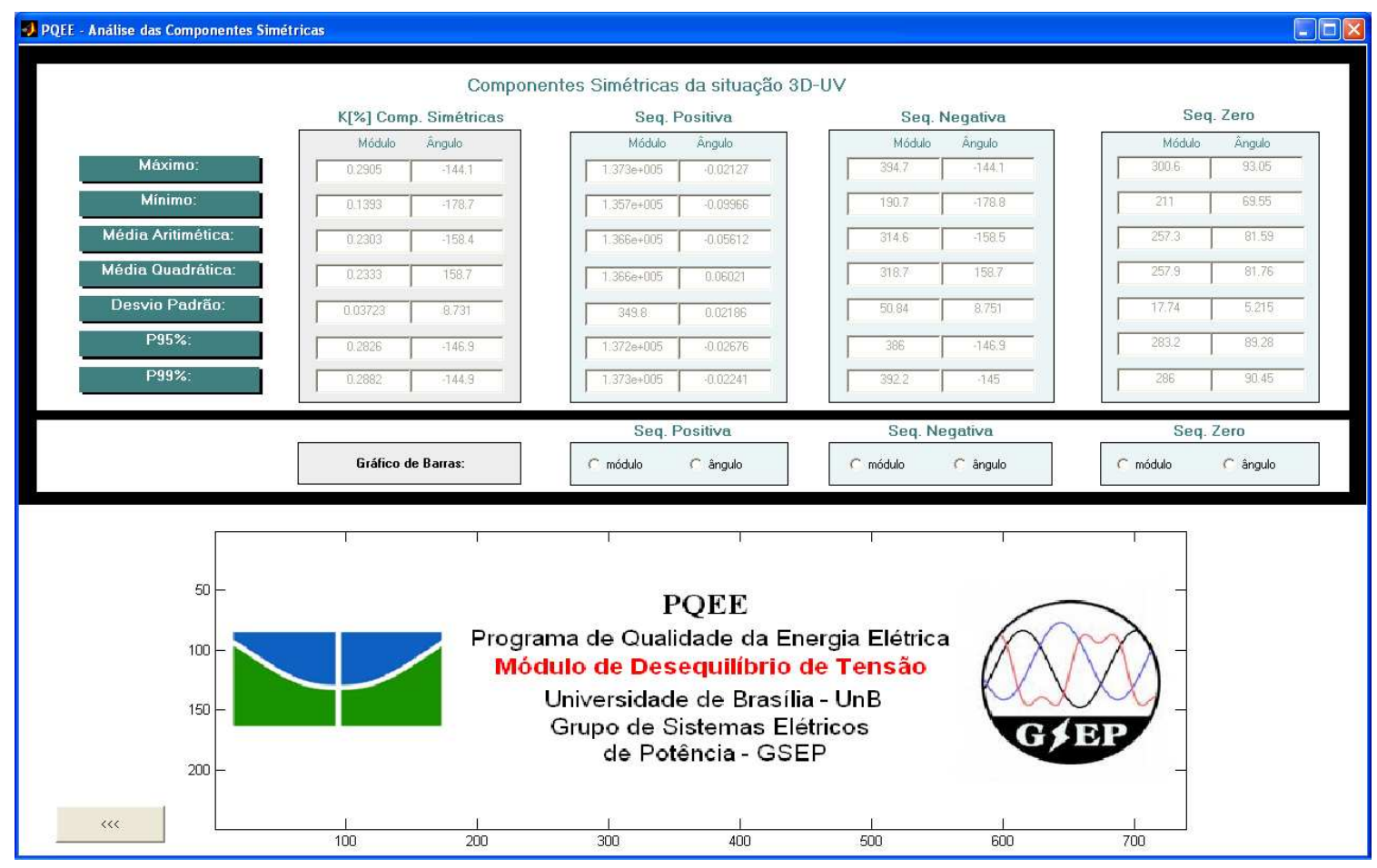

Figura 3.5 - Análise das Componentes Simétricas 
Além dos valores estatísticos das componentes de seqüência positiva, negativa e zero, verifica-se nesta tela a disposição destes valores em gráficos de barras ao clicar nos radio buttons presentes, totalizando seis gráficos compreendendo os módulos e ângulos das componentes simétricas.

\subsection{4 - Análise de Distribuição no Tempo}

Para esta análise, deve-se apertar o botão "OK" da tela inicial (Figura 3.2) situado à direita, referente a "Análise de Distribuição no Tempo". A Figura 3.6 seguinte ilustra a nova tela que se abrirá.

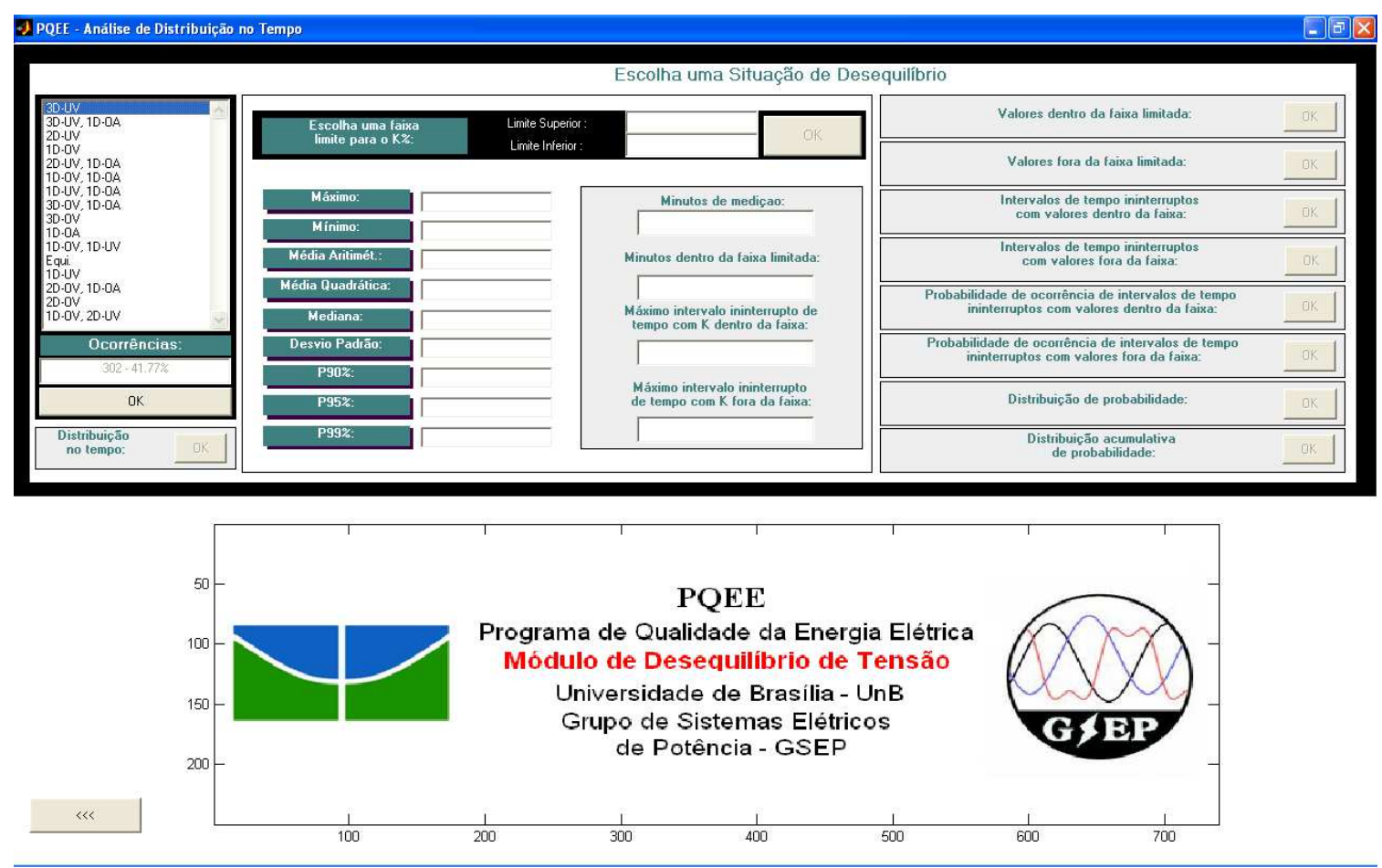

Figura 3.6 - Análise de Distribuição no Tempo

Primeiramente, deve-se selecionar uma situação para análise, feita de forma semelhante à seleção realizada na seção anterior.

Em seguida, é possível observar por meio de um gráfico como a situação de desequilíbrio escolhida está distribuída no tempo, pressionando o botão "OK" indicado por "Distribuição no tempo". 
Após ter sido selecionada uma situação de desequilíbrio, os campos com dados estatísticos são preenchidos com valores referentes ao fator $\mathrm{K}$ correspondente apenas à situação escolhida.

O passo seguinte é a definição, pelo usuário, de uma faixa de valores de $\mathrm{K} \%$ para ser analisada. Devem-se inserir valores nos campos "Limite Superior" e "Limite Inferior" para que se estabeleça a referida faixa. Como parâmetros que auxiliam na escolha dessa faixa, têm-se fornecidos os valores máximo e mínimos de $\mathrm{K} \%$. Assim, caso o usuário deseja investigar o desequilíbrio para todos os valores de $\mathrm{K} \%$ compreendidos entre o máximo e o mínimo, basta que se defina, como limite superior e limite inferior, um valor maior que o máximo e um menor que o mínimo, respectivamente.

Definida a faixa de K\%, aperta-se o botão "OK" à direita dos valores limites estabelecidos. A seguir, têm-se preenchidos os campos restantes, a saber: "Minutos de medição" (que compreende o período de tempo, em minutos, definido para análise ainda na tela inicial, Figura 3.2); "Minutos dentro da faixa limitada" (que indica o somatório de tempo em que $\mathrm{K} \%$ encontra-se contido na faixa definida); além dos campos "Máximo intervalo ininterrupto de tempo com K dentro da faixa" e "Máximo intervalo ininterrupto de tempo com $\mathrm{K}$ fora da faixa".

Há ainda oito gráficos disponibilizados nesta tela, que são visualizados conforme sejam pressionados os botões "OK” à direita da tela.

No primeiro deles, referente a "Valores dentro da faixa", plotam-se apenas os valores de $\mathrm{K} \%$ compreendidos pela faixa definida, sendo possível verificar os instantes que tais valores ocorreram. Um gráfico análogo é obtido em "Valores fora da faixa". Porém, têm-se somente valores de $\mathrm{K} \%$ não-pertencentes à faixa definida.

O gráfico disposto em "Intervalos de tempo ininterruptos com valores dentro da faixa" representa os períodos de tempo em que um equipamento apesentou valores de $\mathrm{K} \%$ compreendidos pela faixa limite estabelecida, quanto que em "Intervalos de tempo ininterruptos com valores fora da faixa" é possível verificar o máximo de minutos que o sistema permaneceu sem apresentar nenhum valor dentro da faixa especificada. 
A probabilidade de ocorrência destes intervalos pode ser observada nos gráficos disponibilizados clicando-se nos botões "OK".

Há, por fim, a possibilidade de visualização dos dados referentes aos desequilíbrios de tensão por meio da distribuição de probabilidade e de probabilidade cumulativa de ocorrências de desequilíbrios de tensão versus as suas amplitudes, a partir dos respectivos gráficos "Distribuição de probabilidade" e "Distribuição cumulativa de probabilidade".

\subsection{5 - Análise de Similaridade entre Situações}

Neste último módulo, podem-se fazer comparações entre até sete situações de desequilíbrios distintas. É preciso que se selecionem as situações que se queiram comparar simultaneamente na caixa de listagem à direita da tela, ilustrada na Figura 3.7, e pressionar “OK” em seguida.
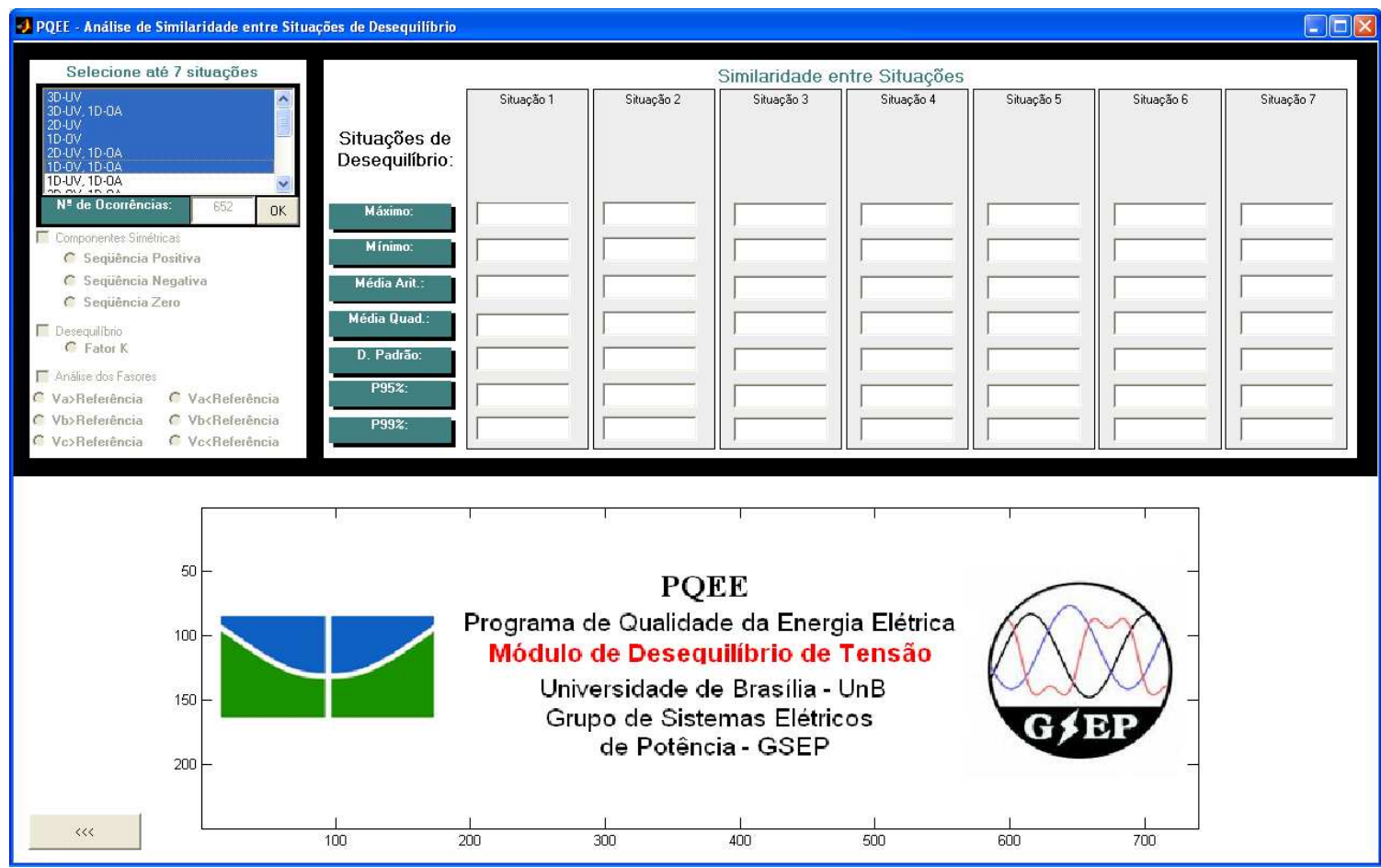

Figura 3.7 - Análise de Similaridade entre Situações de Desequilíbrio

No momento da seleção, o software indica, no campo abaixo da caixa de listagem, o somatório das ocorrências das situações selecionadas. 
Pressionando-se "OK”, as chekboxs "Componentes Simétricas", "Desequilíbrio" e "Análise dos Fasores" tornam-se ativas. Marcando-se a primeira, permite-se que se selecione uma das três componentes, fazendo com que os campos sejam preenchidos com os valores estatísticos calculados, além de serem gerados gráficos de barras correlacionando estes dados estatísticos às suas situações.

De forma análoga, após marcar marcar a checkbox "Desequilíbrio" e selecionar "Fator K", são calculados as estatísticas de $\mathrm{K} \%$ e ilustrado seu respectivo gráfico de barras.

É possível também fazer um estudo das situações de desequilíbrio analisando as tensões dos fasores que caracterizam cada situação. Objetiva-se com esta análise verificar a contribuição de cada fasor para o desequilíbrio das situações.

Assim, após marcar "Análise dos Fasores" pode-se selecionar, por exemplo, "Va (OV)". Esta opção permite examinar os valores de tensão de $V a$ que são responsáveis pela caracterização das situações em que $V a$ esteve em over-voltage (OV), ou seja, quando $V a$ apresentou elevações acima do valor nominal. Portanto, somente nas situações em que $V a$ esteve em over-voltage é que terão os campos preenchidos com o resultado dos cálculos estatísticos. Os campos que ficarem marcados com "0" correspondem às situações que não apresentam casos de OV em $\mathrm{Va}$.

A mesma interpretação é aplicada às demais opções de "Análise dos Fasores".

\section{5 - ESTUDO DE CASO}

Neste tópico serão apresentados resultados de um estudo acerca do desequilíbrio de tensão a partir da utilização dos recursos da ferramenta computacional apresentada e utilizando-se de dados do Cine Casa Park de Brasília. Os dados foram coletados na freqüência de aquisição de 10 minutos e num período de sete dias, de 0h00 do dia 19 a 0 h00 do dia 26 de dezembro de 2006. 


\subsection{1 - Ocorrências das Situações de Desequilíbrio}

As situações de desequilíbrio existentes neste período, juntamente com seu número de ocorrências e probabilidades, estão dispostos na Tabela 3.2. A Figura 3.8 representa o gráfico das situações de desequilíbrio versus probabilidade de suas ocorrências.

Tabela 3.2 - Ocorrências e Probabilidades das situações de desequilíbrio

\begin{tabular}{|c|c|c|}
\hline Situações & Ocorrências & Probabilidade (\%) \\
\hline $3 D-O V$ & 416 & 41,27 \\
\hline $3 D-U V, 1 D-U A$ & 188 & 18,65 \\
\hline $3 D-U V$ & 126 & 12,50 \\
\hline $3 D-U V, 1 D-O A$ & 75 & 7,44 \\
\hline $3 D-U V, 1 D-O A, 1 D-U A$ & 27 & 2,68 \\
\hline $2 D-O V, 1 D-U V$ & 25 & 2,48 \\
\hline $3 D-O V, 1 D-U A$ & 22 & 2,18 \\
\hline $3 D-U V, 2 D-O A$ & 16 & 1,59 \\
\hline $2 \mathrm{D}-\mathrm{OV}$ & 15 & 1,49 \\
\hline $2 D-U V, 1 D-O A$ & 13 & 1,29 \\
\hline $3 D-O V, 1 D-O A$ & 12 & 1,19 \\
\hline $1 D-O V, 1 D-U V$ & 12 & 1,19 \\
\hline $2 D-U V$ & 12 & 1,19 \\
\hline $1 D-U V$ & 10 & 0,99 \\
\hline $2 D-O V, 1 D-U V, 1 D-U A$ & 9 & 0,89 \\
\hline $2 D-O V, 1 D-U A$ & 7 & 0,69 \\
\hline $2 D-O V, 1 D-O A$ & 5 & 0,50 \\
\hline $1 D-O V, 1 D-U V, 1 D-O A$ & 4 & 0,40 \\
\hline $2 D-U V, 1 D-U A$ & 4 & 0,40 \\
\hline $2 D-O V, 1 D-U V, 1 D-O A$ & 3 & 0,30 \\
\hline $1 D-O V, 2 D-U V, 1 D-O A$ & 3 & 0,30 \\
\hline $1 D-O V, 2 D-U V, 1 D-U A$ & 2 & 0,20 \\
\hline
\end{tabular}




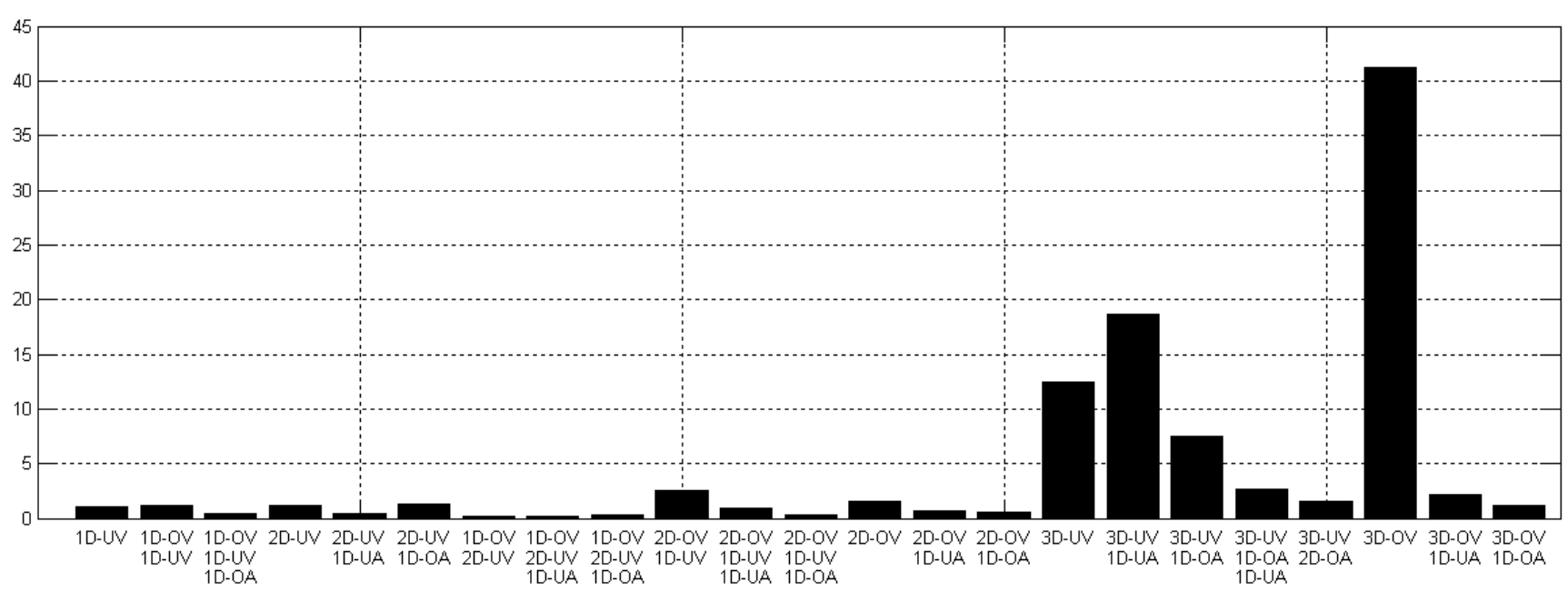

Figura 3.8 - Situações de Desequilíbrio e probabilidade de suas ocorrências

Do total de 22 situações diferentes registradas, destaca-se a situação 3D-OV, com mais de $40 \%$ das ocorrências seguidas por outras três que somadas respondem por quase outros $39 \%$. As restantes foram bem menos expressivas, visto que nenhuma delas atingiu sequer $3 \%$ do total. O fato das três situações que seguem a de maior ocorrência conterem a condição 3D-UV é outro interessante detalhe que vale ser ressaltado.

\subsection{2 - Análise dos métodos de cálculo de K\%}

A partir das informações obtidas no módulo "Análise de uma situação de Desequilíbrio", faz-se a comparação entre os quatro métodos de cálculo do fator K para a situação 3D-OV. A Tabela 3.3 traz os valores estatísticos e a Figura 3.9 o gráfico comparativo.

Tabela 3.3 - Estatísticas de K\% pelos quatro métodos de cálculo para a situação 3D-OV

\begin{tabular}{|c|c|c|c|c|c|}
\hline \multirow{3}{*}{ Estatísticas } & \multicolumn{5}{|c|}{$K \%$} \\
\hline & \multicolumn{2}{|c|}{ Componentes Simétricas } & \multirow{2}{*}{ CIGRÉ } & \multirow{2}{*}{ NEMA } & \multirow{2}{*}{ IEEE } \\
\hline & Módulo & Ângulo & & & \\
\hline Máximo & 0.5310 & 32.4500 & 0.5162 & 0.5077 & 0.8534 \\
\hline Mínimo & 0.0510 & -83.2400 & 0.0464 & 0.0268 & 0.0793 \\
\hline Média Aritmética & 0.2328 & -39.9800 & 0.2248 & 0.2034 & 0.3699 \\
\hline Média Quadrática & 0.2482 & 43.6800 & 0.2403 & 0.2212 & 0.3941 \\
\hline Desvio Padrão & 0.0863 & 17.6200 & 0.0850 & 0.0870 & 0.1361 \\
\hline $\mathrm{P} 95 \%$ & 0.3765 & -6.2680 & 0.3675 & 0.3603 & 0.5885 \\
\hline P99\% & 0.5096 & 16.3000 & 0.5040 & 0.4943 & 0.7698 \\
\hline
\end{tabular}




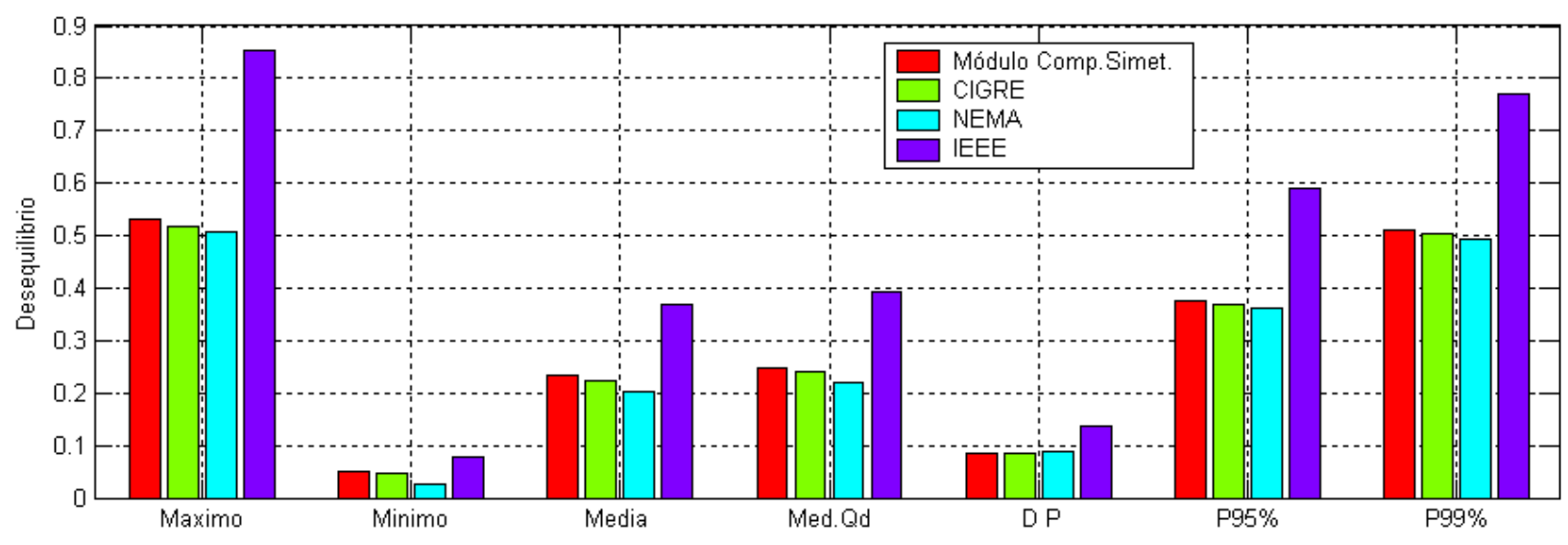

Figura 3.9 - Gráfico de barras comparativo dos métodos de K\% para a situação 3D-OV

Os níveis de desequilíbrio estiveram dentro dos limites comumente utilizados pelas normas e recomendações, conforme índices de conformidade indicados na Tabela 2.3 Da Figura 3.9, constata-se que é significativa a forma como divergem os resultados calculados pelos métodos. Os maiores índices são apresentados pelo IEEE, ao passo que os outros três forneceram valores próximos entre si. Observa-se ainda que, apesar de o IEEE possuir o maior dentre os valores mínimos calculados, ele é o que possui a maior taxa de variação, culminando no maior desvio-padrão.

Numa análise seguinte, para inferir acerca dos valores da Tabela 3.2 e representados no gráfico da Figura 3.10, referentes ao ângulo do fator K, ressalta-se antes que o significado físico deste ângulo dá-se pela diferença entre ângulo de sequiência negativa e o de seqüência positiva, além de ser um parâmetro apresentando como os fasores de tensão estão arranjados. Como os três fasores de tensão de linha devem formar um triângulo, então unicamente pela relação dos lados do triângulo determina-se o nível de $\mathrm{K} \%$ e seu ângulo (WANG, 2001). 


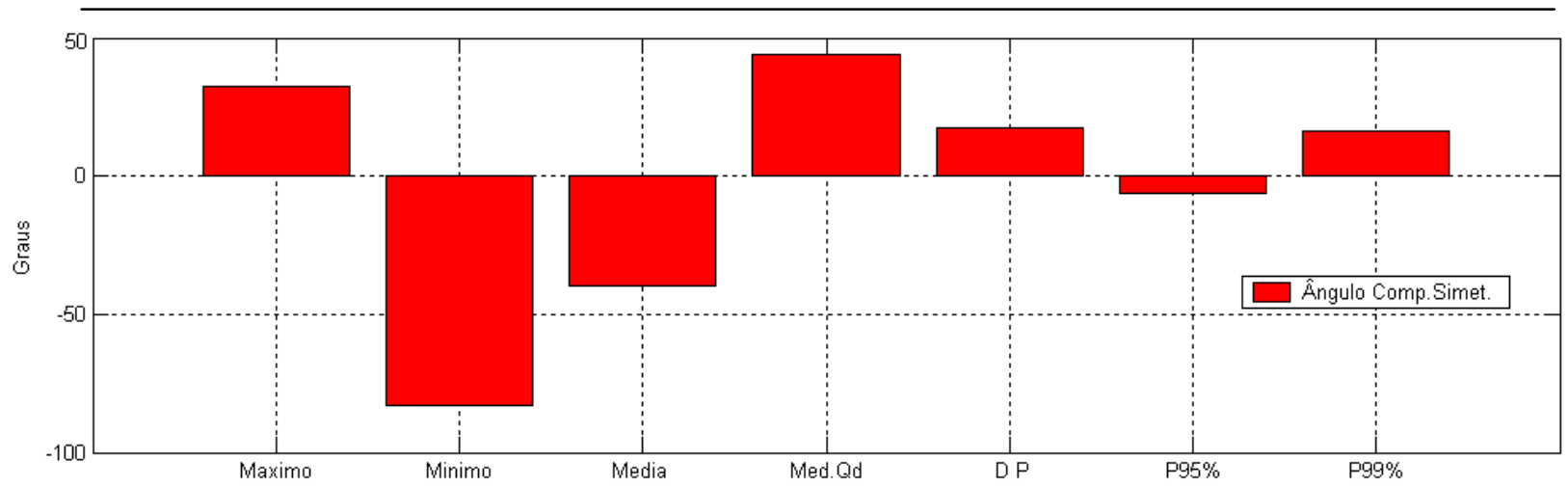

Figura 3.10 - Ângulo do fator K para a situação 3D-OV

Wang (2001) expôs em seu trabalho uma representação gráfica que relaciona as tensões de linha com níveis de K\% e seu ângulo. Ao observar a Figura 3.10 percebe-se para a situação de desequilíbrio analisada que os valores de ângulo de K\% ocupam uma vasta faixa, diagnosticada pela alta variação entre o máximo e o mínimo desses valores, cuja média deu-se por volta de $-40^{\circ}$. No estudo de condições de desequilíbrios de tensão, Lee (1997) considerou efeitos que produzem diferentes casos de desequilíbrio, mas com $\mathrm{K} \%$ de mesma magnitude. Dessa forma, deduz-se que $\mathrm{K} \%$ pode apresentar diferentes ângulos para mesmos valores de magnitude. Trata-se portanto de uma grandeza de significativa representatividade. Wang (2001) faz um estudo mais aprofundado nesse sentido, a fim de verificar uma relação entre o ângulo de $\mathrm{K} \%$ e os efeitos provocados na operação de motores, além de apresentar um método analítico que avalia os melhores e piores casos.

\subsubsection{1 - Quantificação do desequilíbrio abrangendo todas situações presentes}

Pressionando o botão "OK" mais abaixo da caixa de listagem, referente a "Considerar todas as situações", são calculados os valores de K\% com dados de todas situações identificadas no período em análise selecionado. Os seguintes resultados são obtidos (Tabela 3.4): 
Tabela 3.4 - Estatísticas de K\% pelos quatro métodos de cálculo considerando todas situações

\begin{tabular}{|c|c|c|c|c|c|}
\hline \multirow{3}{*}{ Estatísticas } & \multicolumn{5}{|l|}{$K \%$} \\
\hline & \multicolumn{2}{|c|}{ Componentes Simétricas } & \multirow{2}{*}{ CIGRÉ } & \multirow{2}{*}{ NEMA } & \multirow{2}{*}{ IEEE } \\
\hline & Módulo & Ângulo & & & \\
\hline Máximo & 0.9188 & 32.4500 & 0.9097 & 0.8930 & 1.5170 \\
\hline Mínimo & 0.0510 & -83.2400 & 0.0464 & 0.0268 & 0.0793 \\
\hline Média Aritmética & 0.4187 & -42.2500 & 0.4097 & 0.3870 & 0.6702 \\
\hline Média Quadrática & 0.4795 & 45.5600 & 0.4709 & 0.4540 & 0.7681 \\
\hline Desvio Padrão & 0.2338 & 17.0400 & 0.2323 & 0.2374 & 0.3754 \\
\hline P95\% & 0.8103 & -7.6900 & 0.7997 & 0.7925 & 1.2980 \\
\hline P99\% & 0.8839 & 13.8600 & 0.8742 & 0.8441 & 1.4250 \\
\hline
\end{tabular}

Nota-se que ao se analisar o desequilíbrio do banco de dados de modo geral, os valores das médias de $\mathrm{K} \%$ da tabela 3.4 atingem quase o dobro dos apresentados na Tabela 3.3 - que considera apenas os valores de desequilíbrio da situação 3D-OV. Certamente este fato é devido a existência de maiores níveis de desequilíbrio nas situações de menores ocorrências

\subsection{3 - Análise das Componentes Simétricas}

Seguindo com a análise da situação 3D-OV, na tela de análise das componentes, obtiveramse os resultados da Tabela 3.5 referentes aos fasores de sequiência positiva, negativa e zero. As Figuras 3.11 e 3.12 apresentam gráficos para os valores de módulos e ângulos da Seqüência Positiva.

Tabela 3.5 - Estatísticas das Componentes Simétricas para a situação 3D-OV

\begin{tabular}{c|cc|cc|cc}
\hline \multirow{2}{*}{ Estatísticas } & \multicolumn{7}{|c}{ Componentes Simétricas } \\
\cline { 2 - 7 } & \multicolumn{2}{|c|}{ Seqüência Positiva } & \multicolumn{2}{|c}{ Seqüência Negativa } & \multicolumn{2}{c}{ Seqüência Zero } \\
\cline { 2 - 7 } Máximo & Módulo & Ângulo & Módulo & Angulo & Módulo & Ângulo \\
\cline { 2 - 7 } & 233.1000 & 0.1034 & 1.1870 & 32.3500 & 0.8776 & 141.0000 \\
Mínimo & 221.8000 & -0.1407 & 0.1175 & -83.2200 & 0.0364 & 0.9512 \\
Média Aritmética & 226.7000 & 0.0113 & 0.5276 & -39.9700 & 0.3480 & 82.2000 \\
Média Quadrática & 226.7000 & 0.0399 & 0.5625 & 43.6600 & 0.3875 & 88.1300 \\
Desvio Padrão & 2.1810 & 0.0383 & 0.1955 & 17.5900 & 0.1707 & 31.8200 \\
P95\% & 231.0000 & 0.0677 & 0.8649 & -6.2740 & 0.7110 & 127.9000 \\
P99\% & 232.4000 & 0.0823 & 1.1480 & 16.2000 & 0.8291 & 138.0000 \\
\hline
\end{tabular}




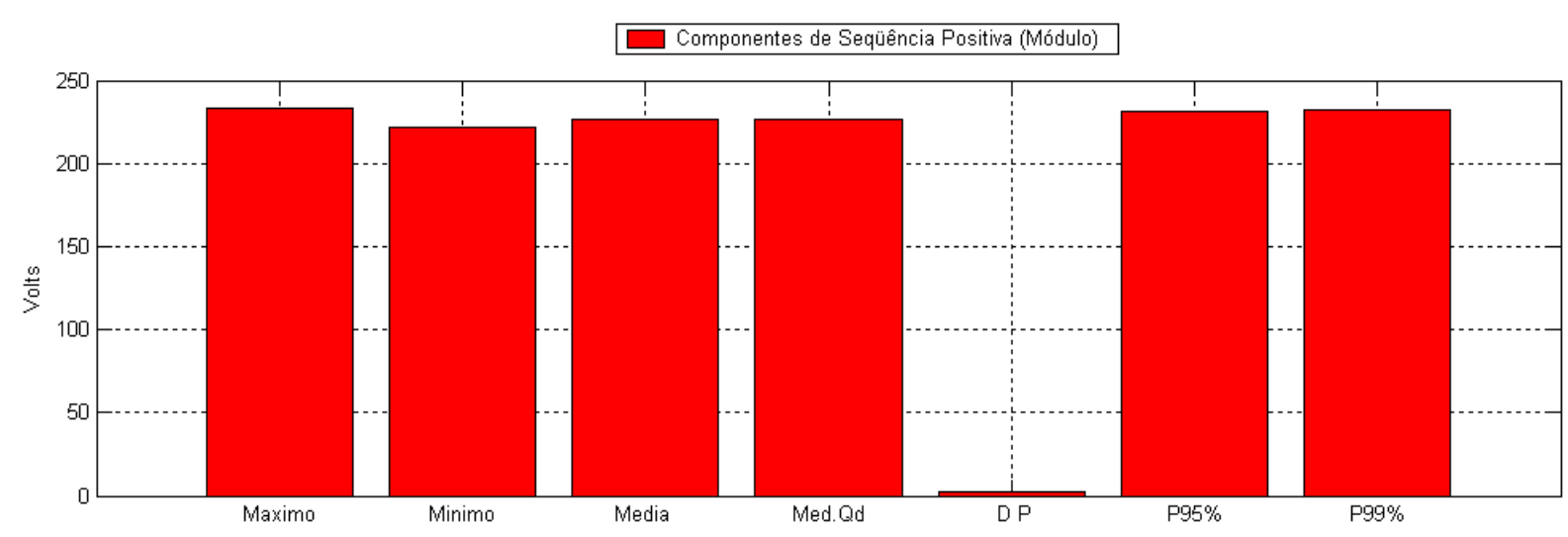

Figura 3.11 - Gráfico de barras das Estatísticas de Módulo da Componente de Seqüência Positiva

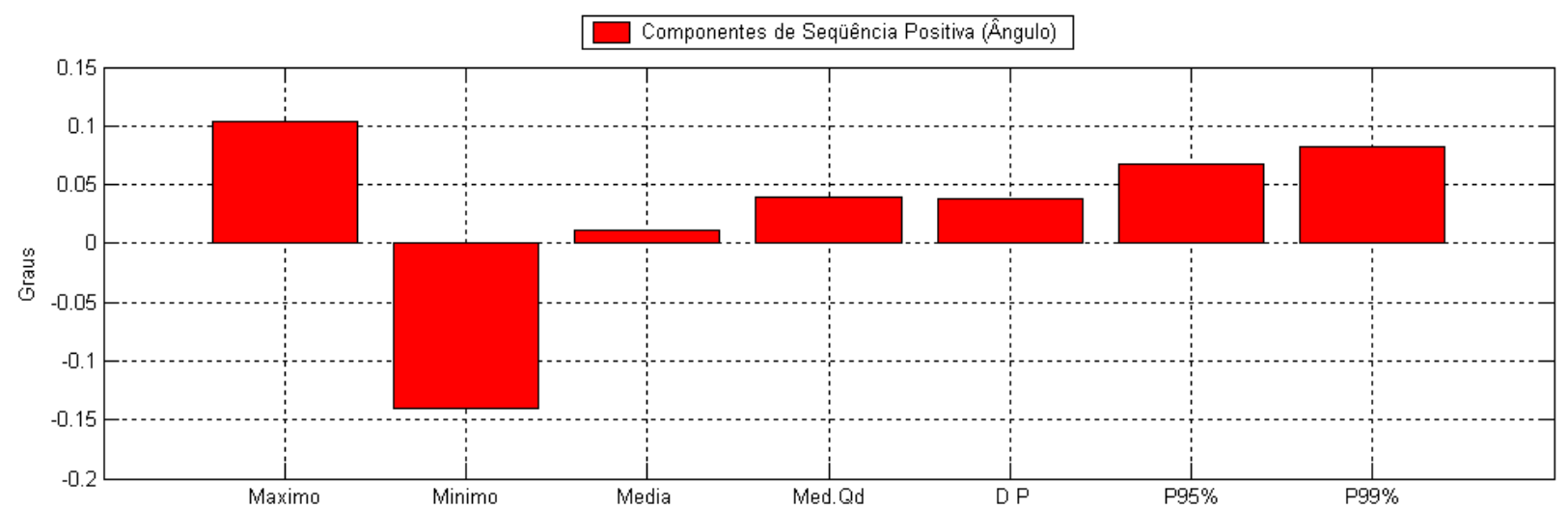

Figura 3.12 - Gráfico de barras das Estatísticas de ângulo da Componente de Seqüência Positiva

Normalmente as tensões de sequiência positiva são muito próximas do valor nominal. Se expressadas em p.u., estarão perto de 1 p.u.. Na Figura 3.11 nota-se que as variações de módulo são muito pequenas, o que justifica um desvio padrão inferior a 3[V]. Mas apesar do baixo desvio padrão, os valores das médias quadrática e aritmética e de P95\% e P99\% são todos superiores à tensão nominal. Uma explicação para este fato decorre da situação analisada conter os três fasores em over-voltage.

Os valores de sequiência positiva também fornecem informações com relação à efeitos em motores de indução. Maiores valores de seqüência positiva proporcionam maior eficiência aos motores, entretanto, causam diminuição do fator de potência (Lee, 1997). 
Da Figura 3.12 verificam-se ser ínfimos os deslocamentos angulares. O maior valor registrado foi em torno de $0.1^{\circ}$.

Para analisar as componentes de seqüência negativa, expõem-se nas Figuras 3.13 e 3.14 os gráficos de módulo e ângulo das estatísticas calculadas.

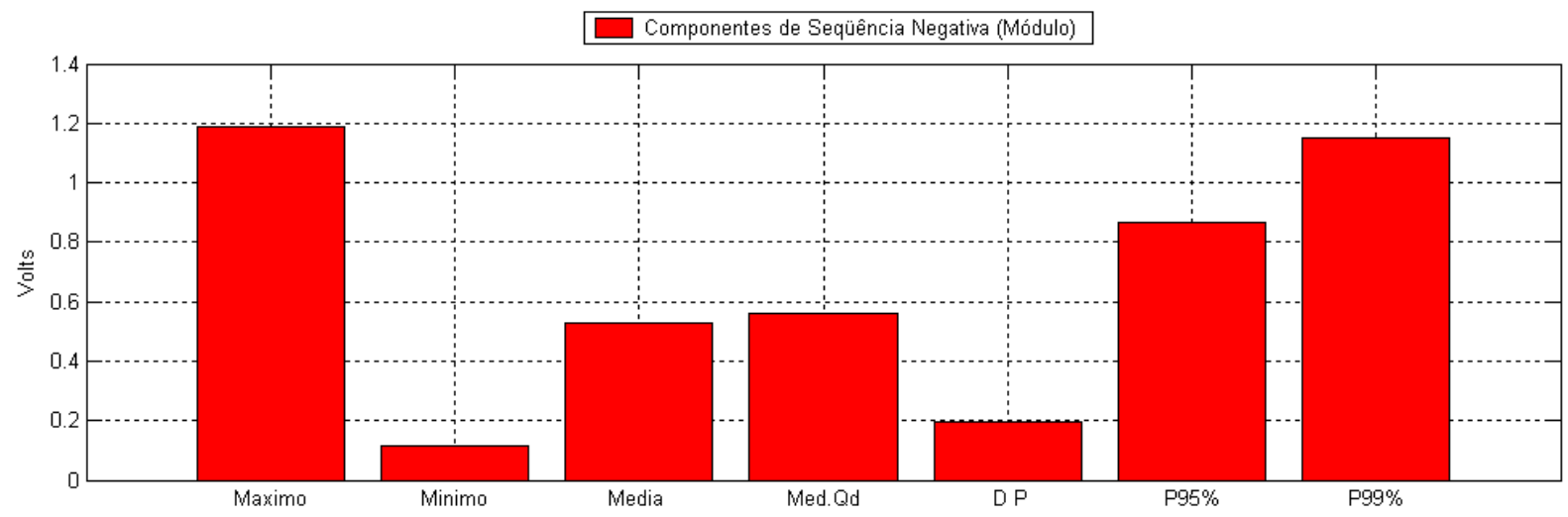

Figura 3.13 - Gráfico de barras das Estatísticas de Módulo da Componente de Seqüência Negativa

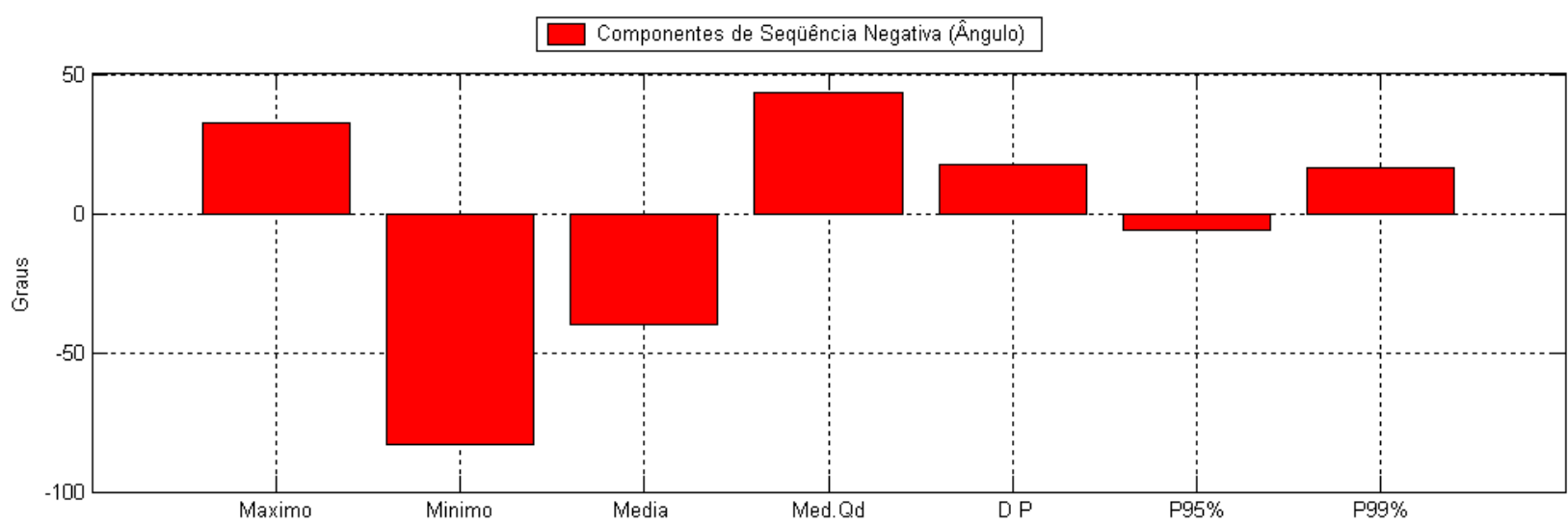

Figura 3.14 - Gráfico de barras das Estatísticas de ângulo da Componente de Sequiência Negativa Como os valores de seqüência positiva são muito próximos a 1 p.u., as correspondentes tensões de seqüência negativa possuem alguma semelhança aos indicadores de K\%. Vê-se na Figura 3.13 que as médias quadráticas e aritméticas são de quase 0.5 [V]. É um valor baixo, o que explica os baixos índices de K\% ilustrado na Figura 3.9.

Quanto aos ângulos, é um indicador de valor representativo por se tratar do maior responsável da composição do ângulo do fator K. Como os ângulos de seqüência positiva 
são praticamente nulos, nota-se que o gráfico da Figura 3.14 é praticamente igual ao gráfico do ângulo de K\% na Figura 3.10.

Por fim investigam-se as tensões de componentes de seqüência zero, que de acordo com o Teorema das Componentes Simétricas, juntamente às de seqüência negativa, perturbam as positivas causando desequilíbrios.

A partir dos perfis analisados nas Figuras 3.15 e 3.16, constata-se que mesmo que os valores de ângulo compreendam a ampla faixa de $0^{\circ}$ a $140^{\circ}$, pouca influência é dada por esta componente, visto que os valores de módulo também são bastante próximos de zero.

Porém, em certos casos ela não deve ser desprezada. Acontece que se a soma dos fasores de tensão de linha for nula, não existem componentes de seqüência zero nas tensões de linha. Mas haverá corrente de seqüência zero em caso de existir um circuito fechado no qual ela possa circular, como em sistemas trifásicos a 4 fios e em sistemas a 3 fios com ligação estrela aterrada.

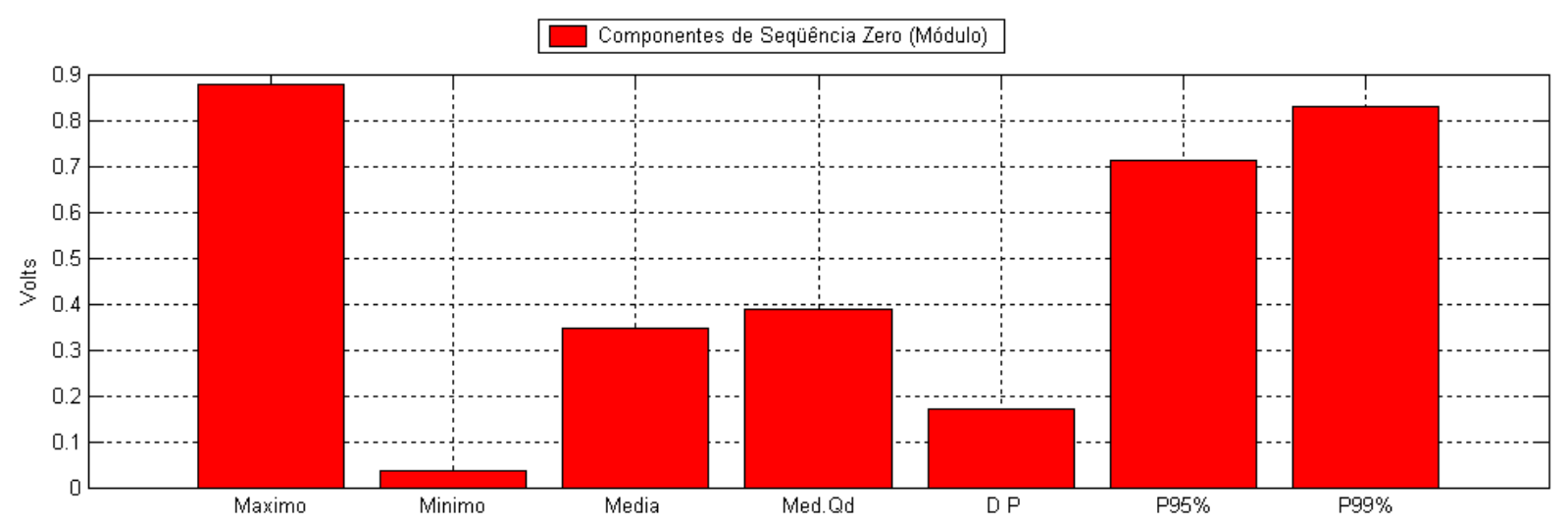

Figura 3.15 - Gráfico de barras das Estatísticas de Módulo da Componente de Seqüência Zero 


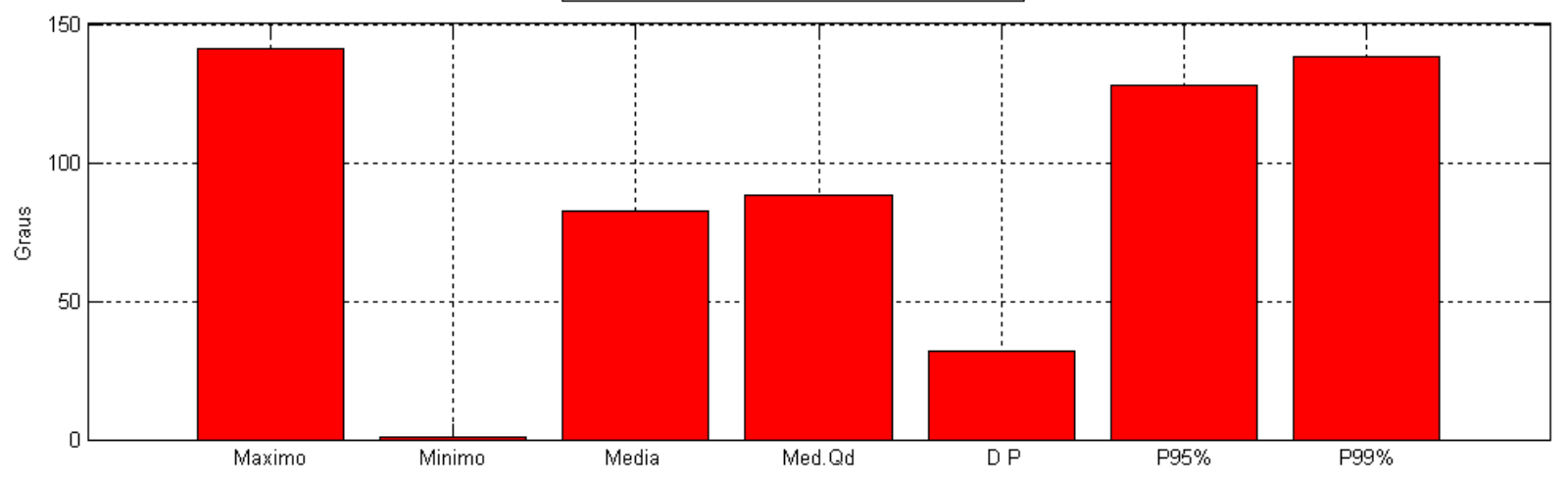

Figura 3.16 - Gráfico de barras das Estatísticas de ângulo da Componente de Seqüência Zero

\subsection{4 - Análise de Distribuição no Tempo}

Procede-se agora à aplicação das avaliações disponíveis no módulo "Análise de Distribuição no Tempo" para a situação 3D-OV. O tempo total que esta situação ocorreu foi de 4.160 minutos, determinado ao definir, no software, uma faixa limite definido pelo mínimo e máximo de K\% para 3D-OV. A Figura 3.17 ilustra a distribuição das ocorrências desta situação em todo o período de análise.

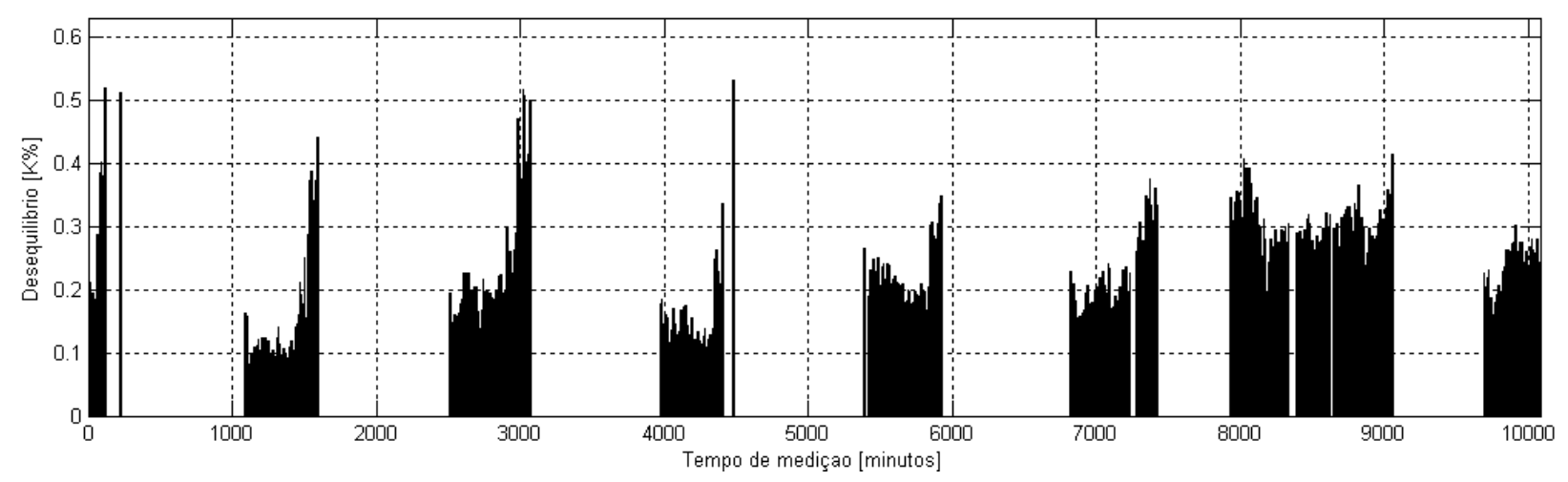

Figura 3.17 - Distribuição no tempo da situação 3D-OV

Nota-se que as aparições da situação $3 \mathrm{D}-\mathrm{OV}$ se dão praticamente intercaladas e periodicamente. Sabe-se que o banco de dados em análise começou a medição dos dados a 0h do dia 19 de dezembro de 2006. Significa que os primeiros registros da situação identificados no gráfico correspondem às primeiras horas do dia 19. Os cinco seguintes conjuntos de aparições de 3D-OV deram-se todos por volta de $18 \mathrm{~h}$ e avançam até cerca de 
2h ou 3 h de cada dia. Já no período situado na faixa de 8.000 a 9.000 minutos, referente a domingo, dia 24 de dezembro, as ocorrências começaram mais cedo que nos dias anteriores. Por se tratar de dados coletados de locais de cinema, conclui-se que as ocorrências registradas devem-se aos principais momentos em que os cinemas estiveram em funcionamento. Em especial no dia de domingo, quando normalmente há uma maior demanda pelo cinema, em relação a outros dias da semana, já no período da tarde.

A seguir, uma análise comparativa será feita entre níveis de $\mathrm{K} \%$ indicados pelos índices P95\%, P99\% e média quadrática, dados por $0.3765 \%, 0.5096 \%$ e $0.2482 \%$, respectivamente. Os referidos índices encontram-se também indicados na Tabela 3.3. As distribuições no tempo destes valores de K serão investigadas.

Para isso, estes três índices foram utilizados na definição da faixa que deve ser estabelecida no software, utilizando-os como limites superiores e estabelecendo, para os inferiores, o valor mínimo de $\mathrm{K} \%$. O período total de medição é de 10.080 minutos. A Tabela 3.6 mostra os seguintes resultados:

Tabela 3.6 - Resultados com relação aos índices P95\%, P99\% e Média Quadrática

\begin{tabular}{|c|c|c|c|}
\hline \multirow[b]{2}{*}{ medidas } & \multicolumn{3}{|c|}{ Índices } \\
\hline & $\begin{array}{c}\text { Média } \\
\text { Quadrática } \\
0.2482 \%\end{array}$ & $\begin{array}{l}\mathrm{P} 95 \% \\
0.3765 \%\end{array}$ & $\begin{array}{l}\mathrm{P} 99 \% \\
0.5096 \%\end{array}$ \\
\hline Minutos dentro da faixa limitada & 2.450 & 3.960 & 4.120 \\
\hline $\begin{array}{l}\text { Máximo intervalo ininterrupto de tempo } \\
\text { com K\% dentro da faixa }\end{array}$ & 420 & 510 & 510 \\
\hline $\begin{array}{l}\text { Máximo intervalo ininterrupto de tempo } \\
\text { com } \mathrm{K} \% \text { fora da faixa }\end{array}$ & 210 & 50 & 10 \\
\hline
\end{tabular}

Observa-se que o tempo que $\mathrm{K} \%$ permaneceu dentro da faixa, quando o limite superior desta foi estabelecida com o valor de probabilidade de $99 \%$ de não ser excedida, foi maior que quando o limite foi definido utilizando-se P95\%. Devido às próprias definições destes índices, esperava-se a obtenção deste resultado. 
$\mathrm{O}$ maior valor de máximo intervalo ininterrupto de tempo com $\mathrm{K} \%$ fora da faixa foi obtido com o limite definido com a média quadrática. Contudo, notam-se variações entre os valores adquiridos para cada estudo, indicando que a distribuição no tempo se dá de forma diferente para cada índice.

As análises prosseguirão mantendo o valor mínimo como limite inferior e considerando cada um dos referidos índices, separadamente, como limite superior

\subsubsection{1 - Análise utilizando a média quadrática como limite superior}

As Figuras 3.18 e 3.19 trazem, respectivamente, o gráfico dos valores de K\% compreendidos pelo intervalo mínimo $\leq \mathrm{K} \% \leq$ média quadrática versus tempo de medição e o gráfico complementar, isto é, dos valores de $\mathrm{K} \%$ que ficaram fora da faixa especificada. Lembrando que os valores mínimos e média quadrática usados são os obtidos para a situação 3D-OV.

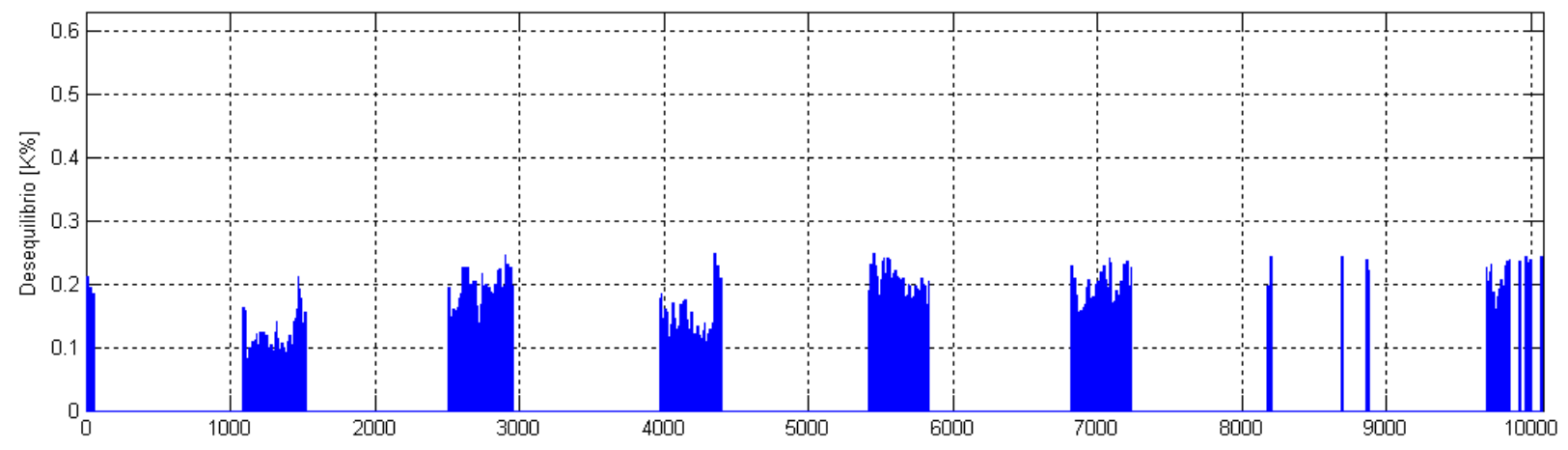

Figura 3.18 - Gráfico dos valores de $\mathrm{K} \%$ dentro da faixa mínimo $\leq \mathrm{K} \% \leq$ média quadrática

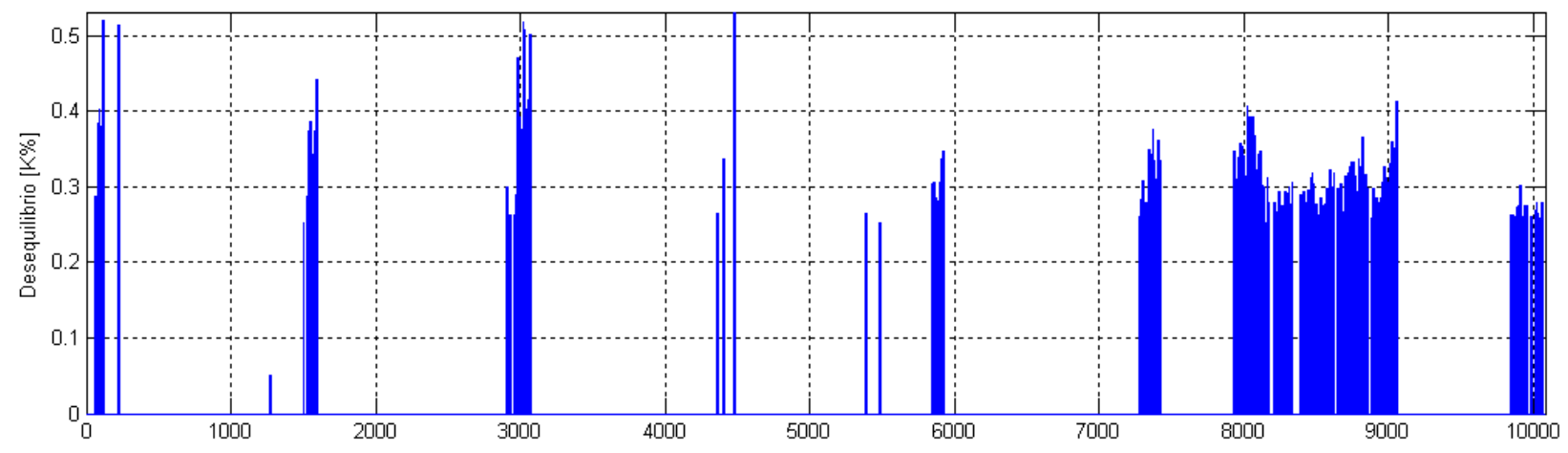

Figura 3.19 - Gráfico dos valores de $\mathrm{K} \%$ fora da faixa mínimo $\leq \mathrm{K} \% \leq$ média quadrática 
Constata-se que, nos grupos de ocorrências de 3D-OV que ocorreram em cada um dos dias de medição do banco, os valores dentro da faixa (Figura 3.18) compreendem a primeira porção desses grupos, e os que excedem essa faixa (Figura 3.19) constituem a porção final e da maioria das ocorrências registradas no dia 24 (situado aproximadamente entre 8000 e 9000 minutos). Como o tempo total de ocorrências desta situação foi de 4.160 minutos e o tempo com $\mathrm{K} \%$ dentro da faixa, de 2.450 minutos, verifica-se que existiram mais ocorrências dentro do que fora da faixa especificada.

As Figuras 3.20 e 3.21 trazem os intervalos ininterruptos de tempo com $\mathrm{K} \%$ dentro e fora da faixa.

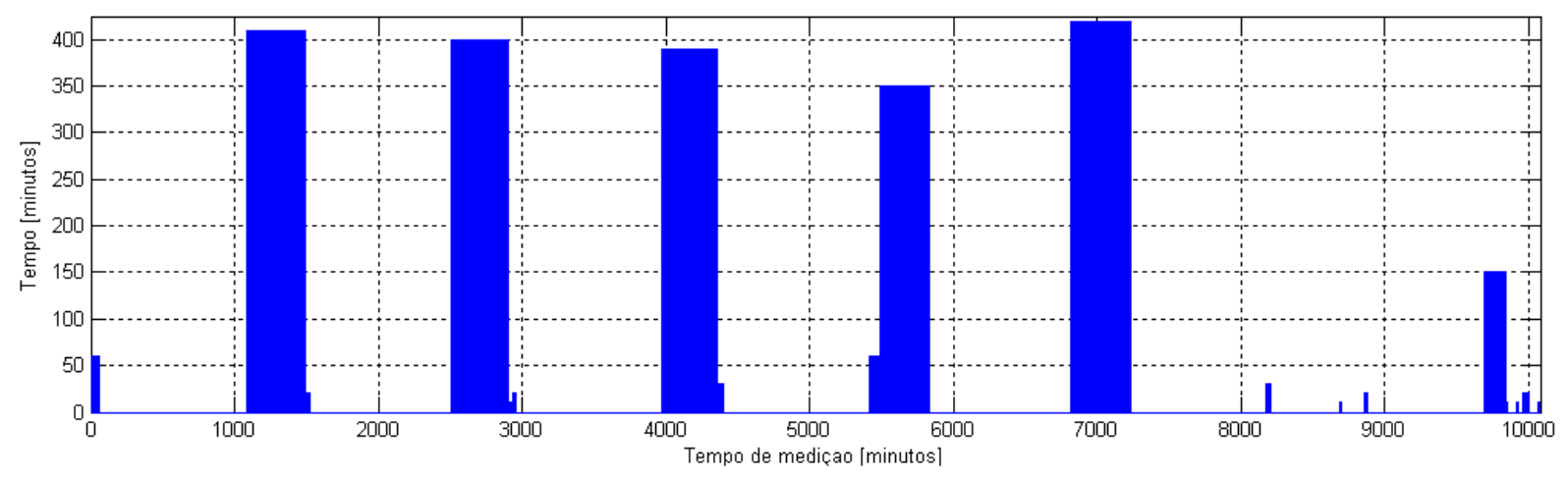

Figura 3.20 - Intervalos ininterruptos com $\mathrm{K} \%$ dentro da faixa mínimo $\leq \mathrm{K} \% \leq$ média quadrática

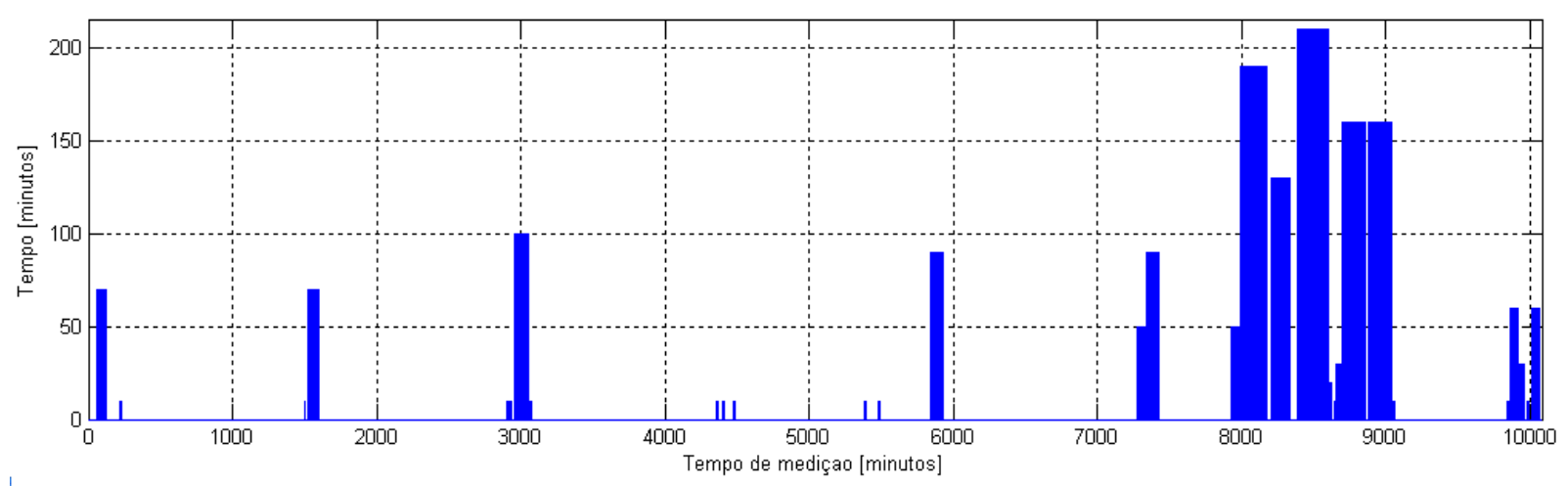

Figura 3.21 - Intervalos ininterruptos com $\mathrm{K} \%$ fora da faixa mínimo $\leq \mathrm{K} \% \leq$ média quadrática

Constata-se que os cinco maiores intervalos da Figura 3.20 possuem mais ou menos o mesmo tempo, com destaque para o de maior duração, sendo um pouco superior 400 minutos, equivalente a quase sete horas. 
Já para o período correspondente a domingo, os níveis de $\mathrm{K} \%$ foram maiores que a média quadrática. Por isso observam-se os maiores intervalos ininterruptos fora da faixa, na Figura 3.21, justamente neste período. O maior deles atinge mais de 200 minutos. A soma destes intervalos dá-se por volta de 1000 minutos, que corresponde a mais de 16 horas. Verificam-se também alguns intervalos de menor duração presentes nos demais dias.

Observam-se ainda as probabilidades de ocorrências destes intervalos ininterruptos nas Figuras 3.22 e 3.23

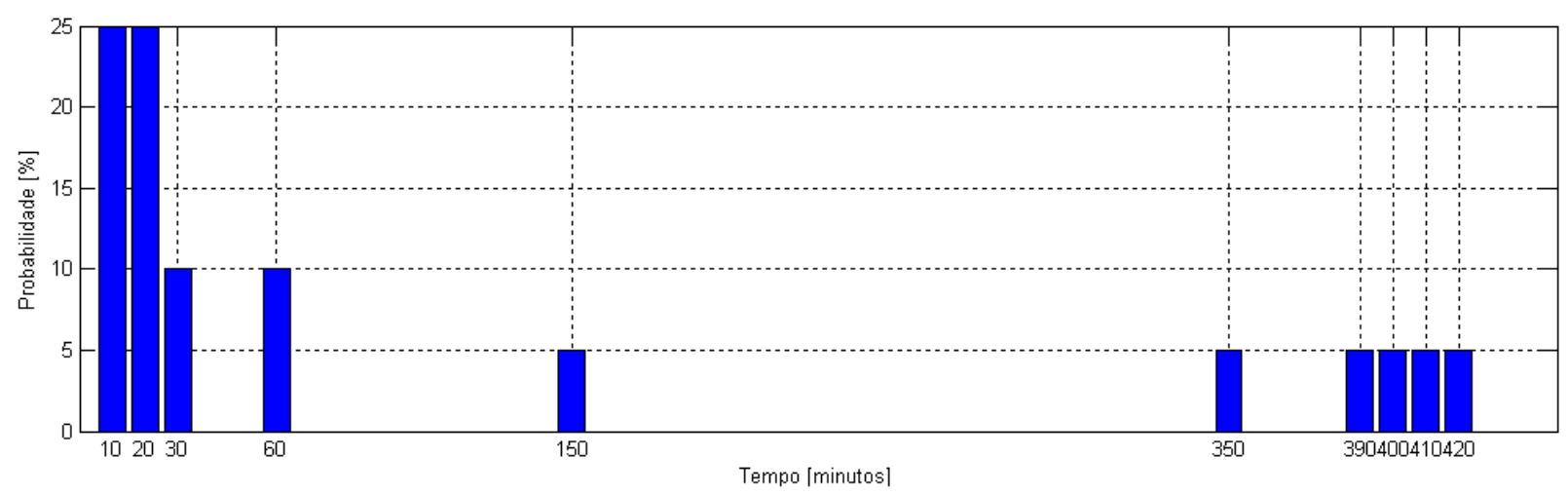

Figura 3.22 - Probabilidade das ocorrências dos intervalos de tempo ininterruptos com valores dentro da faixa mínimo $\leq \mathrm{K} \% \leq$ média quadrática

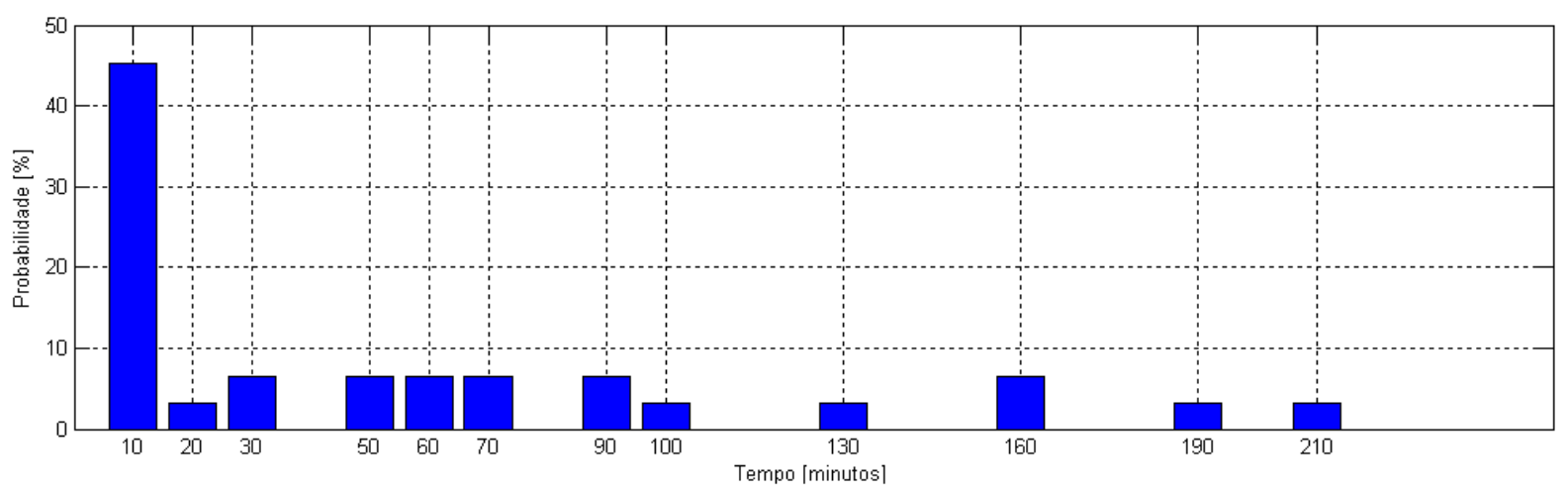

Figura 3.23 - Probabilidade das ocorrências dos intervalos de tempo ininterruptos com valores fora da faixa mínimo $\leq \mathrm{K} \% \leq$ média quadrática

Certifica-se na figura 3.22 que os cinco intervalos de tempo de maior duração possuem probabilidade de 5\%. Já os intervalos menores, de 10 e 20 minutos, somados, compreendem $50 \%$ das probabilidades. 
Na Figura 3.23 predomina o intervalo de 10 minutos, sendo responsável por cerca de $45 \%$ das ocorrências de 3D-OV fora da faixa. No entanto os intervalos maiores não chegaram a atingir $10 \%$ cada, tendo assim suas probabilidades bem distribuídas.

\subsubsection{2 - Análise utilizando P95\% como limite superior}

Os gráficos que compreendem os valores do fator $\mathrm{K}$ dentro e fora da faixa mínimo $\leq \mathrm{K} \% \leq$ P95\% são mostrados nas Figuras 3.24 e 3.25 seguintes.

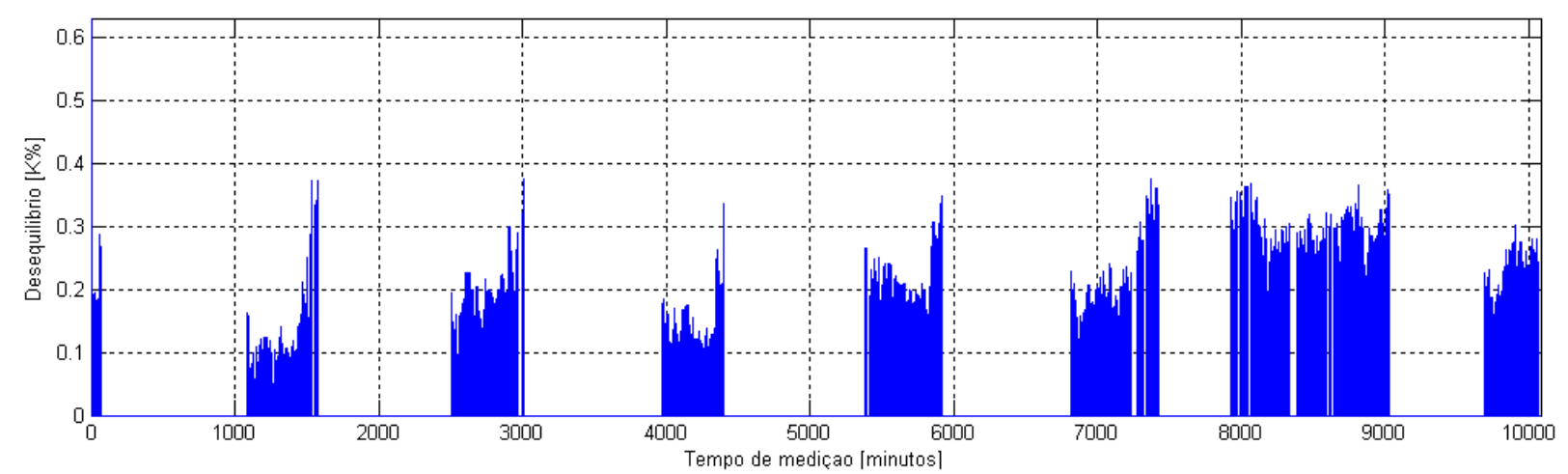

Figura 3.24 - Gráfico dos valores de $\mathrm{K} \%$ dentro da faixa mínimo $\leq \mathrm{K} \% \leq P 95 \%$ versus tempo

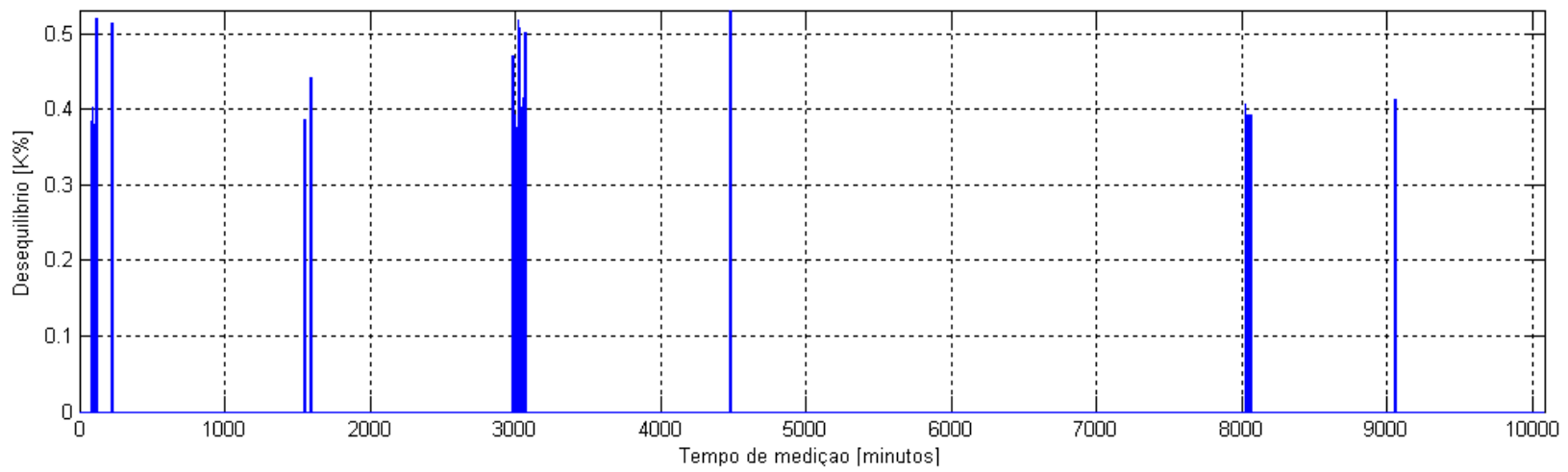

Figura 3.25 - Gráfico dos valores de $\mathrm{K} \%$ fora da faixa mínimo $\leq \mathrm{K} \% \leq P 95 \%$ versus tempo

Nota-se na Figura 3.24 que, com exceção do primeiro dia de análise, nos restantes atingemse valores muito próximos do índice que indica o valor com probabilidade de $95 \%$ de não ser excedido. No período compreendido por volta dos 8.000 a 9.000 minutos da medição teve-se uma representativa ocorrência da situação em análise, fato não observado quando da análise com a faixa limitada pela média quadrática. Isto se deve ao fato de que a maior 
parte das medições de K\% obtidas neste período compõe-se de valores acima da média quadrática.

No que tange ao tempo fora desta faixa, de 210 minutos, correspondentes a $5 \%$ do total 4.160 minutos em que se obtiveram registros de níveis de $\mathrm{K} \%$ maiores que P95\%, o maior destes níveis alcança um valor próximo de 0.53\%, como se verifica na Figura 3.25.

Com relação aos intervalos ininterruptos, nota-se na Figura 3.26, em comparação com os intervalos obtidos na Figura 3.20, que o mais duradouro ultrapassa a marca de 500 minutos. Observam-se ainda intervalos ininterruptos significativos, de duração entre 200 e 400 minutos, correspondentes ao dia 24 (domingo).

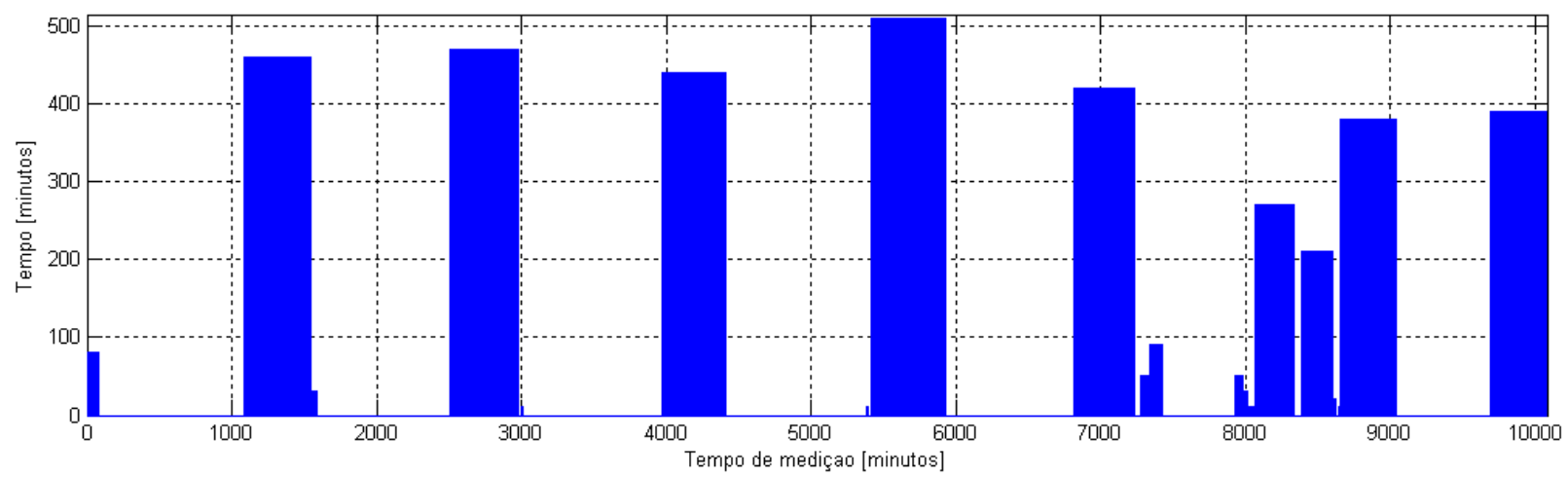

Figura 3.26 - Intervalos ininterruptos com $\mathrm{K} \%$ dentro da faixa mínimo $\leq \mathrm{K} \% \leq P 95 \%$

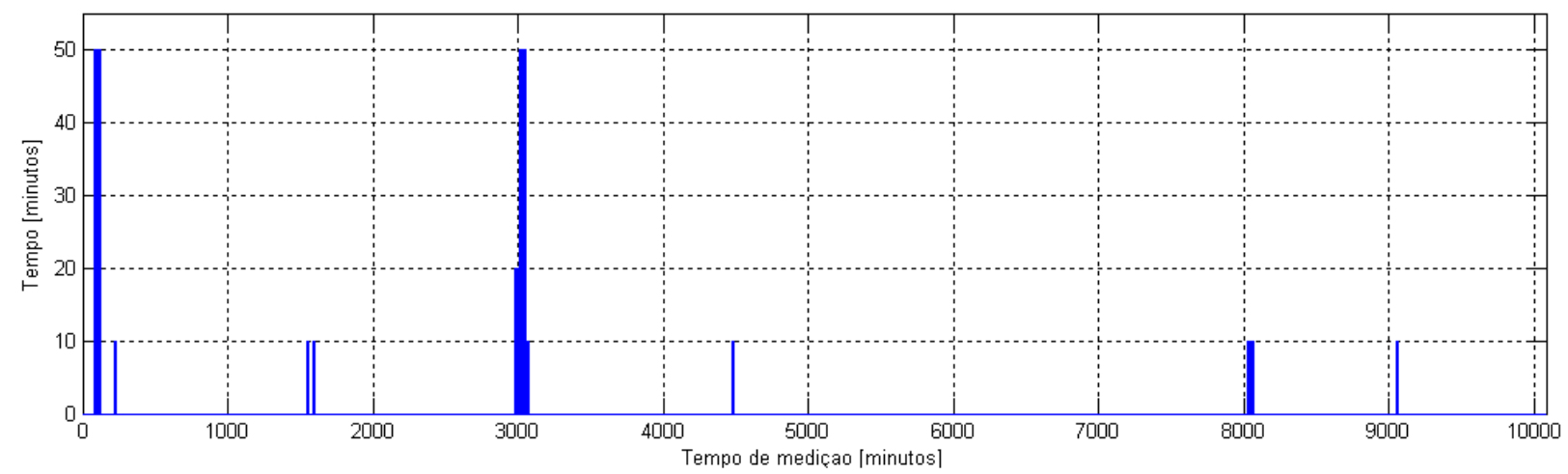

Figura 3.27 - Intervalos ininterruptos com $\mathrm{K} \%$ fora da faixa mínimo $\leq \mathrm{K} \% \leq P 95 \%$ 
Da Figura 3.27 constatam-se apenas os intervalos referentes a K\% > P95\%. Encontram-se esparsos no decurso do tempo de coleta dos dados, havendo dois intervalos que alcançam 50 minutos de duração, um de 20 minutos, quanto que os demais duram 10 minutos.

Informações quanto à durabilidade dos intervalos ininterruptos são trazidas nos gráficos seguintes. No da Figura 3.28 percebe-se que a predominância de intervalos de até 20 minutos é menor que a verificada na Figura 3.22, além da elevação de probabilidades de intervalos superiores a 350 minutos.

Verifica-se na Figura 3.29 que a probabilidade de ocorrência de intervalos ininterruptos de 10 minutos, para os valores de $\mathrm{K} \%$ maiores que P95\%, é de $75 \%$. Ao passo que o de maior duração (50 minutos) é de menos de $20 \%$

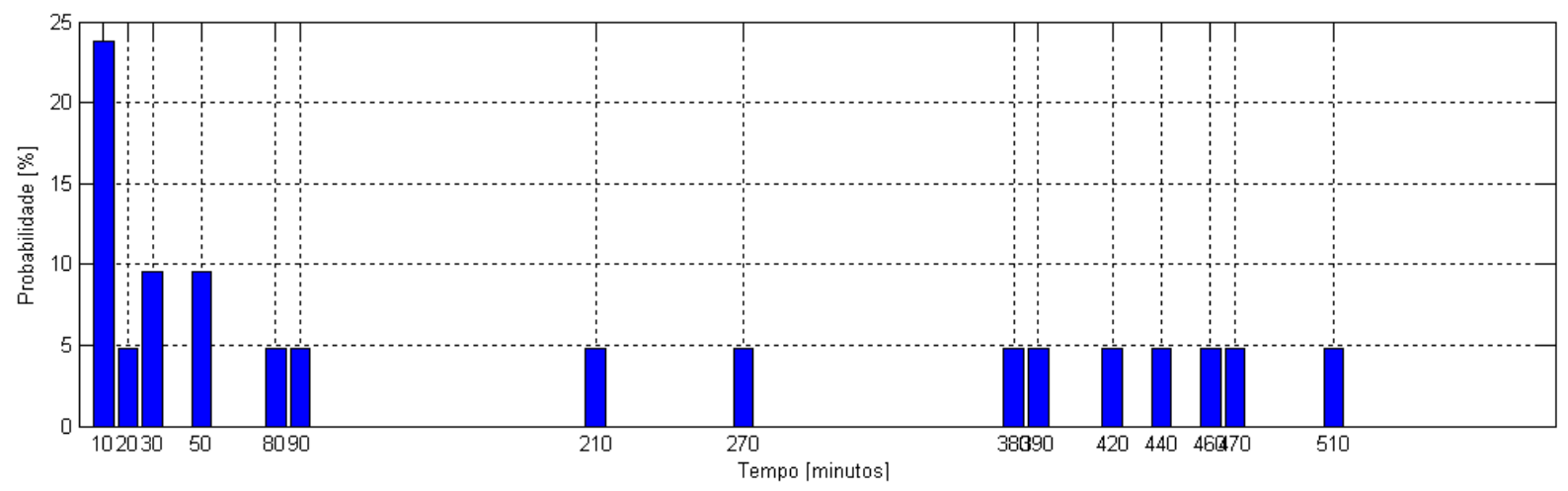

Figura 3.28 - Probabilidade das ocorrências dos intervalos de tempo ininterruptos com valores dentro da faixa mínimo $\leq \mathrm{K} \% \leq P 95 \%$

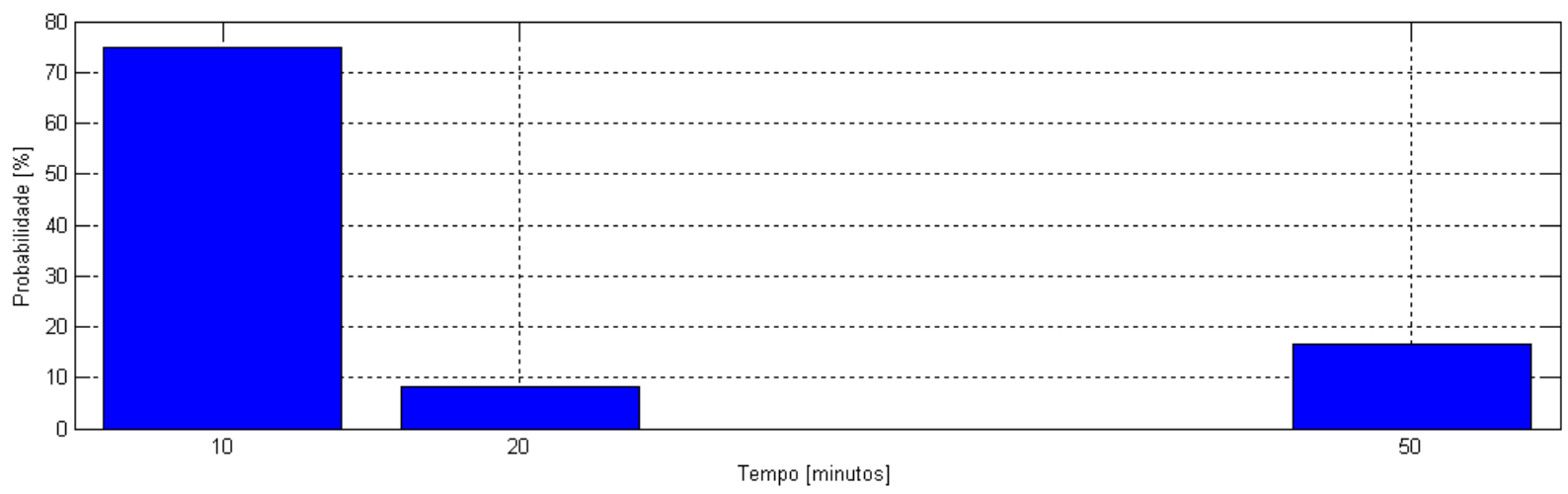

Figura 3.29 - Probabilidade das ocorrências dos intervalos de tempo ininterruptos com valores dentro da faixa mínimo $\leq \mathrm{K} \% \leq P 95 \%$ 


\subsubsection{3 - Análise utilizando P99\% como limite superior}

A faixa, delimitada pelo índice que indica o valor com probabilidade de $99 \%$ de não ser excedido (P99\%), contêm valores de fator K expostos na Figura 3.30. A Figura 3.31 exibe aqueles que ultrapassam este índice.

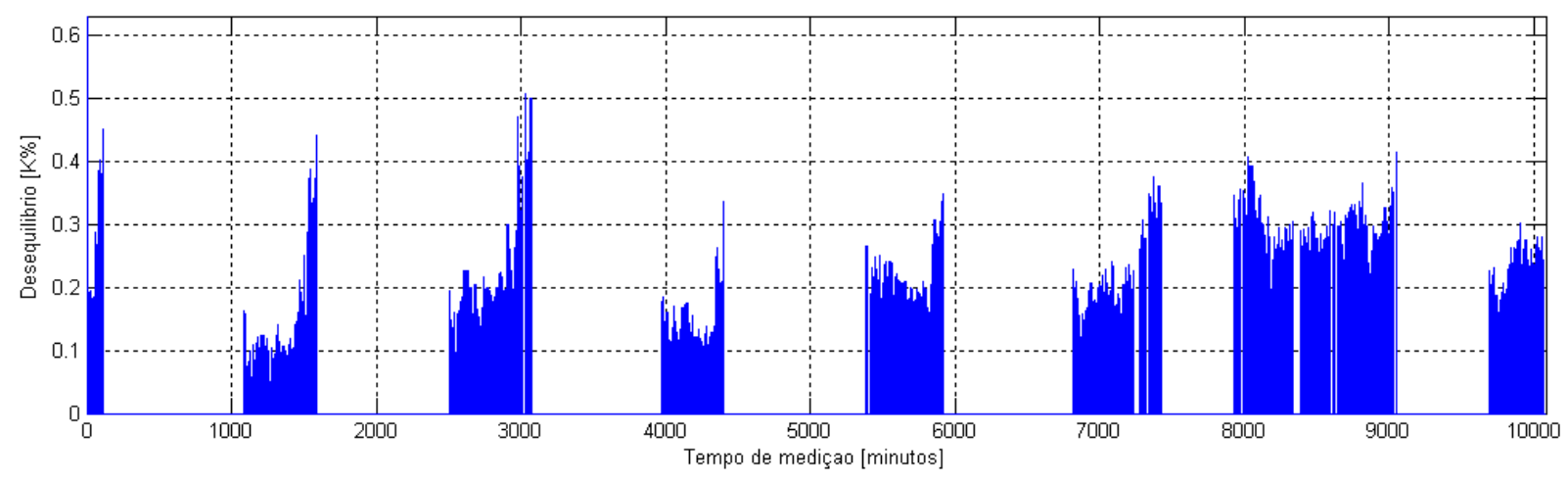

Figura 3.30 - Gráfico dos valores de $\mathrm{K} \%$ dentro da faixa mínimo $\leq \mathrm{K} \% \leq P 99 \%$ versus tempo

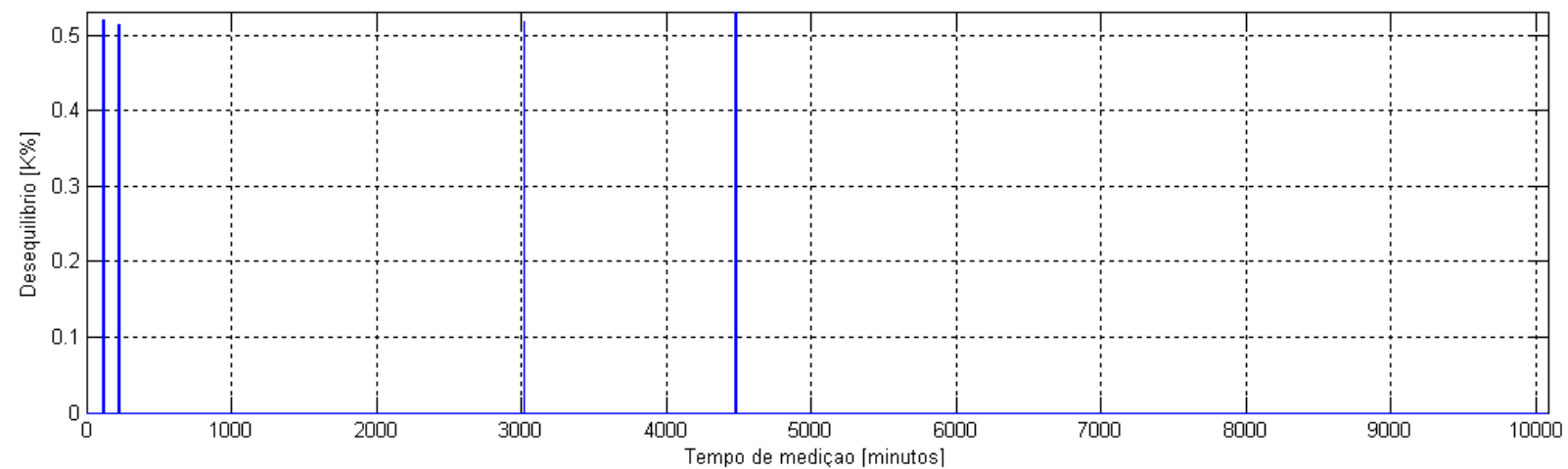

Figura 3.31 - Gráfico dos valores de $\mathrm{K} \%$ fora da faixa mínimo $\leq \mathrm{K} \% \leq P 99 \%$ versus tempo Verifica-se da análise destas Figuras que o índice P99\% de 0.5096\% demarca uma faixa que compreende quase todas as ocorrências de 3D-OV. Pelo seu próprio conceito, observase que os valores na Figura 3.31 representam $1 \%$ dos valores de $\mathrm{K} \%$, que superam $0.5096 \%$, sendo que duas das quatro ocorrências registradas aconteceram mais ao início da medição.

Na análise de intervalos, pode-se notar na Figura 3.32 que há três intervalos ininterruptos que ultrapassam a duração de 500 minutos. E constata-se na Figura 3.33 que as quatro 
aparições dos intervalos correspondentes a valores de $\mathrm{K} \%$ maiores que $\mathrm{P} 99 \%$ possuem duração de 10 minutos cada.

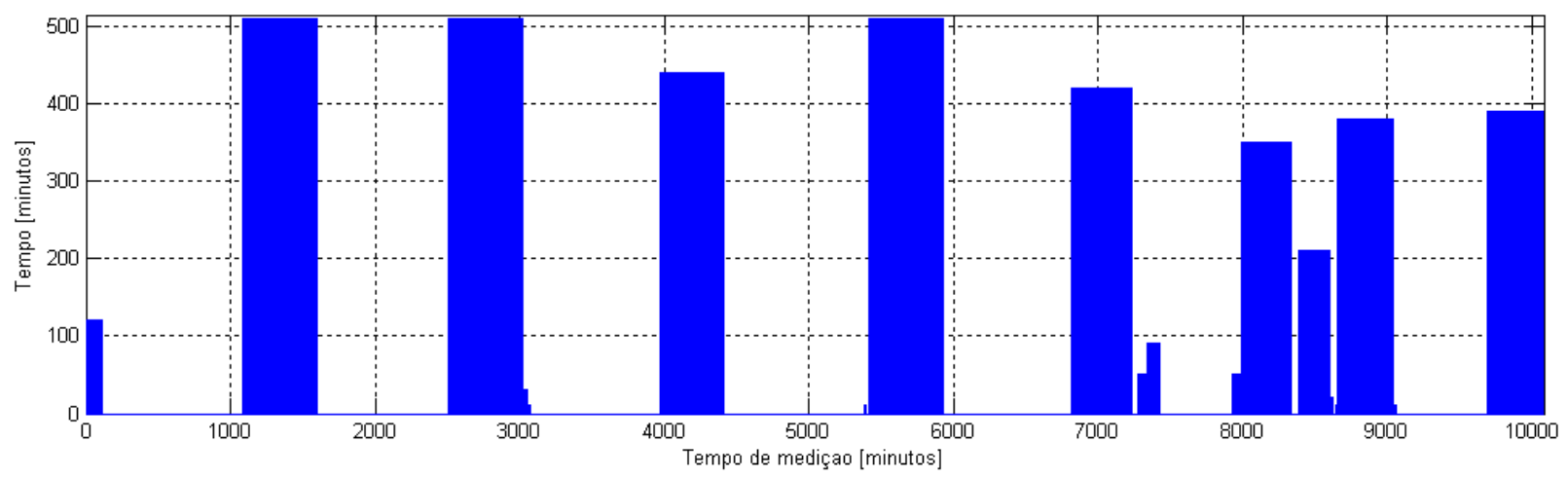

Figura 3.32- Intervalos ininterruptos com K\% dentro da faixa mínimo $\leq \mathrm{K} \% \leq P 99 \%$

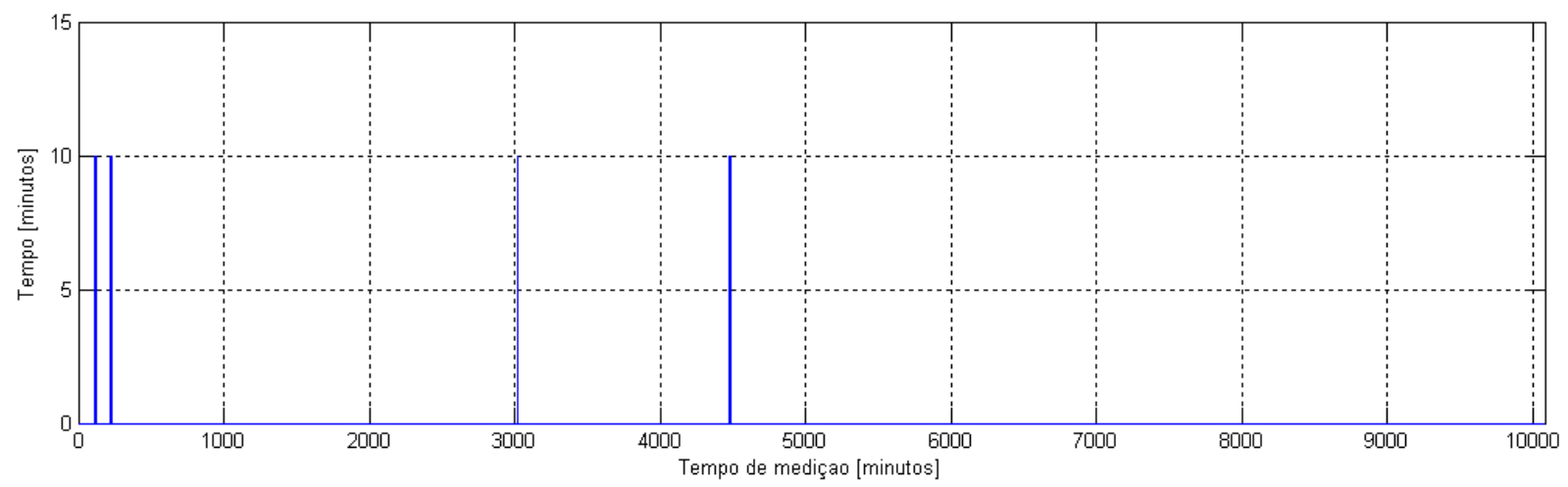

Figura 3.33- Intervalos ininterruptos com $\mathrm{K} \%$ fora da faixa mínimo $\leq \mathrm{K} \% \leq P 99 \%$

Ao avaliar as probabilidades dos intervalos, repara-se uma diminuição da probabilidade de intervalos ininterruptos de 10 minutos em relação à Figura 3.28, contudo, destaca-se uma notável elevação da probabilidade de ocorrências de intervalos de 510 minutos, sendo maior que $15 \%$ e representando a segunda maior das probabilidades mostradas na Figura 3.34 .

Nota-se na Figura 3.35 a confirmação do que foi observado na Figura 3.33, de que só houve intervalos de $10 \mathrm{mim}$ para $\mathrm{K} \%$ superiores a $\mathrm{P} 99 \%$, fato que culmina na probabilidade de ocorrências igual a $100 \%$. 
3 - DESCRIÇÃ O D A FERRAMENTA COMPUTACIONAL PARA ANÁLISE DAS S IT U A Ç Õ S D E DES E Q I LÍB R IO

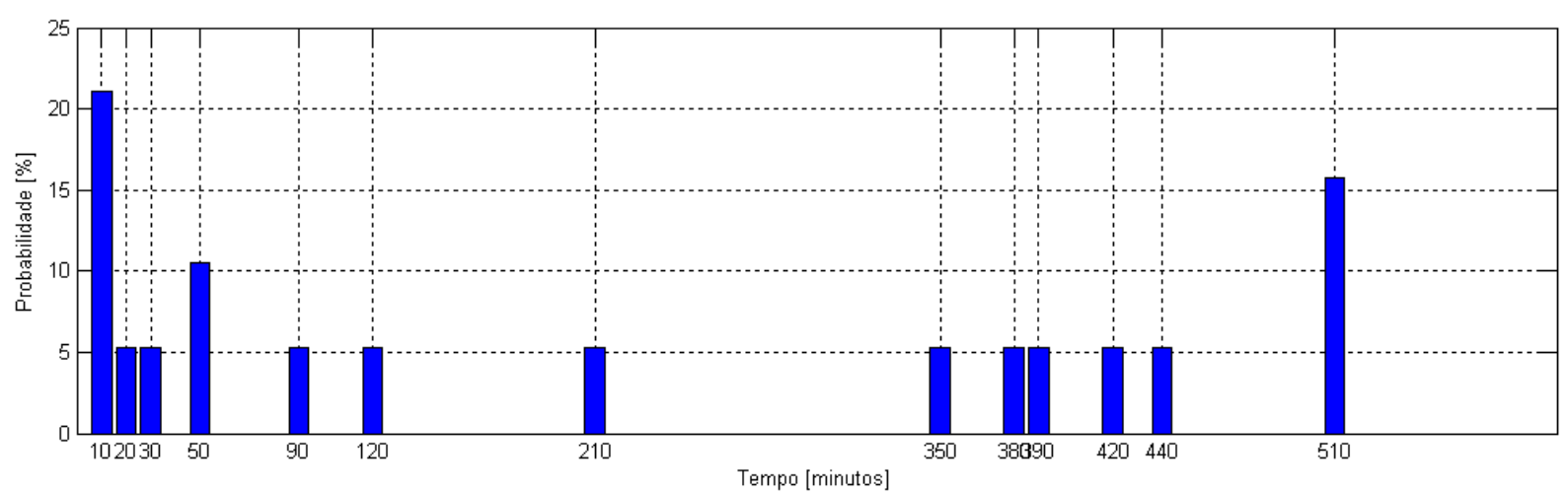

Figura 3.34 - Probabilidade das ocorrências dos intervalos de tempo ininterruptos com valores dentro da faixa mínimo $\leq \mathrm{K} \% \leq P 99 \%$

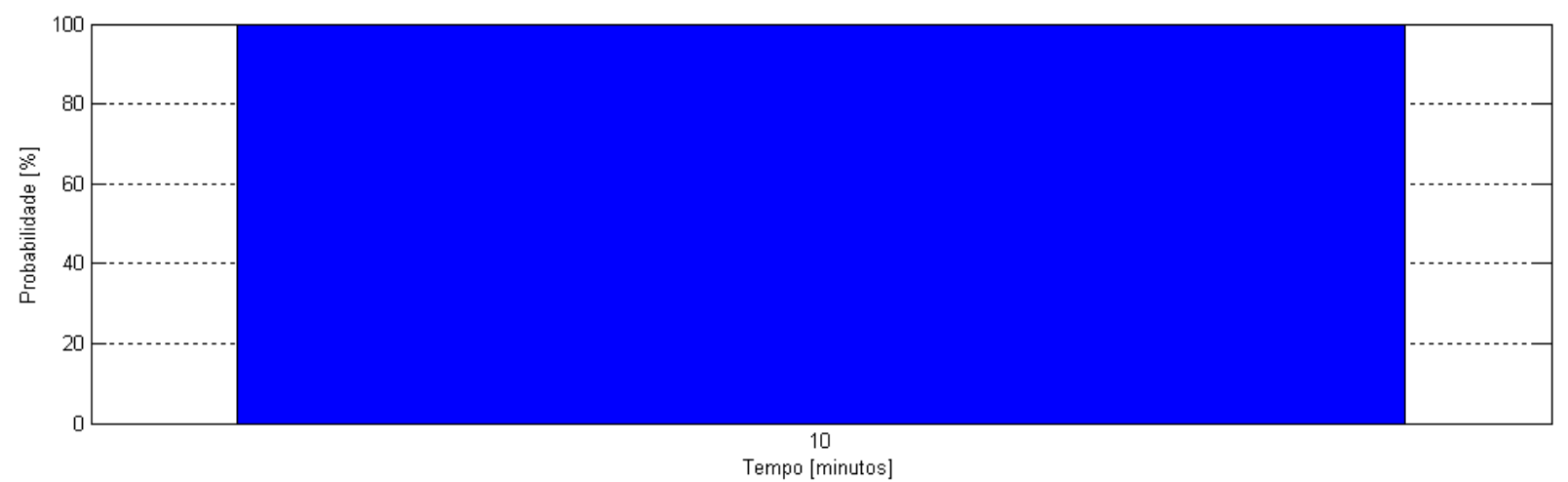

Figura 3.35 - Probabilidade das ocorrências dos intervalos de tempo ininterruptos com valores fora da faixa mínimo $\leq \mathrm{K} \% \leq P 99 \%$

\subsection{5 - Análise de Distribuição de Probabilidade e Distribuição Acumulativa}

Ainda no módulo "Análise de Distribuição no Tempo" é possível fazer análises de Distribuição de Probabilidade, conforme indicado na Figura 3.36.

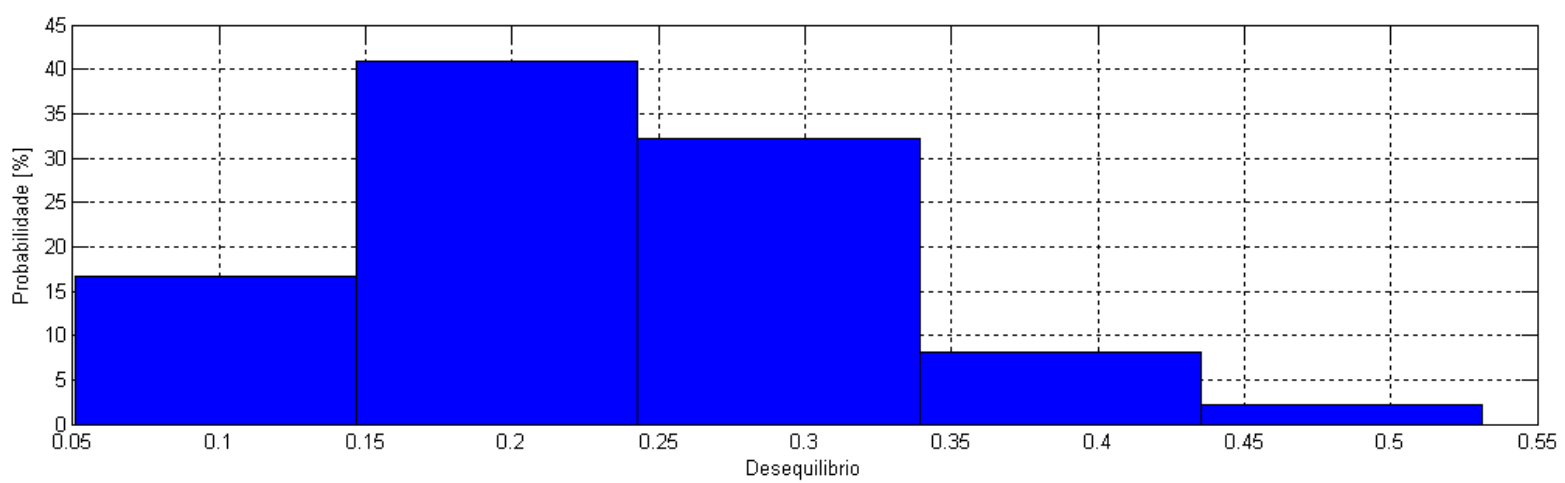

Figura 3.36 - Distribuição de Probabilidade 
Observa-se nesta Figura que cerca de $40 \%$ dos valores de desequilíbrio da situação 3D-OV estiveram entre $0.15 \%$ e $0.25 \%$, seguidos de $32 \%$ de probabilidade de ocorrência de $\mathrm{K} \%$ por volta de $0.25 \%$ a $0.34 \%$. No entanto, os maiores valores do fator $\mathrm{K}$, que atingem um valor perto de $0.53 \%$, possuem probabilidade de ocorrência de apenas $2.5 \%$.

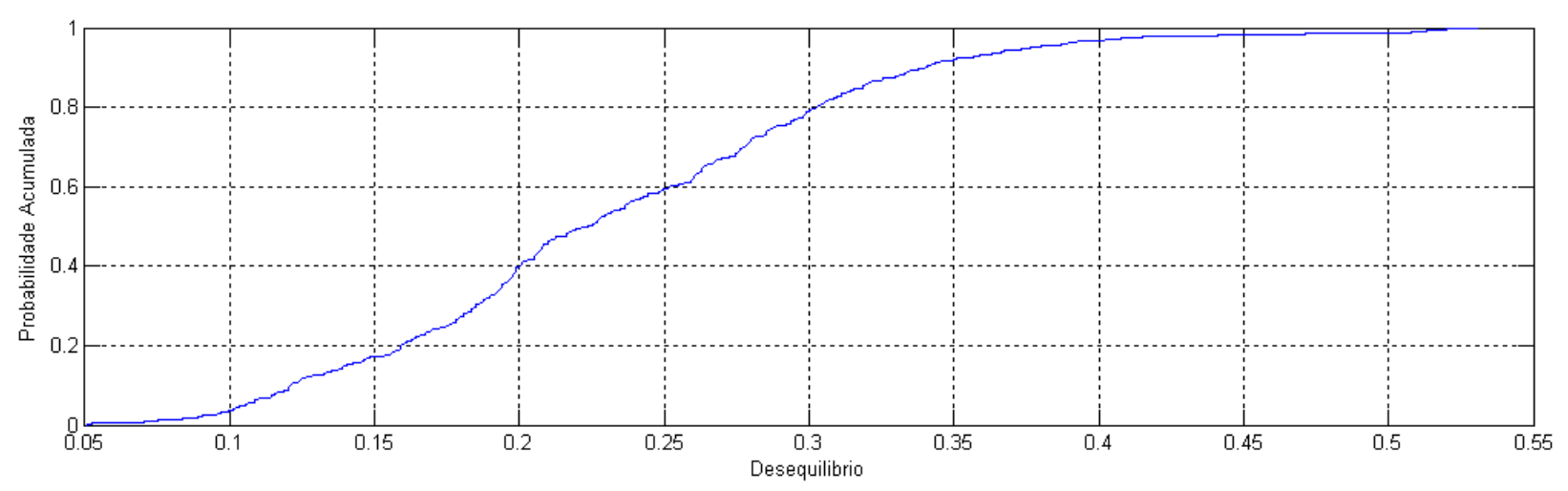

Figura 3.37 - Distribuição Acumulativa de Probabilidade

Nota-se na Figura 3.37 que $40 \%$ dos dados estiveram abaixo de $0,2 \%$ de desequilíbrio. Verifica-se ainda que cerca de $80 \%$ dos desequilíbrios não atingiram $0.3 \%$ do fator $\mathrm{K}$. Temse uma maior concentração dos valores por volta de $0.3 \%$ de desequilíbrio, visto que a inclinação da curva apresenta uma significativa redução após este valor.

\subsection{6 - Análise de Similaridades entre Situações de Desequilíbrio}

Esta análise é realizada no módulo da ferramenta denominada "Similaridade entre Situações", que permite que se comparem dados de até 7 (sete) situações de desequilíbrio simultaneamente.

Contudo, conforme os dados exibidos na Tabela 3.2 e na Figura 3.8, serão selecionadas as quatro situações de maiores ocorrências, por já corresponderem por cerca de $80 \%$ dos desequilíbrios presentes no banco em estudo.

Dessa forma, as análises serão procedidas em três partes: avaliação das Componentes Simétricas, avaliação do Fator K e Análise dos Fasores. 


\subsubsection{1 - Análise das Componentes Simétricas}

Será iniciada com a avaliação das componentes de seqüência positiva. A Tabela 3.7 fornece os seguintes dados para cada uma das quatro situações selecionadas, representados graficamente na Figura 3.38.

Tabela 3.7 - Resultados de cálculos de componentes de seqüência positiva

\begin{tabular}{c|c|c|c|c}
\hline \multirow{2}{*}{ Estatísticas } & \multicolumn{4}{|c}{ Componentes Simétricas - Seqüência Positiva } \\
\cline { 2 - 5 } & 3D-OV & 3D-UV, 1D-UA & 3D-UV & 3D-UV, 1D-OA \\
\cline { 2 - 5 } Máximo & 233.1039 & 217.9450 & 218.6588 & 218.0594 \\
\cline { 2 - 5 } Mínimo & 221.7952 & 199.8772 & 202.8347 & 203.0054 \\
Média Aritmética & 226.7041 & 208.1526 & 210.1184 & 211.6324 \\
Média Quadrática & 226.7145 & 208.1917 & 210.1725 & 211.6770 \\
Desvio Padrão & 2.1807 & 4.0481 & 4.7885 & 4.3748 \\
P95\% & 231.0059 & 215.1434 & 217.8876 & 217.8220 \\
P99\% & 232.4107 & 217.1822 & 218.6225 & 218.0236 \\
\hline
\end{tabular}

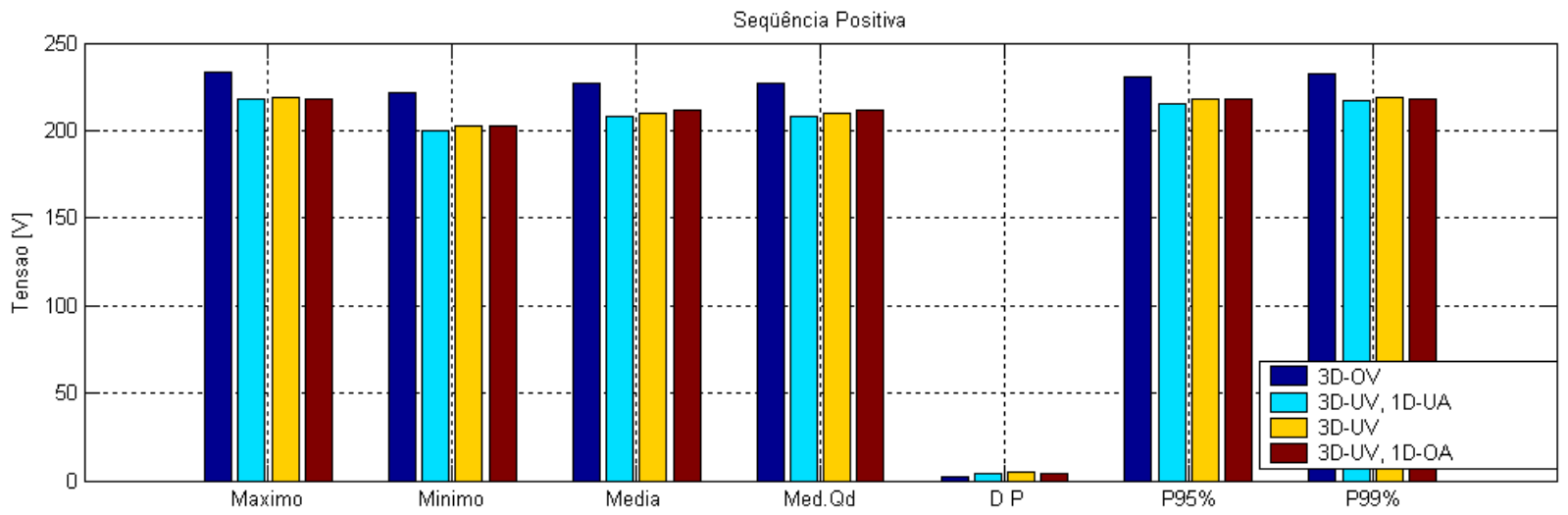

Figura 3.38 - Dados comparativos de seqüência positiva para quatro situações

Cumpre destacar que a situação de desequilíbrio 3D-OV apresentou valores mais elevados que as demais situações, além de apresentar um desvio padrão inferior quase que pela metade com relação aos desvios das outras três situações. Estas se portaram de forma bem semelhante, com pequenas variações entre si.

Verifica-se ainda que a situação 3D-OV, além de apresentar um menor desvio padrão, foi a situação que manteve suas médias quadrática e aritmética mais próximas do valor nominal de 220 [V], com uma diferença de quase 7 [V] acima do nominal. Ao passo que as outras 
situações apresentaram diferenças abaixo de 220 [V], visto que são compostas pela condição 3D-UV, com valores em torno de 9, 10 e 11 [V] distantes do nominal, tratando-se também das médias calculadas.

Por oportuno, nota-se que os valores de seqüência positiva não são afetados de modo significativo pelas condições de desequilíbrio de ângulo, as quais caracterizam a principal diferença das situações formadas pela condição 3D-UV.

Segue-se adiante com análises dos dados de sequiência negativa, cuja representação dos valores encontra-se na Tabela 3.8 e na Figura 3.39.

Tabela 3.8 - Resultados de cálculos de componentes de seqüência negativa

\begin{tabular}{c|c|c|c|c}
\hline \multirow{2}{*}{ Estatísticas } & \multicolumn{4}{|c}{ Componentes Simétricas - Seqüência Negativa } \\
\cline { 2 - 5 } & \multicolumn{4}{|c}{ Situações de Desequilíbrio } \\
\cline { 2 - 5 } Máximo & 3D-OV & 3D-UV, 1D-UA & 3D-UV & 3D-UV, 1D-OA \\
\cline { 2 - 5 } Mínimo & 1.1868 & 1.9032 & 1.4842 & 1.5561 \\
Média Aritmética & 0.1175 & 1.2098 & 0.4347 & 0.2481 \\
Média Quadrática & 0.5276 & 1.5866 & 1.0687 & 0.8354 \\
Desvio Padrão & 0.5625 & 1.5911 & 1.0889 & 0.9239 \\
P95\% & 0.1955 & 0.1204 & 0.2097 & 0.3971 \\
P99\% & 0.8649 & 1.7737 & 1.3456 & 1.4809 \\
\hline
\end{tabular}

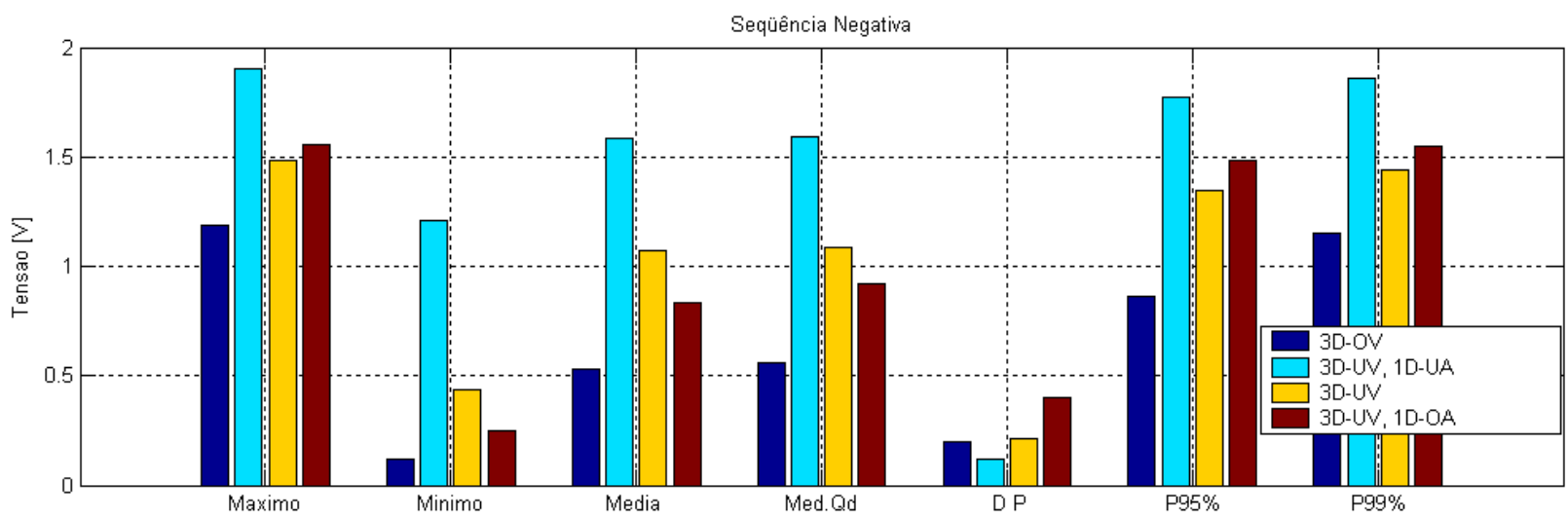

Figura 3.39 - Dados comparativos de seqüência negativa para quatro situações

Vê-se por esses dados que, exceto pelo desvio padrão, a situação 3D-OV apresentou os menores níveis dos dados estatísticos em comparação com as outras situações. Constata-se também que a situação 3D-UV possui seus valores das médias mais elevados que os da 
situação 3D-UV, 1D-OA. No entanto, esta última contém valores de P95\% e P99\% superiores aos de 3D-UV.

Pode-se observar da situação 3D-UV, 1D-UA que, salvo o desvio padrão, que é o menor, foi a que apresentou os maiores valores estatísticos. Estes valores mais elevados vinculam a maiores desequilíbrios de $\mathrm{K} \%$.

Fazem-se as análises das componentes de seqüência zero de forma semelhante, conforme valores da Tabela 3.9 e o gráfico da Figura 3.40.

Tabela 3.9 - Resultados de cálculos de componentes de seqüência zero

\begin{tabular}{c|c|c|c|c}
\hline \multirow{2}{*}{ Estatísticas } & \multicolumn{4}{|c}{ Componentes Simétricas - Sequiência Zero } \\
\cline { 2 - 5 } & \multicolumn{4}{|c}{ Situações de Desequilíbrio } \\
\cline { 2 - 5 } Máximo & 3D-OV & 3D-UV, 1D-UA & 3D-UV & 3D-UV, 1D-OA \\
\cline { 2 - 5 } Mínimo & 0.8776 & 1.1317 & 1.5676 & 1.9536 \\
Média Aritmética & 0.0364 & 0.5430 & 0.4923 & 0.9883 \\
Média Quadrática & 0.3480 & 0.8995 & 0.9893 & 1.4062 \\
Desvio Padrão & 0.3875 & 0.9074 & 1.0122 & 1.4294 \\
P95\% & 0.1707 & 0.1197 & 0.2148 & 0.2582 \\
P99\% & 0.7110 & 1.0718 & 1.3620 & 1.8246 \\
\hline
\end{tabular}

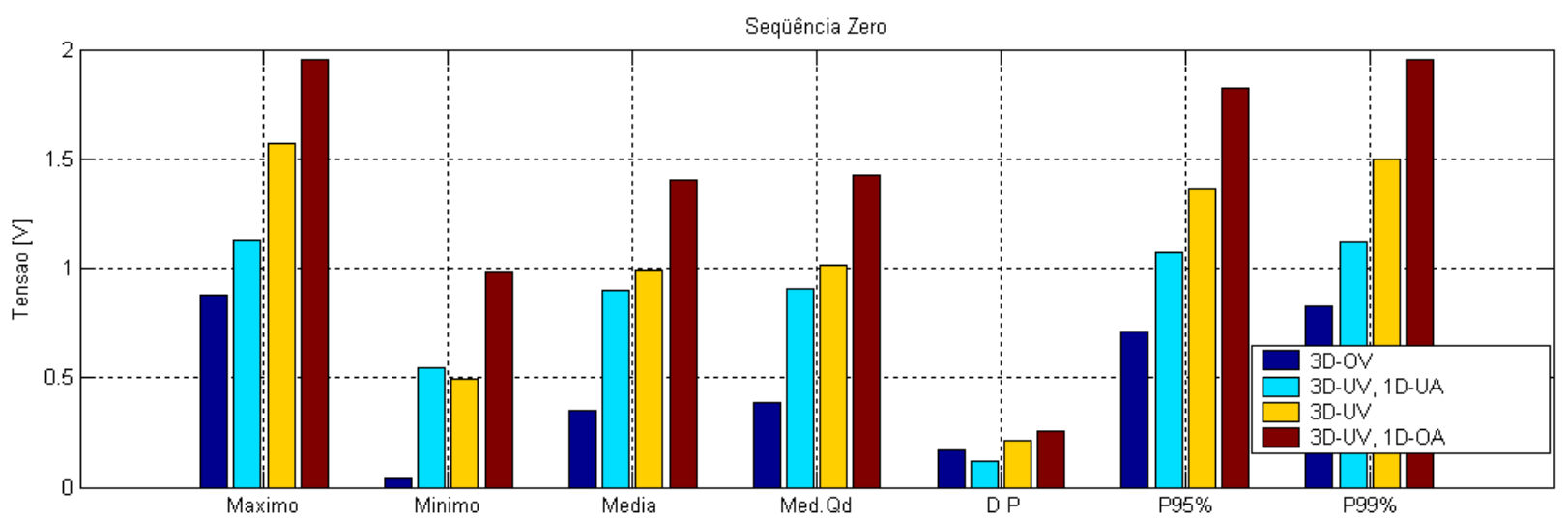

Figura 3.40 - Dados comparativos de sequiência zero para quatro situações

As grandezas de sequiência-zero estão mais comumente associadas ao fato de se envolver com a terra em condições de desbalanço e, por isso, podem ser usadas para detectar faltas fase-terra e fase-fase-terra. Contudo, só apresentarão valores elevados nos casos de faltas 
(ALMEIDA \& FREITAS, 1995). Para os casos em análise, seus valores são bem reduzidos, sendo que o maior índice apresentado alcançou cerca de $2[\mathrm{~V}]$ apenas.

\subsubsection{2 - Análise do fator $K$ de desequilíbrio}

A Tabela 3.10 e a Figura 3.41 mostram os resultados obtidos para os valores de K\% das situações em estudo.

Tabela 3.10 - Resultados de cálculos de fator K

\begin{tabular}{c|c|c|c|c}
\hline \multirow{2}{*}{ Estatísticas } & \multicolumn{4}{|c}{ Componentes Simétricas - Fator K } \\
\cline { 2 - 5 } & \multicolumn{4}{|c}{ Situações de Desequilíbrio } \\
\cline { 2 - 5 } Máximo & 3D-OV & 3D-UV, 1D-UA & 3D-UV & 3D-UV, 1D-OA \\
\cline { 2 - 5 } Mínimo & 0.5310 & 0.9152 & 0.7049 & 0.7460 \\
Média Aritmética & 0.0510 & 0.5667 & 0.1998 & 0.1156 \\
Média Quadrática & 0.2328 & 0.7626 & 0.5104 & 0.3981 \\
Desvio Padrão & 0.2482 & 0.7650 & 0.5214 & 0.4424 \\
P95\% & 0.0863 & 0.0603 & 0.1070 & 0.1944 \\
P99\% & 0.3765 & 0.8520 & 0.6540 & 0.7023 \\
\hline
\end{tabular}

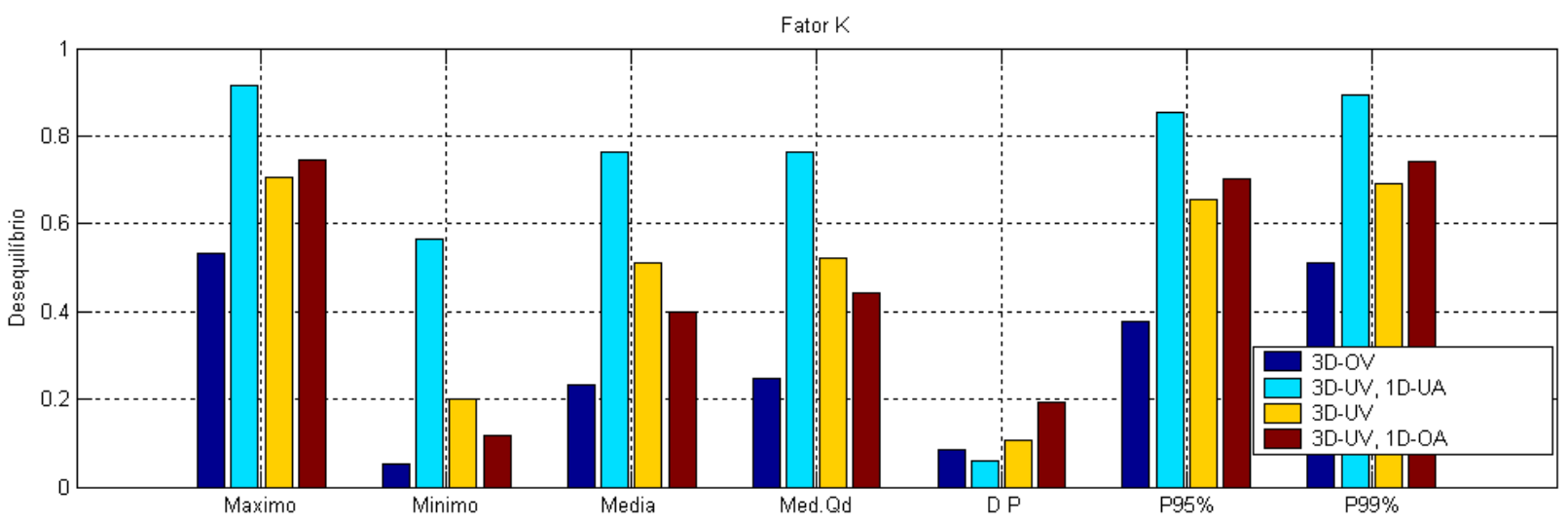

Figura 3.41 - Dados comparativos de K\%

Destaca-se a notável semelhança do gráfico da Figura 3.41 com o da Figura 3.39 justamente pelo fato da componente de seqüência negativa ser a principal responsável para a definição de $\mathrm{K} \%$.

Como já constatado, obteve-se maiores valores de desequilíbrio para a situação 3D-UV, 1D-UA. Porém os valores não atingiram $1 \%$ do fator K. Verifica-se que os índices apresentados pelas quatro situações estão condizentes com os índices de conformidade. 
Cumpre destacar ainda que as situações que tiveram desequilíbrios mais elevados foram nas que ocorreram desvios nos ângulos. Daí a influência das condições de under-angle e overangle serem bastante representativas.

\subsubsection{3 - Análise dos Fasores}

Neste tópico é investigado como se dá a influência dos fasores de tensão nos desequilíbrios de cada situação.

São fornecidos na Tabela 3.11, estatísticas dos valores referentes aos três módulos de tensão nos instantes em que, juntamente, caracterizaram a formação da situação classificada por 3D-OV.

Tabela 3.11 - Estatísticas dos fasores Va, Vb e Vc da situação 3D-OV

\begin{tabular}{c|c|c|c}
\hline \multirow{2}{*}{ Estatísticas } & \multicolumn{3}{|c}{ Fasores } \\
\cline { 2 - 4 } & \multicolumn{3}{|c}{ Situação de Desequilíbrio 3D-OV } \\
\cline { 2 - 4 } Máximo & 233.6000 & 234.4000 & Vc (OV) \\
\cline { 2 - 4 } Mínimo & 222.3000 & 222.0000 & 220.5000 \\
Média Aritmética & 227.1000 & 227.1000 & 226.0000 \\
Média Quadrática & 227.1000 & 227.1000 & 226.0000 \\
Desvio Padrão & 2.1810 & 2.1250 & 2.2880 \\
P95\% & 231.7000 & 231.2000 & 230.5000 \\
P99\% & 232.7000 & 232.6000 & 231.6000 \\
\hline
\end{tabular}

Nota-se por esta Tabela 3.11 que os três fasores se portaram de forma bastante parecida, desviando-se de 220[V] em intensidades praticamente semelhantes.

Este tipo de análise permite diagnosticar que é possível a obtenção de valores semelhantes de $\mathrm{K} \%$ para diferentes configurações dos fasores, mesmo quando estas configurações estejam compreendidas numa mesma situação de desequilíbrio. Isto é, torna-se viável averiguar o quanto desequilibrado está cada fasor com relação à tensão nominal.

Quanto às outras três situações em estudo, é possível avaliá-las a partir dos dados fornecidos na Tabela 3.12. Nota-se que a situação 3D-UV apresentou, para os três fasores, os menores 
valores estatísticos. Sobretudo de $\mathrm{P} 95 \%$ e das médias aritmética e quadrática, que são inferiores aos das situações que tiveram desvios de ângulo.

Tabela 3.12 - Estatísticas dos fasores Va, Vb e Vc das situações (3D-UV), (3D-UV, 1D-UA) e (3D-UV, 1D-OA)

\begin{tabular}{c|cc|c|c|c|c|c|c|c}
\hline \multirow{3}{*}{ Estatísticas } & \multicolumn{9}{|c}{ Fasores } \\
\cline { 2 - 10 } & \multicolumn{3}{|c|}{ 3D-UV } & \multicolumn{3}{c}{ 3D-UV, 1D-UA } & \multicolumn{3}{c}{ 3D-UV, 1D-OA } \\
\cline { 2 - 9 } & $\mathrm{Va}(\mathrm{UV})$ & $\mathrm{Vb}(\mathrm{UV})$ & $\mathrm{Vc}(\mathrm{UV})$ & $\mathrm{Va}(\mathrm{UV})$ & $\mathrm{Vb}(\mathrm{UV})$ & $\mathrm{Vc}(\mathrm{UV})$ & $\mathrm{Va}(\mathrm{UV})$ & $\mathrm{Vb}(\mathrm{UV})$ & $\mathrm{Vc}(\mathrm{UV})$ \\
\cline { 2 - 9 } Máximo & 218.3 & 219.4 & 218.3 & 219.5 & 219.4 & 219.5 & 219.5 & 217.9 & 219.5 \\
Mínimo & 200.9 & 201.4 & 200.9 & 204.0 & 204.0 & 204.0 & 204.7 & 203.8 & 204.7 \\
Média Arit. & 208.9 & 209.6 & 208.9 & 211.3 & 211.0 & 211.3 & 213.2 & 212.0 & 213.2 \\
Média Quad & 209.0 & 209.6 & 209.0 & 211.3 & 211.0 & 211.3 & 213.3 & 212.1 & 213.3 \\
DesvioPadrão & 3.927 & 4.074 & 3.927 & 4.59 & 4.798 & 4.590 & 4.428 & 3.915 & 4.428 \\
P95\% & 215.9 & 216.7 & 215.9 & 218.7 & 218.7 & 218.7 & 219.1 & 217.6 & 219.1 \\
P99\% & 217.7 & 218.8 & 217.7 & 219.3 & 219.3 & 219.3 & 219.5 & 217.9 & 219.5 \\
\hline
\end{tabular}

O gráfico da Figura 3.42 representa os valores do fasor Va para estas três situações.

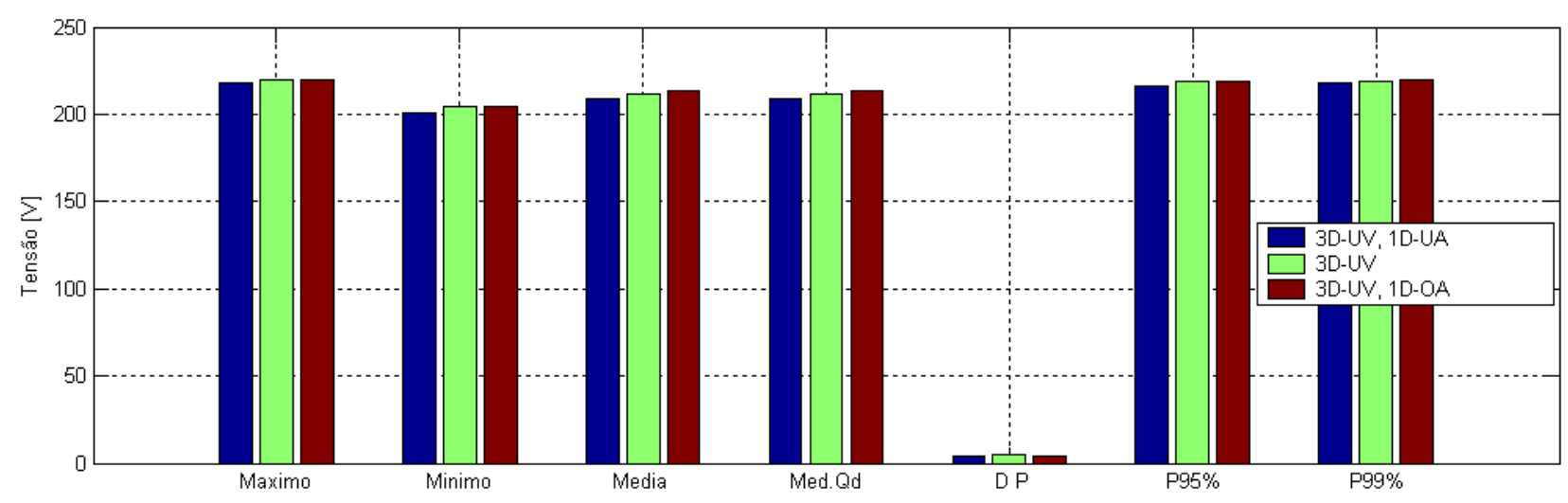

Figura 3.42 - Fasor Va

Os gráficos referentes a $\mathrm{Vb}$ e $\mathrm{Vc}$ possuem um formato bem semelhante ao de $\mathrm{Va}$, por apresentarem comportamento parecidos das variações das estatísticas entre si. Na Figura, observam-se desvios muito pequenos e índices de P95\% quase iguais aos máximos. Essas semelhanças ocorreram por tratar-se de situações também semelhantes, mas que se diferem pelos desvios de ângulo. Porém os efeitos destes desvios não são relatados nesta última análise certamente porque esta avalia apenas as magnitudes dos fasores. Contudo, a análise se mostra de grande valia quando se compara o comportamento dos três fasores com o K\% para distintas situações. 


\section{6 - CONSIDERAÇÕES FINAIS}

Este capítulo expôs a classificação que caracteriza as possíveis situações de desequilíbrio de tensão. Foi apresentada a ferramenta computacional elaborada para o estudo de classificação dos desequilíbrios. Descreveram-se os recursos dos módulos seguindo uma estrutura de suas funcionalidades dispostas por um fluxograma. E por último fez-se um estudo de caso.

As análises fornecidas pelo programa mostraram-se relevantes para o auxílio da caracterização das variadas situações de desequilíbrio existentes nos bancos de dados colhidos em medições, com relação aos desequilíbrios de tensão. O software permite identificar as situações de desequilíbrio presentes bem como as proporções em que ocorrem.

Tornou-se possível efetivarem-se estudos, a partir de dados estatísticos, acerca dos métodos de cálculo do fator $\mathrm{K}$ e das componentes simétricas, para cada situação de desequilíbrio.

Demonstraram-se avaliações com relação a distribuições no tempo realizadas determinando-se faixas que limitam os valores de $\mathrm{K} \%$ que se desejam estudar. Avaliou-se com este estudo, a relevância de se considerarem os índices de P95\%, P99\% e de média quadrática quando de suas utilizações em representação aos demais valores medidos de uma mesma situação de desequilíbrio, para em um local determinado.

E, por fim, procedeu-se a análises comparativas, também por meio de gráficos e valores estatísticos, entre situações de desequilíbrio com informações das componentes simétricas, fator $\mathrm{K}$ e dos fasores de tensão. 


\section{CAPÍTULO 4}

\section{ANÁLISE ESTATÍSTICA DAS SITUAÇÕES DE DESEQUILÍBRIO DE TENSÃO PRESENTES NO SISTEMA ELÉTRICO BRASILEIRO}

\section{1 - CONSIDERAÇÕES INICIAIS}

Neste capítulo serão feitas análises para diversos consumidores do sistema elétrico brasileiro acerca dos níveis de $\mathrm{K} \%$, probabilidades de ocorrência das situações desequilíbrio e suas distribuições no tempo em que tiveram seus dados medidos.

\section{2 - APRESENTAÇÃO DOS LOCAIS EM ESTUDO}

Serão avaliados os resultados das medições de tensão de oito pontos de medição, sendo seis consumidores eletro-intensivos, Figura 4.1, e duas linhas de intercâmbios entre submercados, Figura 4.2. Os dados foram coletados a partir da utilização de TP's e TC's com classe de precisão 0,3 . Significa dizer que a interferência do medidor na veracidade dos dados é a menor possível.

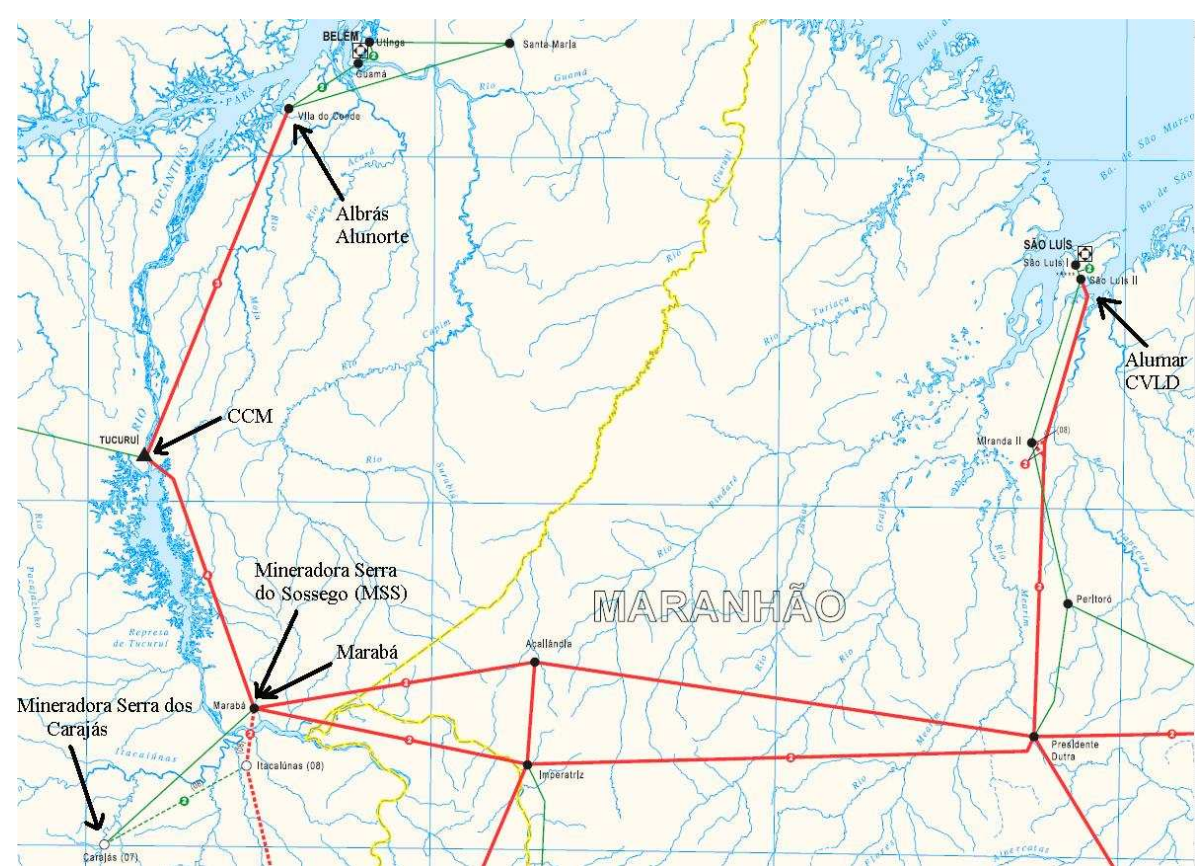

Fonte: Operador Nacional do Sistema Elétrico - ONS (http://www.ons.org.br/conheca_sistema/mapas_sin.aspx, acessado em nov de 2007). Figura 4.1 - Consumidores eletro-intensivos da Eletronorte. 


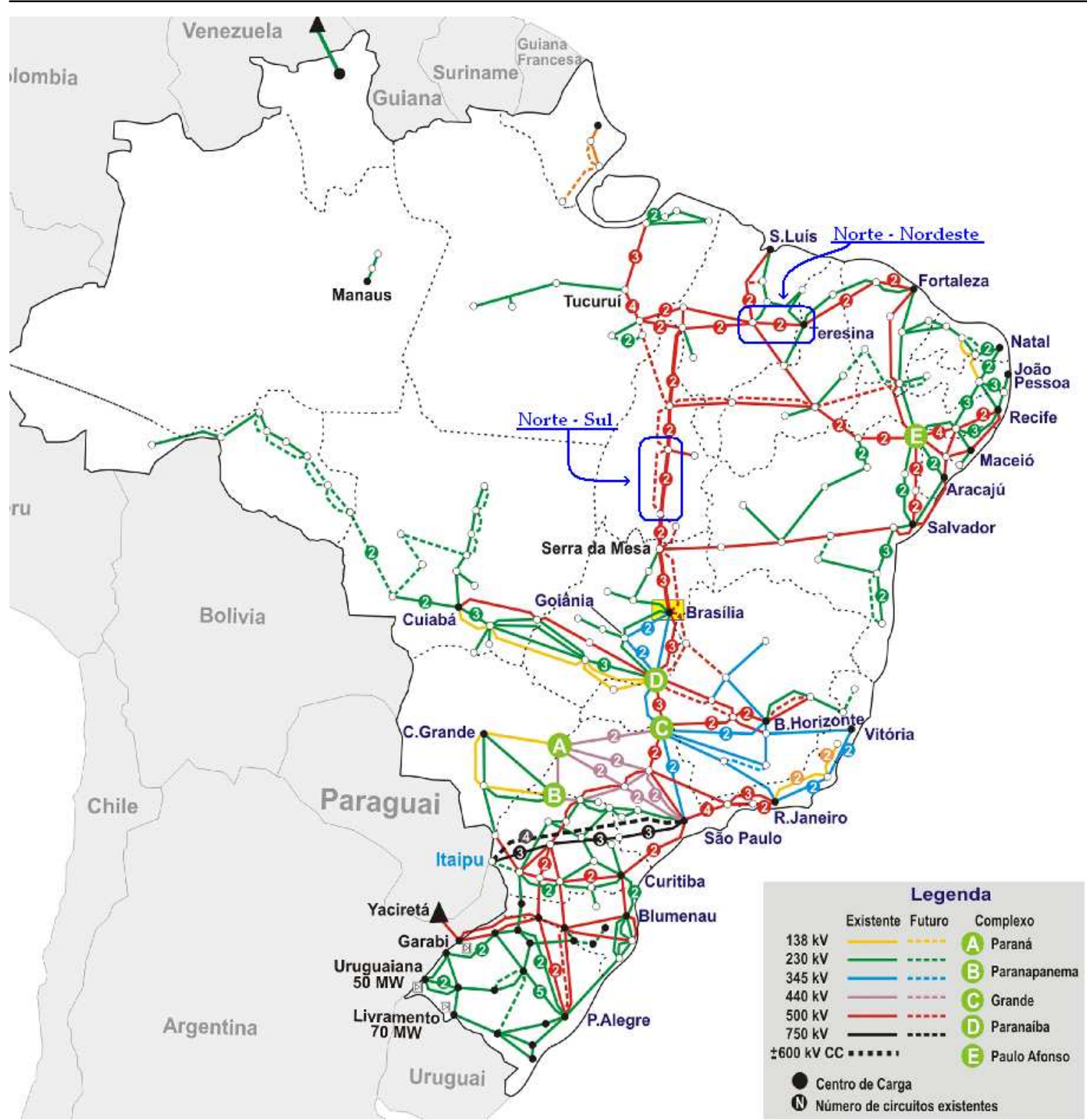

Fonte: Operador Nacional do Sistema Elétrico - ONS (http://www.ons.org.br/conheca_sistema/mapas_sin.aspx, acessado em nov de 2007).

Figura 4.2 - Intercâmbios entre Submercados

\subsection{1 - Consumidores Eletro-Intensivos}

A avaliação dos resultados das medições será feita com dados de desequilíbrio de tensão coletados dos consumidores descritos a seguir. 


\section{$>\quad$ Produção de Alumínio e Alumina}

\section{a) ALBRÁS}

Ponto de Entrega: SE Vila do Conde

Descrição: A ALBRÁS, Alumínio Brasileiro S.A., é uma indústria de produção de alumínio composta basicamente por 4 conjuntos de retificadores industriais a diodo de 36 pulsos, não-controlados, os quais alimentam, em corrente contínua, os processos de produção (4 linhas de cubas).

Esse consumidor, cuja demanda atual é cerca de $800 \mathrm{MW}$, é suprido por meio de uma subestação própria denominada SE ALBRÁS, que, por sua vez, está conectada à Rede Básica na SE Vila do Conde. Tal conexão se dá por meio de uma linha em 230 kV, circuito duplo, de comprimento igual a $1,6 \mathrm{~km}$.

\section{b) ALUNORTE}

Ponto Entrega: SE-Vila do Conde, por serem alimentados através da SE Albrás. De fato, na subestação existem 4 pontos de medição internos para separar os consumidores.

Descrição: A ALUNORTE, Alumina do Norte do Brasil S.A., é destinada a produzir alumina, o principal insumo à produção do alumínio primário. A fábrica é dividida em duas unidades, Alunorte Fabril e Alunorte Vapor. Atualmente, seu suprimento é oriundo da SE ALBRAS, por meio de linha de transmissão em $230 \mathrm{kV}$, circuito simples, de cerca de $2,5 \mathrm{~km}$ de extensão.

A ALUNORTE fabril possui uma capacidade instalada de 70 MW. Já a Alunorte Vapor é composta por três caldeiras de capacidade individual igual a 45 MW. A ALUNORTE possui ainda uma central termoelétrica de $25 \mathrm{MW}$, que opera na modalidade de autoprodução local.

A Figura 4.3 mostra a conexão da Vila do Conde com a Albrás e a Alunorte. 


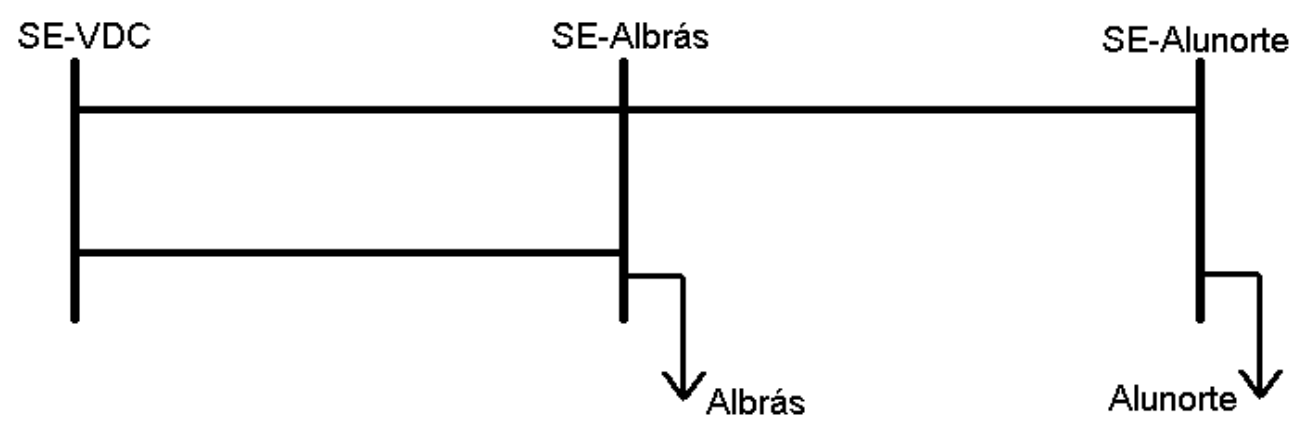

Figura 4.3 - Conexão VDC - Albrás - Alunorte.

\section{c) ALUMAR}

Ponto de Entrega: SE-São Luis II

Descrição: A ALUMAR é uma indústria metalúrgica de produção de alumina e alumínio primário, localizada no município de São Luís, Estado do Maranhão. Com demanda atual de $825 \mathrm{MW}$, seu suprimento se dá pelo sistema de $230 \mathrm{kV}$ da ELETRONORTE, a partir da SE São Luís II (500/230 kV).

A carga dessa indústria, em operação desde 1984, é composta por retificadores (620 MW), motores assíncronos (45 MW), compressores (15 MW) e outras menores com cerca de $20 \mathrm{MW}$, constituídas por caldeiras, pré-aquecedores, fornos de indução e motores síncronos.

Com a expansão da unidade de redução da ALUMAR (a terceira linha de cubas da empresa) a demanda total dessa planta de alumínio atingiu o montante de $825 \mathrm{MW}$.

A partir de São Luís saem duas linhas de transmissão em $230 \mathrm{kV}$ que se ramificam para alimentar as fábricas de redução e a de refino.

A Figura 4.4 mostra o ponto de conexão de São Luís II com a Alumar refinaria e a Alumar redução. 


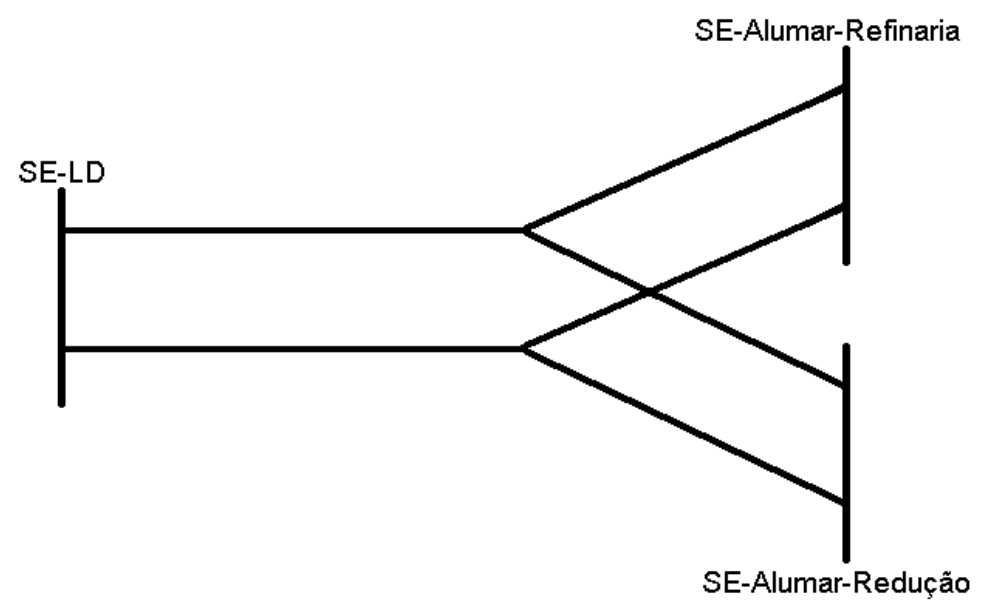

Figura 4.4 - Conexão LD - Alumar refinaria - Alumar redução.

\section{$>\quad$ Produção de Silício}

\section{d) CAMARGO CORREA METAIS}

\section{Ponto de Entrega: SE Tucuruí Linha - TCCA-LT6-01}

Descrição: A Camargo Correa metais é uma indústria de Silício metálico, alimentada através da SE-Tucuruí, em $230 \mathrm{kV}$. Sua demanda é de aproximadamente 73 MW.

\section{Mineradoras}

\section{e) MARABÁ}

Ponto de conexão: SE-Marabá

Descrição: Este ponto de conexão da rede básica abrange dois consumidores eletro-intensivo e uma cidade atendida pela Rede Celpa.

Tratam-se de duas mineradoras da Companhia Vale do Rio Doce (CVRD) a saber: a mina de minério de ferro Serra dos Carajás, com capacidade instalada de 
$4-$ ANÁlise ESt A Tística D A

SITUAÇÕES DE DESEQUILÍBRIO DE

TENSÃO PRESENTES NO SISTEMA

E LÉTR I C O B R A S I LEIRO

80 MW, e a mina de cobre Mineradora Serra do Sossego (MSS), com capacidade de 64 MW.

\section{$>\quad$ Porto e Pelotização}

\section{f) CVRD SÃO LUÍS}

Ponto de Conexão: SE-São Luis II

Descrição: Este consumidor divide-se em CVRD-CPPM (Complexo Portuário de Ponta do Madeira) e CVRD-Pelotização. A interligação a Eletronorte se dá através de uma linha de transmissão de $230 \mathrm{kV}$ junto a SE - São Luís II.

O Complexo da CVRD engloba as principais atividades do terminal portuário do Estado do Maranhão. Hoje, o Porto se ocupa da logística de exportação de commodities como minério de ferro, manganês, soja, minério semi-beneficiado, além do ferro gusa.

A Unidade de Pelotização, recentemente implantada, é uma usina de produção de pelotas voltada aos grandes produtores de aço.

\subsection{2 - Pontos de Intercâmbio}

\section{Pontos de medição dos Intercâmbios entre Submercados}

a) Miracema

Ponto de conexão: SE-Miracema

Descrição: Trata-se de um ponto de intercâmbio da rede básica Norte-Sul. Nesse ponto existe uma linha de transmissão de $500 \mathrm{kV}$ que interliga Miracema a Gurupi.

\section{b) Presidente Dutra}

Ponto de conexão: SE - Presidente Dutra - TSPD

Descrição: Trata-se de um ponto de intercâmbio da rede básica Norte-Nordeste. Neste ponto existem duas linhas de transmissão de $500 \mathrm{kV}$ que interligam Presidente Dutra a Teresina. 
$4-$ ANÁlise ESTATÍSTICA DAS

S IT U AÇÕ ES DE DESEQUILÍBRIO DE

TENSÃO PRESENTES NO S ISTEMA

E LÉTRICO B R A S ILEIRO

\section{3 - IDENTIFICAÇÃO DOS NÍVEIS DE DESEQUILÍBRIO}

A seguir, realizam-se análises com dados dos locais descritos na seção anterior, coletados a partir de 0 h00 de $1^{\circ}$ de agosto a 0h00 de 12 de setembro de 2007.

Utilizando-se do software desenvolvido para mensuração dos desequilíbrios presentes em cada um dos locais, obtém-se os resultados descritos na Tabela 4.1.

Tabela 4.1 - Estatísticas de K\% de cada consumidor

\begin{tabular}{l|c|c|c|c|c|c|c|c}
\hline \multirow{2}{*}{ Estatísticas } & \multicolumn{7}{c}{ K\% - Componentes Simétricas } \\
\cline { 2 - 9 } & \multicolumn{7}{|c}{ Locais em estudo } \\
\cline { 2 - 8 } Máximo & Albrás & Alumar & Alunorte & CCM & CVRD & Marabá & Miracema & TSPD \\
\cline { 2 - 8 } Mínimo & 0.5711 & 0.3739 & 0.2021 & 0.4704 & 18.6300 & 1.7910 & 19.000 & 0.1708 \\
Méd.Aritmética & 0.0945 & 0.0892 & 0.0024 & 0.0637 & 0.0491 & 0.7386 & 0.3633 & 0.0006 \\
Méd.Quadrática & 0.1983 & 0.2345 & 0.0725 & 0.2140 & 0.2339 & 0.9217 & 0.5081 & 0.0592 \\
Desvio Padrão & 0.2028 & 0.2377 & 0.0851 & 0.2172 & 0.4315 & 0.9268 & 0.6110 & 0.0652 \\
P95\% & 0.0424 & 0.0375 & 0.0445 & 0.0366 & 0.3172 & 0.0719 & 0.2376 & 0.0271 \\
P99\% & 0.2749 & 0.2964 & 0.1604 & 0.2736 & 0.2945 & 1.0354 & 0.5596 & 0.1061 \\
\hline
\end{tabular}

Dos níveis de desequilíbrio presentes em cada consumidor, verifica-se, por meio das suas médias aritmética e quadrática, que em todos os locais o fator $\mathrm{K}$ apresentou valores aceitáveis, de acordo com os índices de conformidade apresentados na Tabela 2.3.

Todavia, observando-se os valores máximos, constatam-se dois elevados registros de desequilíbrio. Um de 18,63\%, ocorrido em certo instante no consumidor CVRD São Luis, e outro de $19 \%$ no ponto de intercâmbio entre submercados Miracema. Ao investigar seus respectivos bancos de dados, viu-se que no momento de ocorrência destes casos houve desvios de quase $20 \mathrm{kV}$ nos três fasores, além de elevadíssimos desvios de ângulo em 
$4-$ ANÁlise ESTATÍSTCA D A S

S ITU A ÇÕES DE DESEQUILÍBRIO DE

TENSÃO PRESENTES NO S ISTEMA

E LÉ T R I C O B R A S ILEIR O

Universidade de Brasília - UnB

Departamento de Engenharia Elétrica - ENE

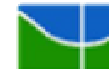

relação ao padrão nominal. Certamente esses valores deram-se por alguma deficiência por parte do medidor no instante coletado, inclusive por terem ocorrido isoladamente, sem correspondência com os valores medidos imediatemente antes e após seus registros.

No ponto de intercâmbio de Presidente Dutra, são verificados os menores valores de desequilíbrio dentre os locais em estudo. Seu índice mínimo foi praticamente nulo. Quanto que o máximo também foi bastante reduzido, visto que sequer atingiu $0.2 \%$.

Da Tabela 4.1, constata-se ainda que os consumidores Albrás, Alumar, Camargo Corrêa Metais e CVRD São Luis apresentaram níveis de K\% bastante semelhantes para média aritmética. Marabá possui valores mais elevados, próximos de 1\%, quase o dobro dos apresentados por Miracema.

\section{4 - DISTRIBUIÇÃO DE PROBABILIDADE DE OCORRÊNCIAS DAS SITUAÇÕES DE DESEQUILÍBRIO}

Neste tópico são determinadas as distribuições de probabilidade das situações de desequilíbrio de cada consumidor.

A Tabela 4.2 informa como se dá a distribuição das situações registradas para os oito locais em análise. Ao final do trabalho, no apêndice "A", encontram-se as probabilidades de ocorrências para cada situação durante as seis semanas em que se obtiveram os dados utilizados. 
$4-$ AnÁlise ESTATística D A

SITU AÇÕES DE DESEQUILÍBRIO DE

TENSÃO PRESENTES NO S ISTEMA

E LÉTRICO B R A S ILEIRO

Tabela 4.2 - Probabilidade de Ocorrência de cada Situação de Desequilíbrio

\begin{tabular}{c|cccccccc}
\hline \multirow{2}{*}{$\begin{array}{c}\text { Situações } \\
\text { Equilibrado }\end{array}$} & \multicolumn{7}{|c}{ Probabilidade de Ocorrência } \\
\cline { 2 - 8 } & Albrás & Alumar & Alunorte & $C C M$ & $C V R D$ & Marabá & Miracema & TSPD \\
\cline { 2 - 8 } 3D-OV & - & $0,02 \%$ & - & $0,05 \%$ & $0,18 \%$ & - & - & - \\
\hline 3D-OV / 1D-OA & $82,19 \%$ & $1,36 \%$ & $98,74 \%$ & $0,25 \%$ & $93,92 \%$ & $1,44 \%$ & $0,03 \%$ & $99,44 \%$ \\
\hline 3D-OV / 1D-OA / 1D-UA & $17,79 \%$ & $34,92 \%$ & $1,26 \%$ & - & - & $0,36 \%$ & $99,85 \%$ & $0,02 \%$ \\
\hline 3D-OV / 1D-UA & - & $50,45 \%$ & - & - & - & - & $0,07 \%$ & - \\
\hline 2D-OV / 1D-OA / 1D-UA & - & $6,18 \%$ & - & - & - & $56,46 \%$ & - & $0,55 \%$ \\
\hline 2D-OV/ 1D-UV/ 1D-OA/ 1D-UA & - & $2,89 \%$ & - & - & - & - & - & - \\
\hline 3D-UV & - & $1,88 \%$ & - & - & - & - & - & - \\
\hline 2D-UV & - & - & - & $1,80 \%$ & $0,79 \%$ & - & - & - \\
\hline 2D-UV / 1D-OA / 1D-UA & - & - & - & - & $0,02 \%$ & - & - & - \\
\hline 1D-UV & - & - & - & $2,30 \%$ & $0,50 \%$ & - & - & - \\
\hline 3D-UV / 1D-UA & - & - & - & $0,93 \%$ & - & - & - & - \\
\hline 3D-UV / 1D-OA / 1D-UA & - & - & - & - & $0,08 \%$ & - & $0,05 \%$ & - \\
\hline 2D-OV & $0,02 \%$ & - & - & $0,81 \%$ & $1,85 \%$ & - & - & - \\
\hline 1D-OV & - & - & - & $0,46 \%$ & $1,97 \%$ & - & - & - \\
\hline 1D-OV / 1D-UV & - & - & - & $0,03 \%$ & $0,18 \%$ & - & - & - \\
\hline 1D-OV/ 1D-UV/ 1D-OA/ 1D-UA & - & $0,60 \%$ & - & - & - & - & - & - \\
\hline 3D-OV / 2D-UA & - & - & - & - & - & $36,34 \%$ & - & - \\
\hline 3D-OV / 2D-OA & - & - & - & - & - & $5,39 \%$ & - & - \\
\hline
\end{tabular}

Analisando a Tabela 4.2, verifica-se, na Albrás, duas situações que somam quase a totalidade das ocorrências. Dentre elas, constata-se a predominância da situação 3D-OV, com mais de $80 \%$ das ocorrências. Uma parcela inferior, de $17.79 \%$, corresponde a segunda situação que também possui seus três fasores apresentando valores superiores ao padrão nominal, contudo também ocorre a condição de um desvio de ângulo acima do valor nominal (1D-OA).

A indústrica metalúrgica Alumar apresentou diversas situações de desequilíbrio. Nota-se que duas situações correspondem pela maioria das ocorrências. Porém suas distribuições são diferentes em cada semana do período analisado, conforme verifica-se na Tabela 2 do apêndice "A". Percebe-se também uma maior diversidade de situações se comparado às 
$4-$ ANÁlise ESTATístCA D A

SituAÇÕES DE DESEQUILÍBRIO DE

TENSÃO PRESENTES NO SISTEMA

E LÉ T R I C O B R A S ILEIR O

Universidade de Brasília - UnB

Departamento de Engenharia Elétrica - ENE

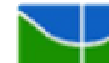

identificadas na Albrás. Têm-se ainda ocorrências de poucas situações equilibradas, que respondem por apenas $0,02 \%$ do total. São poucos os registros de situações que contém condições de under-voltage. E as ocorrências mais significativas compreendem elevações acima do padrão nominal em todos três fasores simultaneamente. Os desvios de ângulo são as condições que caracterizam a diferença entre as situações que mais apareceram.

A fábrica Alunorte representa um caso muito parecido ao analisado de Albrás, pois as situações de desequilíbrio registradas são as mesmas das duas mais ocorrentes em Albrás. Sendo que em Alunorte, a situação 3D-OV torna-se mais significativa por abranger quase a totalidade dos desequilíbrios identificados, com cerca de $99 \%$ das ocorrências. Por conta do desvio de ângulo em uma das fases, verificam-se os $1,26 \%$ restantes referentes à situação 3D-OV / 1D-OA.

Para indústria de silício metálico CCM, a situação 3D-UV teve a grande maioria das ocorrências. Repara-se que as três situações que procedem a de maior ocorrência também só apresentam desvios de tensão do tipo under-voltage, diferentemente dos locais já analisados, em que houve a predominância de over-voltage. Notou-se ainda uma parcela muito reduzida de situações equilibradas que, assim como as situações que contiveram condições de over-voltage, possuem probabilidade inferior a $1 \%$ do total.

O consumidor CVRD São Luís apresentou uma enorme probabilidade de ocorrência para situações que possuem apenas condições de over-voltage, cumprindo destacar a situação 3D-OV, por ultrapassar a marca dos $90 \%$ em todas as semanas. Outro importante aspecto a ressaltar deste consumidor foi a ínfima ocorrência de situações que apresentaram desvios de ângulo, que somadas dão apenas $0,1 \%$. Menor até que a probabilidade de casos equilibrados. Confirmando o predomínio da situação 3D-OV, na última semana esta representou 99,9\% das ocorrências identificadas, como vê-se na Tabela 5 do apêndice "A".

As mineradoras de Marabá apresentaram algumas situações, dentre elas, duas de forma mais significativa, com parcelas de $36,34 \%$ e $56,46 \%$. As condições que formam estas duas situações são bem semelhantes, se diferenciando apenas por um desvio a mais de ângulo. 
$4-$ ANÁlise ESTATÍSTCA D A S

S ITU A ÇÕES DE DESEQUILÍBRIO DE

TENSÃO PRESENTES NO S ISTEMA

E LÉ T R I C O B R A S ILEIR O

Não houve casos equilibrados. E todos os desequilíbrios obtidos se caracterizaram por desbalanço de magnitude nos três fasores acima do padrão nominal.

No ponto de intercâmbio da rede básica Norte-Sul, Miracema, ocorreu praticamente um tipo de situação, visto que as demais registradas, apresentam índices de probabilidade extremamente baixos. Novamente as ocorrências de desequilíbrio do tipo over-voltage prevaleceram.

Todas as ocorrências de desequilíbrio, no ponto de intercâmbio Presidente Dutra, contiveram a condição 3D-OV. Sendo que as situações que possuem desvio de ângulo têm baixíssima probabilidade de ocorrência e, de acordo com a Tabela 8 do apêndice "A", elas foram registradas em apenas duas das seis semanas de medição.

\section{5 - AVALIAÇÃO DOS NÍVEIS DE DESEQUILÍBRIO DAS SITUAÇÕES DE DESEQUILÍBRIO}

Na seção 4.3 foram identificados os valores de desequilíbrio, de forma mais abrangente, ou seja, sem distinção das situações, mensurados para cada local em estudo. No entanto, para que se avalie a relação existente entre as situações de desequilíbrio com o fator $\mathrm{K}$, devemse considerar os valores de $\mathrm{K} \%$ das principais situações, no que concerne às de maiores ocorrências, dadas pelo levantamento feito na seção precedente.

Por meio de análises de situação de desequilíbrio, disponíveis na ferramenta computacional, quantificam-se os desequilíbrios de cada local e de cada situação separadamente. Dispõe-se na Tabela 4.3 os resultados obtidos para os consumidores em análise. 
$4-$ ANÁlise ESTATÍSTICA D A

S ITU AÇÕES DE DESEQUILÍBRIO DE

TENSÃO PRESENTES NO SISTEMA

E LÉ T R I C O B R A S ILEIR O

Tabela 4.3 - Níveis de K\% para cada situação de desequilíbrio

\begin{tabular}{|c|c|c|c|c|c|c|c|c|}
\hline \multirow{3}{*}{$\begin{array}{c}\text { Situações } \\
\text { 3D-OV }\end{array}$} & \multicolumn{8}{|c|}{$K \%$} \\
\hline & Albrás & Alumar & Alunorte & $C C M$ & $C V R D$ & Marabá & Miracema & $T S P D$ \\
\hline & $0,21 \%$ & $0,15 \%$ & $0,07 \%$ & - & $0,22 \%$ & $0,98 \%$ & - & $0,06 \%$ \\
\hline 3D-OV / 1D-OA & $0,17 \%$ & - & $0,19 \%$ & - & - & - & - & - \\
\hline 3D-OV / 1D-OA / 1D-UA & - & $0,26 \%$ & - & - & - & - & - & - \\
\hline 3D-OV / 1D-UA & - & $0,20 \%$ & - & - & - & $0,93 \%$ & - & - \\
\hline 2D-OV / 1D-OA / 1D-UA & - & $0,25 \%$ & - & - & - & - & - & - \\
\hline 2D-OV/ 1D-UV/ 1D-OA/ 1D-UA & - & $0,26 \%$ & - & - & - & - & - & - \\
\hline 3D-OV / 1D-OA & - & $0,21 \%$ & - & - & - & - & $0,50 \%$ & - \\
\hline 3D-UV & - & - & - & $0,21 \%$ & - & - & - & - \\
\hline 2D-UV & - & - & - & $0,22 \%$ & - & - & - & - \\
\hline 1D-UV & - & - & - & $0,21 \%$ & - & - & - & - \\
\hline 3D-UV / 1D-UA & - & - & - & $0,35 \%$ & - & - & - & - \\
\hline $2 \mathrm{D}-\mathrm{OV}$ & - & - & - & $0,22 \%$ & $0,24 \%$ & - & - & - \\
\hline 1D-OV & - & - & - & - & $0,22 \%$ & - & - & - \\
\hline 3D-OV / 2D-UA & - & - & - & - & - & $0,85 \%$ & - & - \\
\hline 3D-OV / 2D-OA & - & - & - & - & - & $1,26 \%$ & - & - \\
\hline
\end{tabular}

A partir desta Tabela 4.3, constata-se que, dentre os locais analisados, a situação que mais se repete é 3D-OV.

Todavia, não se verifica uma relação direta da intensidade do valor de desequilíbrio com a situação ocorrente. Isso pode ser notado quando da avaliação do valores de $\mathrm{K} \%$, para a situação 3D-OV de diferentes consumidores, haja vista que a quantificação dos desequilíbrios desta situação em Marabá atinge valores próximos de $1 \%$ de fator $\mathrm{K}$ e, no caso de TSPD, tem-se esse valor praticamente nulo.

Percebe-se, portanto, que a intensidade dos níveis de desequilíbrio depende da intensidade dos desvios de magnitude e ângulo dos fasores de tensão e não do tipo de situação em que se enquadra. As situações de desequilíbrio caracterizam apenas as condições como os fasores se encontram. Mas para que estas condições sejam esclarecidas, a fim de que o desequilíbrio seja avaliado, é preciso que se conheçam informações de magnitude e de ângulo dos fasores. 
$4-$ AnÁlise ESTATística D A

SITU AÇÕES DE DESEQUILÍBRIO DE

TENSÃO PRESENTES NO S ISTEMA

E LÉ T R I C O B R A S ILEIR O

Universidade de Brasília - UnB

Departamento de Engenharia Elétrica - ENE

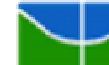

Verifica-se também na Tabela 4.3 que existe uma certa proximidade entre os níveis de desequilíbrio de diferentes situações, mas para um mesmo local. É o que se observa, por exemplo, na coluna referente a Alumar, ou na coluna CCM, ou ainda, na CVRD. Para conferir esse fato, pode-se observar que os valores de $\mathrm{K} \%$ das situações de cada consumidor possuem semalhanças se comparados às médias globais de desequilíbrio de cada local, mostrados na Tabela 4.1.

Cumpre destacar que a situação que apresentou o maior nível de desequilíbrio para o consumidor Camargo Correa Metais, dentre as cinco registradas, foi a única destas cinco que possui uma condição de desvio de ângulo. GARCIA (2006), em estudos de sensibilidade do desequilíbrio de tensão frente a variações nos ângulos e magnitudes das tensões, constatou ser notório que o fator K é mais sensível às variações nos ângulos das tensões que às variações nas amplitudes. Isso contribui no entendimento de a referida localidade CCM possuir os maiores desequilíbrios, haja vista que alterações nos módulos e ângulos das tensões respondem por diferentes parcelas do desequilíbrio (GARCIA, 2006).

\section{6 - AVALIAÇÃO DA DISTRIBUIÇÃ̃ NO TEMPO DAS OCORRÊNCIAS DE CADA SITUAÇÃO}

De forma a avaliar como se deram as ocorrências das situações de desequilíbrio ao decorrer do período de medição dos dados em análise, faz-se utilizar o módulo "Distribuição no Tempo" da ferramenta computacional.

O estudo que se segue é feito para todos os locais descritos na seção 4.2.

Como verificado anteriormente, na Tabela 4.2, basicamente houve duas situações de desequilíbrio apresentados na Albrás: 3D-OV (82,19\% das ocorrências) e 3D-OV/1D-OA $(17,79 \%)$. A Figura 4.5 ilustra a maneira como a primeira destas situações esteve disposta durante a quinta semana de medição, que foi quando registrou-se o maior intervalo de tempo de sua ocorrência, com 2750 minutos. A Figura também mostra o correspondente nível de desequilíbrio em cada instante. A distribuição em todo o período de medição pode ser visualizada no apêndice "B". 


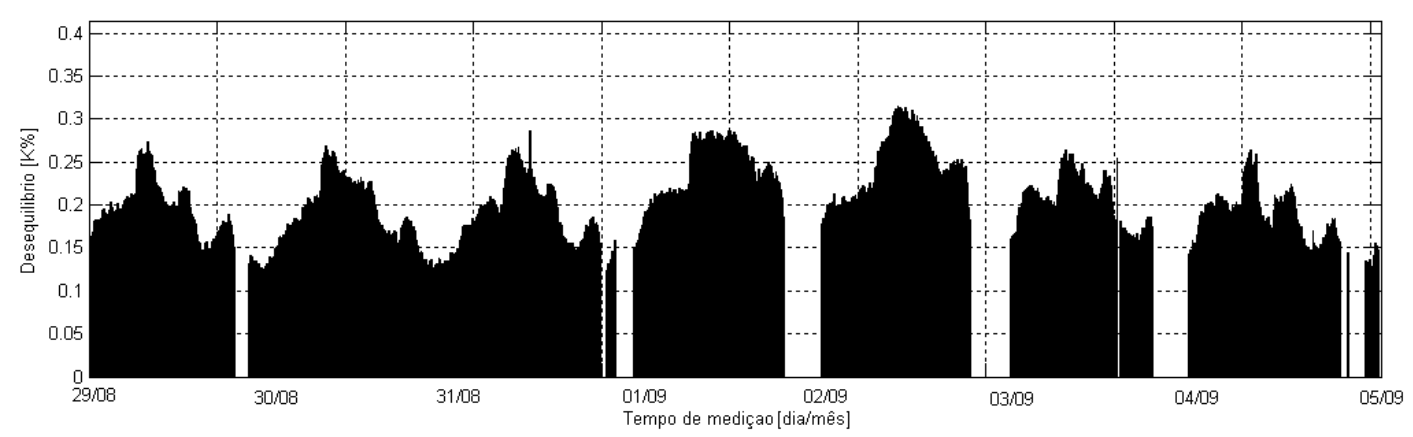

Figura 4.5 - Distribuição no tempo de 3D-OV na Albrás de 29/08 a 04/09 de 2007

Repara-se na ocorrência desta situação em todos os dias em estudo. Durante toda a análise, os momentos em que suas ocorrências não foram identificadas correspondem aos instantes em que se tem presente a situação 3D-OV/1D-OA. Percebe-se que esta última tende a ocorrer em meados da passagem entre um dia e outro ocupando curtos intervalos.

No que se refere à distribuição no tempo na Alumar, verificou-se na que as distribuições neste consumidor variou bastante entre as semanas do período analisado. $\mathrm{O}$ apêndice “A”traz a Tabela 2, da qual nota-se essa variação.

Observa-se nas Figura 4.6 e 4.7 seguintes que, nas semanas de $1^{\circ}$ a 14 de agosto de 2007, houve o predomínio de 3D-OV/1D-OA/1D-UA. Mas em alguns momentos, como nos dias 4, 6, 10 e 13, faz-se presente a situação 3D-OV / 1D-UA. O maior intervalo ininterrupto registrado desta última situação foi de 540 minutos, no dia 6 . 


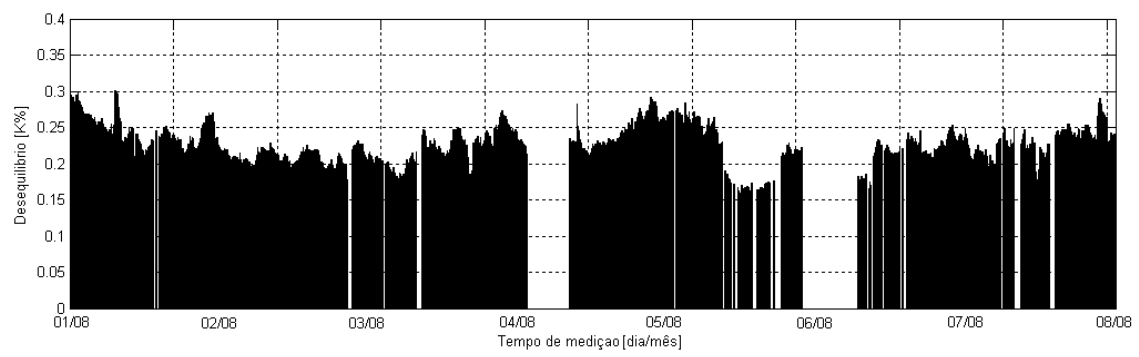

3D-OV/1D-OA/1D-UA

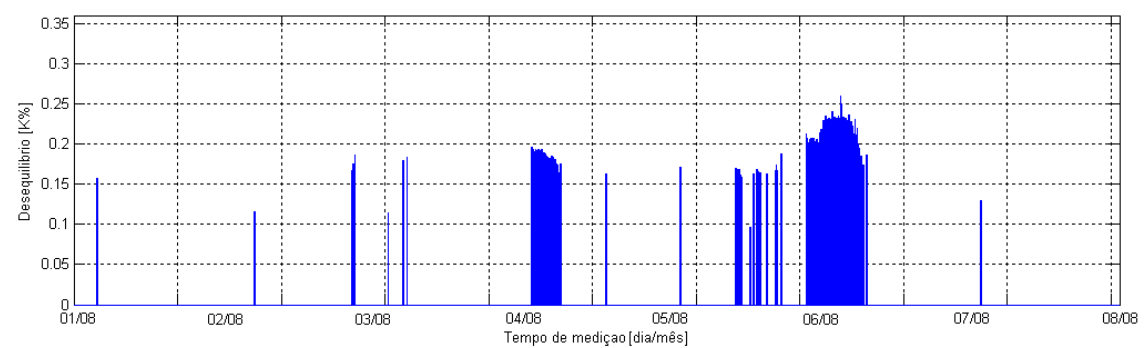

3D-OV / 1D-UA

Figura 4.6 - Distribuição no tempo em Alumar de 01 a 07/08 de 2007

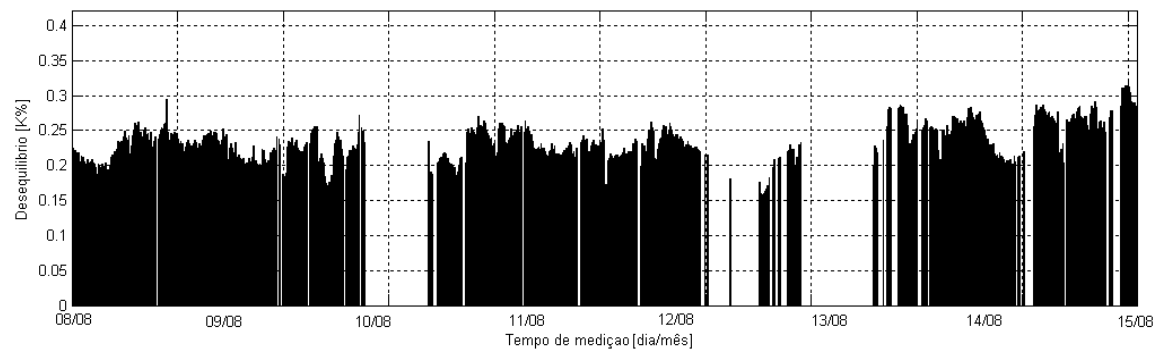

3D-OV/1D-OA/1D-UA

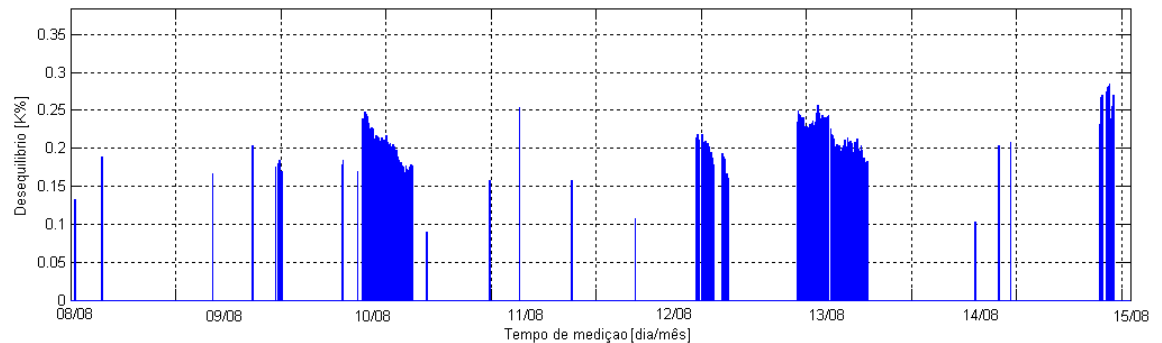

3D-OV / 1D-UA

Figura 4.7 - Distribuição no tempo em Alumar de 08 a 14/08 de 2007

Não se constatou ocorrências de 3D-OV / 1D-UA na terceira semana. Neste período, a situação 3D-OV / 1D-OA / 1D-UA também aparece mais vezes. Pequenas ocorrências de 
$4-$ ANÁlise ESTATÍSTICA D A S

S ITU AÇÕES DE DESEQUILÍBRIO DE

TENSÃO PRESENTES NO SISTEMA

E LÉTRICO B R A S ILEIRO

Universidade de Brasília - UnB Departamento de Engenharia Elétrica - ENE

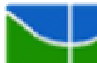

outras situações completam o tempo restante. Contudo, na semana de 22 a 28 de agosto de 2007 (quarta semana), há uma redução, com relação às semanas anteriores, da situação 3D-OV / 1D-OA / 1D-UA, para 39,79\% das ocorrências. Por outro lado passa a se verificar significativos registros de 3D-OV / 1D-OA por volta do dia 25 adiante, com mais de $50 \%$. Adiante, na penúltima semana, esta passa a responder por cerca de $86 \%$ das ocorrências. Maiores detalhes dos gráficos dessa distribuição podem ser visualizados nas Figuras 2 e 3 do apêndice "B".

Uma maior parcela de 3D-OV/1D-OA/1D-UA, com 20\% é obtido na última semana (5 a 11 de setembro). Todavia, 3D-OV/1D-OA permanece respondendo pela maioria das ocorrências, conforme se verifica na Figura 4.8.

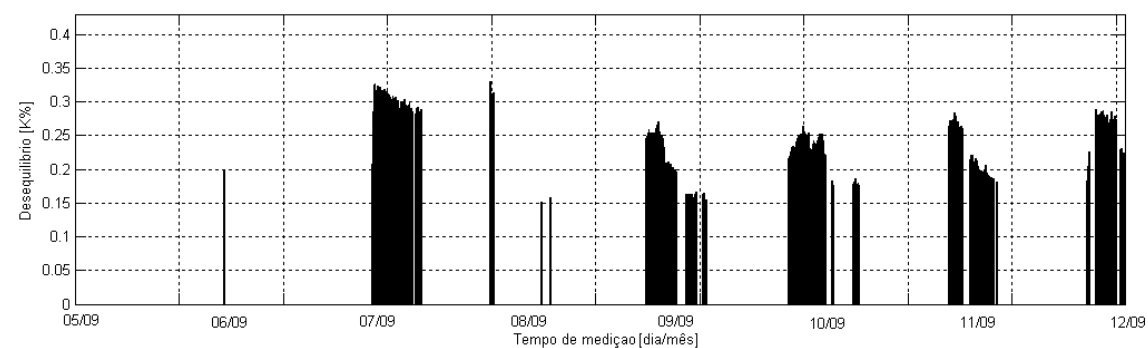

3D-OV/1D-OA/1D-UA

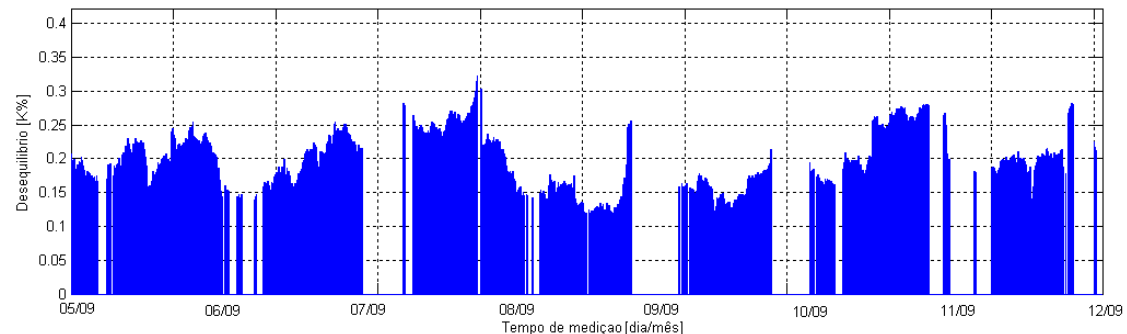

3D-OV / 1D-OA

Figura 4.8 - Distribuição no tempo em Alumar de 05 a 11/09 de 2007

A ALUNORTE, Alumina do Norte do Brasil S.A., tem praticamente distribuída, em todo período de análise, a situação 3D-OV, com uma correspondência de quase $100 \%$ das ocorrências. A Figura 4.9 mostra como se deu sua distribuição na semana 05 a 11/09 de 2007. Para as demais semanas de medição, a distribuição portou-se de forma semelhante. 


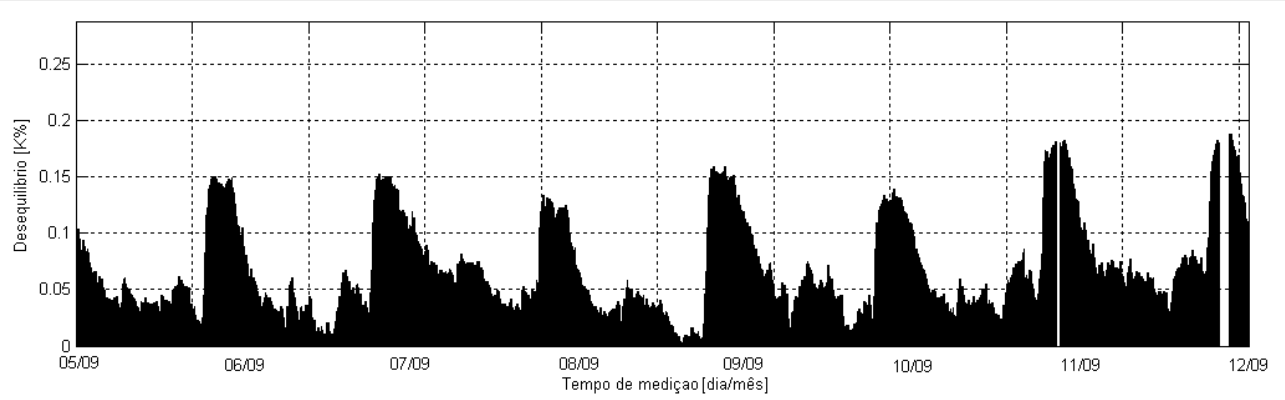

Figura 4.9 - Distribuição no tempo de 3D-OV em Alunorte

Vale ressaltar a variação dos níveis de desequilíbrio que se verifica para esta situação, atingindo seus valores mais elevados nas transições de um dia para o outro. Isso confirma a avaliação feita na seção 4.5, constantando-se que as situações não são caracterizadas pelos níveis de desequilíbrio, pois esses podem alcançar diversos valores numa mesma situação.

Diferentemente dos demais consumidores em avaliação, nos quais prevaleceram desequilíbrios de over-voltage, a indústria de silício Camargo Correa Metais apresentou a situação de três fasores em under-voltage. Da Tabela 4.2 vê-se que que a probabilidade de ocorrência das demais situações nesse consumidor são muito reduzidas. Representa-se na Figura 4.10 a distribuição no tempo de 3D-UV logo na primeira semana.

Notam-se pequenas lacunas que não foram preenchidos pela situação 3D-UV. Esses instantes correspondem às situações de desequilíbrio que também caracterizam undervoltage, contudo, em um (1D-UV) e em dois fasores apenas (2D-UV). Verificam-se ainda variações bastante reduzidas do nível de desequilíbrio.

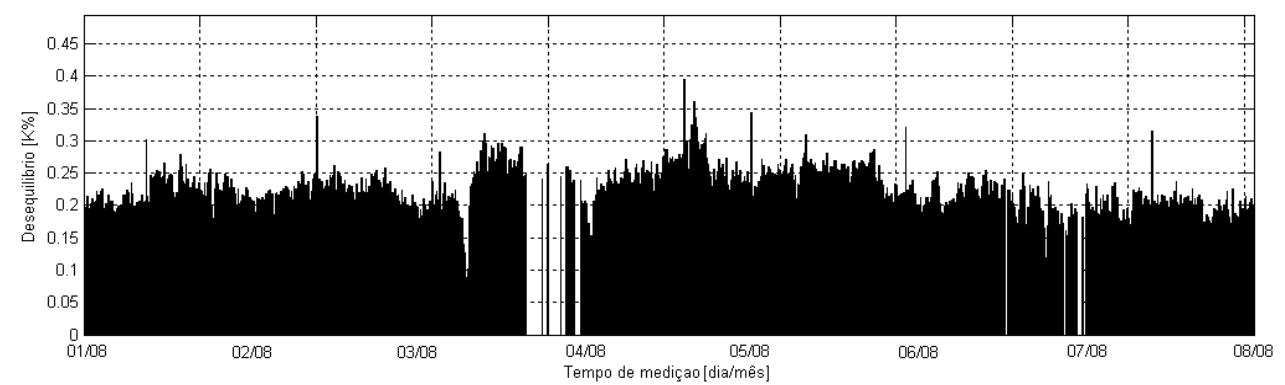

Figura 4.10 - Distribuição no tempo de 3D-UV em CCM de 01 a 07/08 de 2007 
$4-$ ANÁlise ESTATÍSTICA D A S

SITUAÇÕES DE DESEQUILÍBRIO DE

TENSÃO PRESENTES NO SISTEM A

E LÉ T R I C O B R A S ILEIR O

Ilustra-se na Figura 4.11 os intervalos ininterruptos da última semana em que o desequilíbrio correspondeu à situação 3D-UV. O maior foi de 4220 minutos, que também é o maior em todo o período de 01/08 a 11/09 de 2007 em que se coletaram os dados.

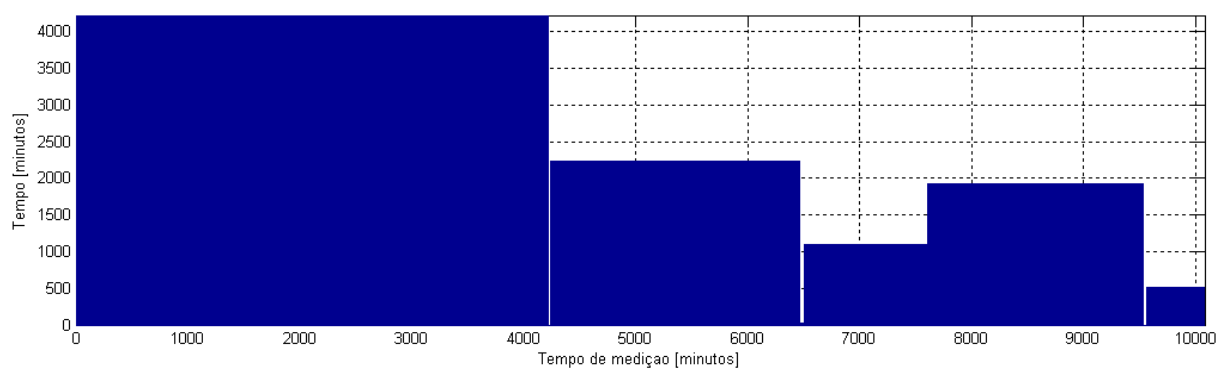

Figura 4.11 - Intervalos ininterruptos de tempo da situação 3D-UV em CCM de 5 a 11/09 de 2007

Já para o consumidor CVRD São Luís, constatou-se a presença de diversas situações. Todavia, houve um grande predomínio da situação 3D-OV, como se verifica na Figura 4.12, correspondente à primeira semana do período em estudo. Durante todo o tempo de medição, $\mathrm{K} \%$ teve valores baixos, variando por volta de 0,2 a $0,3 \%$. Baixas probabilidades de outras situações referem-se às ocorrências nos curtos instantes em que não se obteve 3D-OV. Demonstra-se o predomínio desta situação ao verificar-se que o desequilíbrio que lhe corresponde sustentou-se por mais de 6 dias, mais precisamente, por 9110 minutos na última semana.

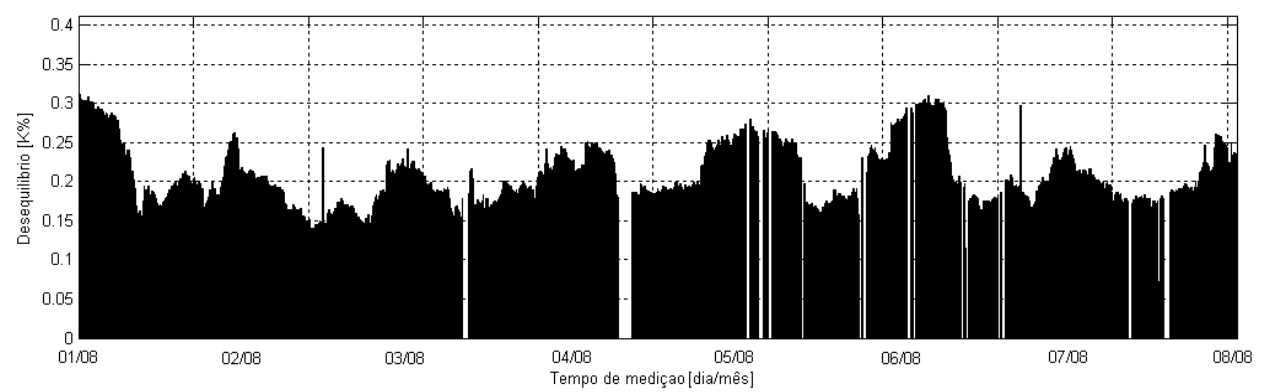

Figura 4.12 - Distribuição no tempo de 3D-OV em CVRD São Luís de 01 a 07/08 de 2007 
$4-$ ANÁlise ESTATÍSTICA D A S

SITUAÇÕES DE DESEQUILÍBRIO DE

TENSÃO PRESENTES NO SISTEMA

E LÉ T R I C O B R A S ILEIR O

Universidade de Brasília - UnB

Departamento de Engenharia Elétrica - ENE

Em Marabá verificou-se poucos registros da situação apenas com a condição 3D-OV. As situações que mais apareceram apresentam seus três fasores em over-voltage, mas elas contêm ainda condições de desvios de ângulo. O apêndice "A" traz os percentuais de probabilidade dessas situações.

As mais significativas são 3D-OV/1D-UA e 3D-OV/2D-UA, com desequilíbrios próximos de $1 \%$ de fator $\mathrm{K}$. A primeira predominou nas três primeiras semanas. Também representou a maioria dos desequilíbrios na quarta semana, mas em menor parcela que nas anteriores, com pouco mais de 60\%, como mostrado na Figura 4.13. Já 3D-OV/2D-UA apareceu com cerca de $17 \%$ de ocorrências na segunda semana e teve ocorrências também na quarta semana, com quase $40 \%$

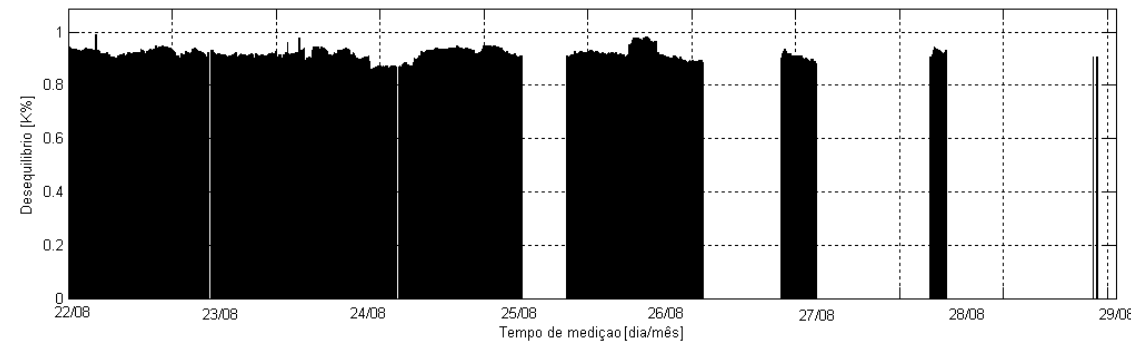

3D-OV/1D-UA

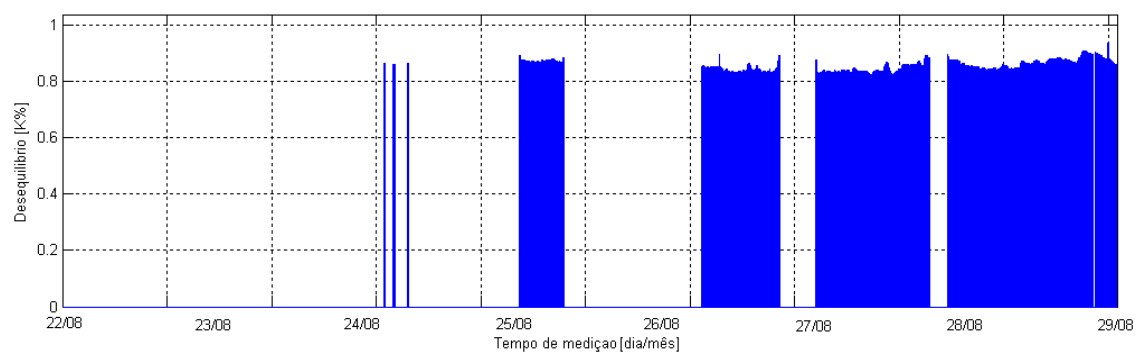

3D-OV/2D-UA

Figura 4.13 - Distribuição no tempo em Marabá de 22 a 28 de agosto

Ainda com relação à situação 3D-OV/2D-UA, ela foi predominante na semana de 29/08 a 04/09 e correspondeu por cerca de $60 \%$ das ocorrências na última semana. Uma outra situação 3D-OV/2D-OA, que até então não tinha quase nenhuma ocorrência, aparece com cerca de $32 \%$, completando o restante das ocorrências da última semana, conforme mostra a Figura 4.14. Esta situação representa os índices mais elevados de K\%, com uma média em torno de $1,2 \%$. 


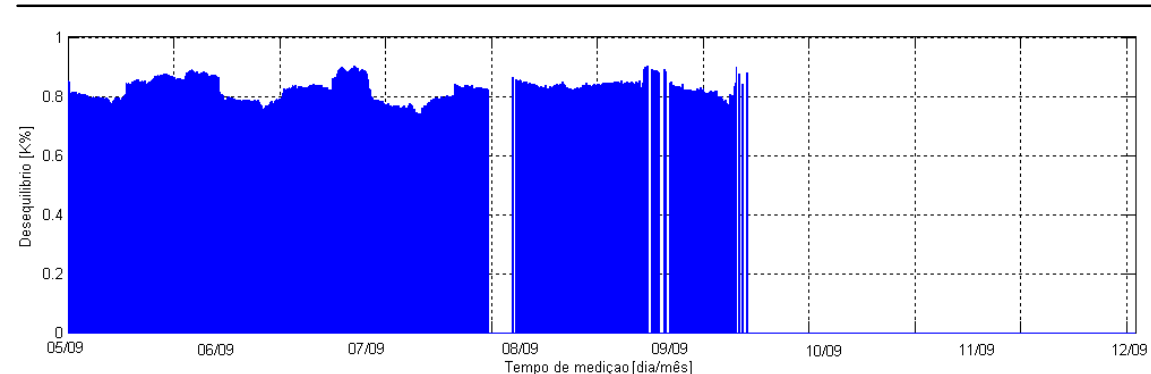

3D-OV/2D-UA

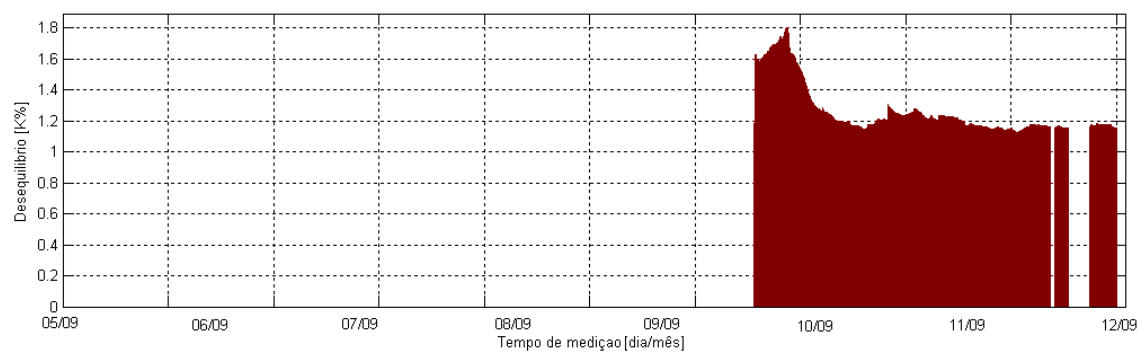

$3 \mathrm{D}-\mathrm{OV} / 2 \mathrm{D}-\mathrm{OA}$

Figura 4.14 - Distribuição no tempo em Marabá de 5 a 11/09 de 2007

Em Miracema, a situação 3D-OV / 1D-OA foi praticamente absoluta e ininterrupta no decurso de todo o período analisado. Os níveis de desequilíbrio não tiveram variações elevadas, ficando sempre em torno de $0,5 \%$.

E no ponto de intercâmbio Presidente Dutra - TSPD, também houve o predomínio de apenas uma situação de desequilíbrio. De $1^{\circ}$ de agosto a 11 de setembro de 2007 , registraram-se ocorrências de 3D-OV com variações irregulares dos níveis de desequilíbrio, mas com valores bem reduzidos. Desduz-se que os fasores de tensão, embora se encontrem acima do valor nominal, possuem valores bastante próximos.

Os gráficos que ilustram a distribuição em Miracema e em TSPD encontram-se no apêndice "B". 
$4-$ ANÁlise ESTATÍSTICA D A S

SITU AÇÕES DE DESEQUILÍBRIO DE

TENSÃO PRESENTES NO S ISTEMA

E LÉTRICO B R A S ILEIRO

Universidade de Brasília - UnB Departamento de Engenharia Elétrica - ENE

\section{7 - CONSIDERAÇÕES FINAIS}

Da investigação dos resultados obtidos neste capítulo, utilizando-se a ferramenta computacional apresentada nesse trabalho, certificou-se que as médias de $\mathrm{K} \%$ para todos os locais foram baixas. Marabá teve o valor de média mais alto dos consumidores avaliados, no entanto, foi inferior a $1 \%$.

Situações com a condição 3D-OV foram as que mais ocorreram em todos os locais estudados, exceto pelo consumidor Camargo Correa Metais, que apresentou significativas ocorrências de fasores em under-voltage, sobretudo nas três fases (3D-UV). Verificou-se ainda que as condições que mais diferenciaram as situações mais presentes foram do tipo de desvios de ângulo, over-angle ou under-angle.

Poucos locais tiveram casos de situações equilibradas. Todavia, nos que houve, apresentou poucas ocorrências, não chegando a compreender representativos percentuais de probabilidade.

Quando do levantamento dos níveis de K\% para cada situação de desequilíbrio, verificouse que não há uma correspondência direta entre a intensidade dos valores de desequilíbrio e sua correlata situação. $\mathrm{O}$ que se observou foi uma semelhança dos valores dos níveis de K\% de várias situações de desequilíbrio, mas para um mesmo consumidor.

Dessa forma, constatou-se que há uma maior conformidade da intensidade dos níveis de desequilíbrio com a intensidade dos desvios de amplitude e ângulo dos fasores, do que com o tipo de situação correspondente.

Da análise de distribuição no tempo, certos locais, como Albrás e Alunorte, tiveram suas principais situações distribuídas com pequenas variações dos níveis de desequilíbrio, que ocorreram praticamente de forma periódica. Outros não apresentaram essa regularidade, mas a avaliação da distribuição no tempo permitiu observar quando determinadas situações passaram a apresentar menores ocorrências, ao mesmo tempo que outras tiveram maiores registros identificados. 


\section{CAPÍTULO 5}

\section{CONCLUSÃO}

Este trabalho apresentou uma ferramenta computacional que foi desenvolvida e permitiu que se efetuassem avaliações de diversas situações de desequilíbrio de tensão.

Para tornar possível a realização dessas avaliações, primeiramente apresentaram-se, no capítulo 2, as metodologias de cálculo de quantificação do desequilíbrio de tensão. Optouse, dentre elas, pelo método das Componentes Simétricas na implementação da ferramenta computacional, porque esse método é o que melhor representa o grau de desequilíbrio por levar em conta tanto a amplitude como os ângulos das tensões. O mesmo capítulo apura os índices de referência para o desequilíbrio a partir de normas e recomendações que tratam os fenômenos de QEE.

Para a formulação da ferramenta computacional, consideraram-se as situações de desequilíbrio formadas a partir das condições definidas, no capítulo 3, de acordo com as possibilidades que as amplitudes e os ângulos dos fasores podem se encontrar a qualquer instante.

Com a ferramenta desenvolvida, fez-se sua apresentação no capítulo 3. Realizou-se a descrição detalhada de seus módulos e funcionalidades, seguidos de um estudo de caso que ilustra os possíveis resultados que podem ser alcançados com ela, como estatísticas do desequilíbrio quantificado para cada situação, bem como avaliações de suas componentes simétricas, as quais são relevantes, haja vista existir relação, analisada em estudos anteriores (Lee, 1997), entre os valores se sequiência positiva e o desempenho de motores de indução.

Dentro do módulo de distribuição no tempo, o software permitiu visualizar a disposição das situações de desequilíbrio ao longo do tempo, permitindo-se que se avaliasse seu comportamento também no que diz respeito aos níveis de desequilíbrio apresentados em cada momento em que se tiveram dados coletados. 
Essa análise de distribuição no tempo também possibilitou observar quais os intervalos ininterruptos de tempo com valores de $\mathrm{K} \%$ dentro de uma faixa especificada pelo usuário, identificando-se aqueles de maior e menor duração, além de verificar a probabilidade de ocorrência de cada um desses intervalos. Nesse mesmo módulo, pôde-se observar acerca dos valores de $\mathrm{K} \%$ e identificar aqueles mais significativos para determinada situação por meio de gráficos que ilustram a probabilidade das ocorrências dos níveis de desequilíbrio presentes, bem como a distribuição acumulativa dessas probabilidades.

No módulo da ferramenta denominada "Similaridade entre Situações" foi possível comparar as situações de desequilíbrio, avaliando-se estatisticamente seus níveis de desequilíbrio, bem como cada uma de suas componentes simétricas e análise de seus fasores de tensão, a qual permite concluir o quão desequilibrados estão os fasores.

No capítulo 4, efetuaram-se análises estatísticas de desequilíbrio de tensão considerando dados de diversos consumidores do sistema elétrico brasileiro. Descreveram-se suas características e identificaram-se as situações de desequilíbrio presentes em cada um. Assim, pôde-se analisar os níveis de desequilíbrio por eles apresentados e constatou-se que os desequilíbrios foram bem reduzidos para todos os locais estudados.

Identificou-se, para quase todos os locais, que 3D-OV foi a condição mais presente, e o principal tipo de condição que distiguiu as situações que mais ocorreram foi aquele que caracteriza os desvios de ângulo.

Apesar dos baixos níveis de desequilíbrio, observaram-se poucos registros de situações equilibradas. Houve, sobretudo, locais em que estas não foram constatadas no decorrer do período analisado. Compreende-se, portanto, que durante quase todo o período de análise, o sistema encontrou-se em desequilíbrio.

É importante destacar que não há uma conexão imediata da intensidade dos níveis de desequilíbrio com sua correspondente situação, pois observaram-se diferentes níveis de desequilíbrio quando da comparação de mesmas situações observadas em consumidores diferentes. Porém, constataram-se valores próximos de desequilíbrio identificados num mesmo local e para situações diferentes. 
Isso pode ser explicado pela forte influência nos níveis de desequilíbrio causados em conformidade com a intensidade dos desvios de amplitude e ângulo dos fasores.

Pequenas variações dos níveis de desequilíbrio foram observados ao analisar a distribuição no tempo desses consumidores. Com essas análises, pôde-se identificar a disposição das situações ao longo do tempo, observando os instantes de maior e menor ocorrência de cada uma, e levantar os intervalos de maior duração em que se deu o desequilíbrio de cada situação.

Este trabalho se caracterizou como a primeira fase de um estudo que trata da relação entre cada condição de desequilíbrio e os efeitos que são causados por desbalanços de tensão sobre motores de indução. Prevê-se o prosseguimento desse estudo por meio de simulações computacionais e ensaios em laboratório para inspecionar o comportamento térmico e a conseqüente influência na expectativa de vida útil do MIT, por meio de suprimentos desequilibrados caracterizados por situações de desequilíbrio. 


\section{REFERÊNCIAS BIBLIOGRÁFICAS}

\section{REFERÊNCIAS}

ALMEIDA \& FREITAS, F. Damasceno, W.G. (1995). "Circuitos Polifásicos" - Livro Fundação de Empreendimentos Científicos e Tecnológicos, FINATEC, UnB, Brasília.

DECKMANN, S.M. (2000). .Variações Momentâneas de Tensão. ANEEL . Estudos sobre Qualidade da Energia Elétrica.

DUGAN, R.C., McGranaghan, M.F., Beaty, H.W. (1996). "Electrical Power Systems Quality”. Editora McGraw-Hill, E.U.A.

DUGAN, R.C., McGranaghan, M.F., Beaty, H.W. (2000). "Electrical power systems quality". 2.ed. USA: McGraw-Hill, 528p.

FAIZ J.; Ebrahimpour H.; Pillay P. "Influence of Unbalanced Voltage on the Steady-State Performance of a Three-Phase Squirrel-Cage Induction Motor". - IEEE TRANSACTIONS ON ENERGY CONVERSION, vol. 19, no. 4, 2004.

GARCIA, M. P. (2006). “Uma Contribuição para o Estudo do Desequilíbrio de Tensão nos Sistemas Elétricos de Potência”. Projeto Final de Graduação em Engenharia Elétrica, Publicação ENE-1/06, Departamento de Engenharia Elétrica, Universidade de Brasília, Brasília, DF, 198p.

JOUANNE A.V. e Ben, B. (2001). "Assessment of Voltage Unbalance”, IEEE Transaction on Power Delivery, Vol. $16 \mathrm{~N}^{\circ} 4$.

KERSTING, W. H. "Causes and Effects of Unbalanced Voltages Serving an Induction Motor". In: IEEE TRANSACTIONS ON INDUSTRY APPLICATIONS, vol 37, no. 1, 2001. 
LEE, C.Y, Chen, B.K., Lee, W.J., Hsu, Y.F. (1997). "Effects of Various Voltages on the Operation Performance of an Induction Motor under the Same Unbalance Factor Condition" - IEEE explore.

OLIVEIRA, J. C. (2000). "Contribuições para a Normalização da Qualidade da Energia Elétrica - Harmônicos e Desequilíbrios nas Redes Elétricas”. Protocolos de Medição. Universidade Federal de Uberlândia, Faculdade de Engenharia Elétrica.

Oliveira, D. (2001). .Quantificação e Qualificação dos Desequilíbrios de Tensão. Projeto Final de Graduação, UnB, Brasília.

SOUTO, O. C. N. (2001). "Modelagem e Análise do Desempenho Térmico de Motores de Indução sob Condições não Ideais de Alimentação". Dissertação de Mestrado, Departamento de Engenharia Elétrica, Universidade Federal de Uberlândia, Uberlândia, MG.

RAMOS, A.J.P. (2000). "Monitoração, Avaliação e Controle da Qualidade da Energia Elétrica - Procedimentos de Medição e Monitoração" - ANEEL, Recife.

SIDDIQUE A.; YADAVA G. S.; SINGH B. "Effects of Voltage Unbalance on Induction Motors" - Conference Record of the 2004 IEEE International Symposium on Elecnical Insulation, Indianapolis, E.U.A. 2004.

XAVIER, P.A. (2005). .Avaliação das Características Elétricas de Reatores Eletrônicos Utilizados em Lâmpadas Fluorescentes Tubulares. Dissertação. Universidade de Brasília, Brasília.

WANG, Y.J. (2000). "Simulation of Random Variation of Three-phase Voltage Unbalance Resulting from Load Fluctuation Using Correlating Gaussian Random Variables”, IEEE Proc. Natl. Counc. Vol. 24, No. 3, pp. 216-225, Taiwan.

WANG, Y.J. (2001). “Analysis of Effects of Three-Phase Voltage Unbalance on Induction Motors with Emphasis on the Angle of the Complex Voltage Unbalance Factor", IEEE Transactions on Energy Conversion Vol. 16, No.3, pp. 270-275, Taiwan. 


\section{APÊNDICE A}

Neste apêndice, encontram-se listadas as tabelas de distribuição de probabilidade das situações de desequilíbrio presentes nos consumidores descritos e analisados no capítulo 4 .

\section{1 - PROBABILIDADE DE OCORRÊNCIAS NA ALBRÁS}

Tabela 1- Situações na Albrás

\begin{tabular}{c|rrrrrr|r}
\hline Situações & $1 / 8$ a $7 / 8$ & $8 / 8$ a 14/8 & $15 / 8$ a 21/8 & $22 / 8$ a $28 / 8$ & $29 / 8$ a $4 / 9$ & $5 / 9$ a $11 / 9$ & $1 / 8$ a 11/9 \\
\cline { 2 - 8 } 2D-OV & $0,00 \%$ & $0,00 \%$ & $0,00 \%$ & $0,00 \%$ & $0,00 \%$ & $0,10 \%$ & $\mathbf{0 , 0 2} \%$ \\
3D-OV / 1D-OA & $31,65 \%$ & $12,60 \%$ & $19,64 \%$ & $14,68 \%$ & $13,89 \%$ & $14,29 \%$ & $\mathbf{1 7 , 7 9 \%}$ \\
3D-OV & $68,35 \%$ & $87,40 \%$ & $80,36 \%$ & $85,32 \%$ & $86,11 \%$ & $85,62 \%$ & $\mathbf{8 2 , 1 9 \%}$ \\
\hline TOTAL & $100,00 \%$ & $100,00 \%$ & $100,00 \%$ & $100,00 \%$ & $100,00 \%$ & $100,00 \%$ & $\mathbf{1 0 0 , 0 0 \%}$ \\
\hline
\end{tabular}

\section{2 - PROBABILIDADE DE OCORRÊNCIAS NA ALUMAR}

Tabela 2 - Situações na Alumar

\begin{tabular}{c|rrrrrr|r}
\hline Situações & $1 / 8$ a $7 / 8$ & $8 / 8$ a 14/8 & $15 / 8$ a $21 / 8$ & $22 / 8$ a $28 / 8$ & $29 / 8$ a $4 / 9$ & $5 / 9$ a 11/9 & $\mathbf{1 / 8}$ a 11/9 \\
\cline { 2 - 7 } Equilibrado & $0,00 \%$ & $0,00 \%$ & $0,00 \%$ & $0,00 \%$ & $0,10 \%$ & $0,00 \%$ & $\mathbf{0 , 0 2 \%}$ \\
1D-OV / 1D-UV / 1D-OA / 1D-UA & $0,69 \%$ & $2,68 \%$ & $0,20 \%$ & $0,00 \%$ & $0,00 \%$ & $0,00 \%$ & $\mathbf{0 , 6 0 \%}$ \\
3D-OV & $0,10 \%$ & $0,00 \%$ & $0,00 \%$ & $0,50 \%$ & $3,27 \%$ & $4,27 \%$ & $\mathbf{1 , 3 6 \%}$ \\
2D-OV / 1D-UV / 1D-OA / 1D-UA & $0,30 \%$ & $1,29 \%$ & $8,04 \%$ & $1,69 \%$ & $0,00 \%$ & $0,00 \%$ & $\mathbf{1 , 8 8 \%}$ \\
2D-OV / 1D-OA / 1D-UA & $2,68 \%$ & $3,97 \%$ & $7,54 \%$ & $3,17 \%$ & $0,00 \%$ & $0,00 \%$ & $\mathbf{2 , 8 9 \%}$ \\
3D-OV / 1D-UA & $11,31 \%$ & $16,37 \%$ & $0,00 \%$ & $2,28 \%$ & $3,77 \%$ & $3,37 \%$ & $\mathbf{6 , 1 8 \%}$ \\
3D-OV / 1D-OA & $0,00 \%$ & $0,10 \%$ & $0,20 \%$ & $51,19 \%$ & $86,21 \%$ & $71,83 \%$ & $\mathbf{3 4 , 9 2 \%}$ \\
3D-OV / 1D-OA / 1D-UA & $83,04 \%$ & $72,62 \%$ & $83,43 \%$ & $38,79 \%$ & $4,27 \%$ & $20,54 \%$ & $\mathbf{5 0 , 4 5 \%}$ \\
Outras & $1,88 \%$ & $2,98 \%$ & $0,60 \%$ & $2,38 \%$ & $2,38 \%$ & $0,00 \%$ & $\mathbf{1 , 7 0 \%}$ \\
\hline TOTAL & $100,00 \%$ & $100,00 \%$ & $100,00 \%$ & $100,00 \%$ & $100,00 \%$ & $100,00 \%$ & $\mathbf{1 0 0 , 0 0 \%}$ \\
\hline
\end{tabular}




\section{3 - PROBABILIDADE DE OCORRÊNCIAS NA ALUNORTE}

Tabela 3 - Situações na Alunorte

\begin{tabular}{c|rrrrrr|r}
\hline Situações & $1 / 8$ a 7/8 & $8 / 8$ a 14/8 & $15 / 8$ a $21 / 8$ & $22 / 8$ a 28/8 & $29 / 8$ a 4/9 & $5 / 9$ a 11/9 & $\mathbf{1 / 8}$ a 11/9 \\
\cline { 2 - 8 } 3D-OV & $96,33 \%$ & $99,90 \%$ & $99,11 \%$ & $99,40 \%$ & $99,01 \%$ & $98,71 \%$ & $\mathbf{9 8 , 7 4 \%}$ \\
3D-OV / 1D-OA & $3,67 \%$ & $0,10 \%$ & $0,89 \%$ & $0,60 \%$ & $0,99 \%$ & $1,29 \%$ & $\mathbf{1 , 2 6 \%}$ \\
\hline TOTAL & $100,00 \%$ & $100,00 \%$ & $100,00 \%$ & $100,00 \%$ & $100,00 \%$ & $100,00 \%$ & $\mathbf{1 0 0 , 0 0 \%}$ \\
\hline
\end{tabular}

\section{4 - PROBABILIDADE DE OCORRÊNCIAS NA CAMARGO CORRÊA METAIS}

Tabela 4 - Situações na Camargo Corrêa Metais

\begin{tabular}{c|rrrrrr|r}
\hline \multirow{2}{*}{$\begin{array}{c}\text { Situações } \\
\text { 1D-OV / 1D-UV }\end{array}$} & $1 / 8$ a 7/8 & $8 / 8$ a 14/8 & $15 / 8$ a 21/8 & $22 / 8$ a $28 / 8$ & $29 / 8$ a $4 / 9$ & $5 / 9$ a $11 / 9$ & $1 / 8$ a 11/9 \\
\cline { 2 - 8 } Equilibrado & $0,00 \%$ & $0,00 \%$ & $0,20 \%$ & $0,00 \%$ & $0,00 \%$ & $0,00 \%$ & $\mathbf{0 , 0 3 \%}$ \\
3D-OV & $0,00 \%$ & $0,00 \%$ & $0,00 \%$ & $0,00 \%$ & $0,30 \%$ & $0,00 \%$ & $\mathbf{0 , 0 5 \%}$ \\
1D-OV & $0,00 \%$ & $0,20 \%$ & $0,00 \%$ & $0,20 \%$ & $1,09 \%$ & $0,00 \%$ & $\mathbf{0 , 2 5 \%}$ \\
2D-OV & $0,00 \%$ & $0,40 \%$ & $0,79 \%$ & $0,10 \%$ & $1,49 \%$ & $0,00 \%$ & $\mathbf{0 , 4 6 \%}$ \\
3D-UV / 1D-UA & $0,00 \%$ & $1,19 \%$ & $0,50 \%$ & $1,09 \%$ & $2,08 \%$ & $0,00 \%$ & $\mathbf{0 , 8 1 \%}$ \\
2D-UV & $0,10 \%$ & $1,59 \%$ & $1,88 \%$ & $0,60 \%$ & $1,09 \%$ & $0,30 \%$ & $\mathbf{0 , 9 3 \%}$ \\
1D-UV & $2,68 \%$ & $1,88 \%$ & $0,99 \%$ & $0,79 \%$ & $4,37 \%$ & $0,10 \%$ & $\mathbf{1 , 8 0 \%}$ \\
3D-UV & $2,38 \%$ & $2,78 \%$ & $0,69 \%$ & $0,60 \%$ & $6,94 \%$ & $0,40 \%$ & $\mathbf{2 , 3 0 \%}$ \\
\hline TOTAL & $94,84 \%$ & $91,96 \%$ & $94,94 \%$ & $96,63 \%$ & $82,64 \%$ & $99,21 \%$ & $\mathbf{9 3 , 3 7 \%}$ \\
\hline
\end{tabular}

\section{5 - PROBABILIDADE DE OCORRÊNCIAS NA CVRD SÃO LUÍS}

Tabela 5 - Situações na CVRD São Luís

\begin{tabular}{c|rrrrrr|c}
\hline Situações & $1 / 8$ a 7/8 & $8 / 8$ a 14/8 & $15 / 8$ a 21/8 & $22 / 8$ a 28/8 & $29 / 8$ a $4 / 9$ & $5 / 9$ a 11/9 & $\mathbf{1 / 8} a$ 11/9 \\
\cline { 2 - 8 } 2D-UV / 1D-OA / 1D-UA & $0,00 \%$ & $0,00 \%$ & $0,10 \%$ & $0,00 \%$ & $0,00 \%$ & $0,00 \%$ & $\mathbf{0 , 0 2} \%$ \\
3D-UV / 1D-OA / 1D-UA & $0,10 \%$ & $0,20 \%$ & $0,20 \%$ & $0,00 \%$ & $0,00 \%$ & $0,00 \%$ & $\mathbf{0 , 0 8 \%}$ \\
Equilibrado & $0,30 \%$ & $0,69 \%$ & $0,10 \%$ & $0,00 \%$ & $0,00 \%$ & $0,00 \%$ & $\mathbf{0 , 1 8 \%}$ \\
\hline
\end{tabular}




\begin{tabular}{c|rrrrrr|r}
\hline 1D-OV / 1D-UV & $0,00 \%$ & $0,10 \%$ & $0,50 \%$ & $0,40 \%$ & $0,10 \%$ & $0,00 \%$ & $\mathbf{0 , 1 8 \%}$ \\
1D-UV & $0,30 \%$ & $0,69 \%$ & $0,79 \%$ & $0,60 \%$ & $0,60 \%$ & $0,00 \%$ & $\mathbf{0 , 5 0 \%}$ \\
3D-UV & $1,19 \%$ & $1,49 \%$ & $0,40 \%$ & $0,00 \%$ & $0,00 \%$ & $0,00 \%$ & $\mathbf{0 , 5 1 \%}$ \\
2D-UV & $0,60 \%$ & $0,79 \%$ & $0,69 \%$ & $1,79 \%$ & $0,89 \%$ & $0,00 \%$ & $\mathbf{0 , 7 9 \%}$ \\
2D-OV & $1,98 \%$ & $2,38 \%$ & $2,58 \%$ & $2,88 \%$ & $1,19 \%$ & $0,10 \%$ & $\mathbf{1 , 8 5 \%}$ \\
1D-OV & $1,59 \%$ & $3,57 \%$ & $2,18 \%$ & $2,68 \%$ & $1,79 \%$ & $0,00 \%$ & $\mathbf{1 , 9 7 \%}$ \\
3D-OV & $93,95 \%$ & $90,08 \%$ & $92,46 \%$ & $91,67 \%$ & $95,44 \%$ & $99,90 \%$ & $\mathbf{9 3 , 9 2 \%}$ \\
\hline TOTAL & $100 \%$ & $100 \%$ & $100 \%$ & $100 \%$ & $100 \%$ & $100 \%$ & $\mathbf{1 0 0 \%}$ \\
\hline
\end{tabular}

\section{6 - PROBABILIDADE DE OCORRÊNCIAS EM MARABÁ}

Tabela 6 - Situações em Marabá

\begin{tabular}{c|rrrrrr|r}
\hline Situações & $1 / 8$ a $7 / 8$ & $8 / 8$ a 14/8 & $15 / 8$ a $21 / 8$ & $22 / 8$ a $28 / 8$ & $29 / 8$ a $4 / 9$ & $5 / 9$ a $11 / 9$ & $\mathbf{1} / 8$ a 11/9 \\
\cline { 2 - 7 } 3D-OV / 1D-OA & $0,00 \%$ & $0,10 \%$ & $0,00 \%$ & $0,00 \%$ & $0,00 \%$ & $2,08 \%$ & $\mathbf{0 , 3 6 \%}$ \\
3D-OV & $0,10 \%$ & $0,00 \%$ & $6,05 \%$ & $0,20 \%$ & $0,00 \%$ & $2,28 \%$ & $\mathbf{1 , 4 4 \%}$ \\
3D-OV / 2D-OA & $0,10 \%$ & $0,20 \%$ & $0,40 \%$ & $0,00 \%$ & $0,00 \%$ & $31,65 \%$ & $\mathbf{5 , 3 9 \%}$ \\
3D-OV / 2D-UA & $3,27 \%$ & $17,36 \%$ & $0,10 \%$ & $38,79 \%$ & $99,21 \%$ & $59,33 \%$ & $\mathbf{3 6 , 3 4 \%}$ \\
3D-OV / 1D-UA & $96,53 \%$ & $82,34 \%$ & $93,45 \%$ & $61,01 \%$ & $0,79 \%$ & $4,66 \%$ & $\mathbf{5 6 , 4 6 \%}$ \\
\hline TOTAL & $100,00 \%$ & $100,00 \%$ & $100,00 \%$ & $100,00 \%$ & $100,00 \%$ & $100,00 \%$ & $\mathbf{1 0 0 , 0 0 \%}$ \\
\hline
\end{tabular}

\section{7 - PROBABILIDADE DE OCORRÊNCIAS EM MIRACEMA}

Tabela 7 - Situações em Miracema

\begin{tabular}{c|rrrrrr|r}
\hline Situações & $1 / 8$ a $7 / 8$ & $8 / 8$ a 14/8 & $15 / 8$ a $21 / 8$ & $22 / 8$ a $28 / 8$ & $29 / 8$ a $4 / 9$ & $5 / 9$ a 11/9 & $\mathbf{1 / 8} a \mathbf{1 1 / 9}$ \\
\cline { 2 - 8 } 3D-OV & $0,00 \%$ & $0,20 \%$ & $0,00 \%$ & $0,00 \%$ & $0,00 \%$ & $0,00 \%$ & $\mathbf{0 , 0 3 \%}$ \\
3D-UV / 1D-OA / 1D-UA & $0,00 \%$ & $0,10 \%$ & $0,20 \%$ & $0,00 \%$ & $0,00 \%$ & $0,00 \%$ & $\mathbf{0 , 0 5 \%}$ \\
3D-OV / 1D-OA / 1D-UA & $0,10 \%$ & $0,20 \%$ & $0,10 \%$ & $0,00 \%$ & $0,00 \%$ & $0,00 \%$ & $\mathbf{0 , 0 7 \%}$ \\
3D-OV / 1D-OA & $99,90 \%$ & $99,50 \%$ & $99,70 \%$ & $100,00 \%$ & $100,00 \%$ & $100,00 \%$ & $\mathbf{9 9 , 8 5 \%}$ \\
\hline TOTAL & $100,00 \%$ & $100,00 \%$ & $100,00 \%$ & $100,00 \%$ & $100,00 \%$ & $100,00 \%$ & $\mathbf{1 0 0 , 0 0 \%}$ \\
\hline
\end{tabular}




\section{8 - PROBABILIDADE DE OCORRÊNCIAS EM PRESIDENTE DUTRA - TSPD}

Tabela 8 - Situações em Presidente Dutra - TSPD

\begin{tabular}{c|rrrrrr|r}
\hline Situações & $1 / 8$ a 7/8 & $8 / 8$ a 14/8 & $15 / 8$ a 21/8 & $22 / 8$ a 28/8 & $29 / 8$ a $4 / 9$ & $5 / 9$ a 11/9 & $\mathbf{1 / 8}$ a 11/9 \\
\cline { 2 - 8 } 3D-OV / 1D-OA & $0,00 \%$ & $0,00 \%$ & $0,10 \%$ & $0,00 \%$ & $0,00 \%$ & $0,00 \%$ & $\mathbf{0 , 0 2 \%}$ \\
3D-OV / 1D-UA & $0,00 \%$ & $0,00 \%$ & $0,00 \%$ & $0,00 \%$ & $0,00 \%$ & $3,27 \%$ & $\mathbf{0 , 5 5 \%}$ \\
3D-OV & $100,00 \%$ & $100,00 \%$ & $99,90 \%$ & $100,00 \%$ & $100,00 \%$ & $96,73 \%$ & $\mathbf{9 9 , 4 4 \%}$ \\
\hline TOTAL & $100,00 \%$ & $100,00 \%$ & $100,00 \%$ & $100,00 \%$ & $100,00 \%$ & $100,00 \%$ & $\mathbf{1 0 0 , 0 0 \%}$ \\
\hline
\end{tabular}




\section{APÊNDICE B}

Os gráficos resultantes das avaliações de distribuição no tempo das situações de desequilíbrio dos locais estudados no capítulo 4 encontram-se relacionados neste apêndice.

\section{1 - DISTRIBUIÇÃO NO TEMPO NA ALBRÁS}
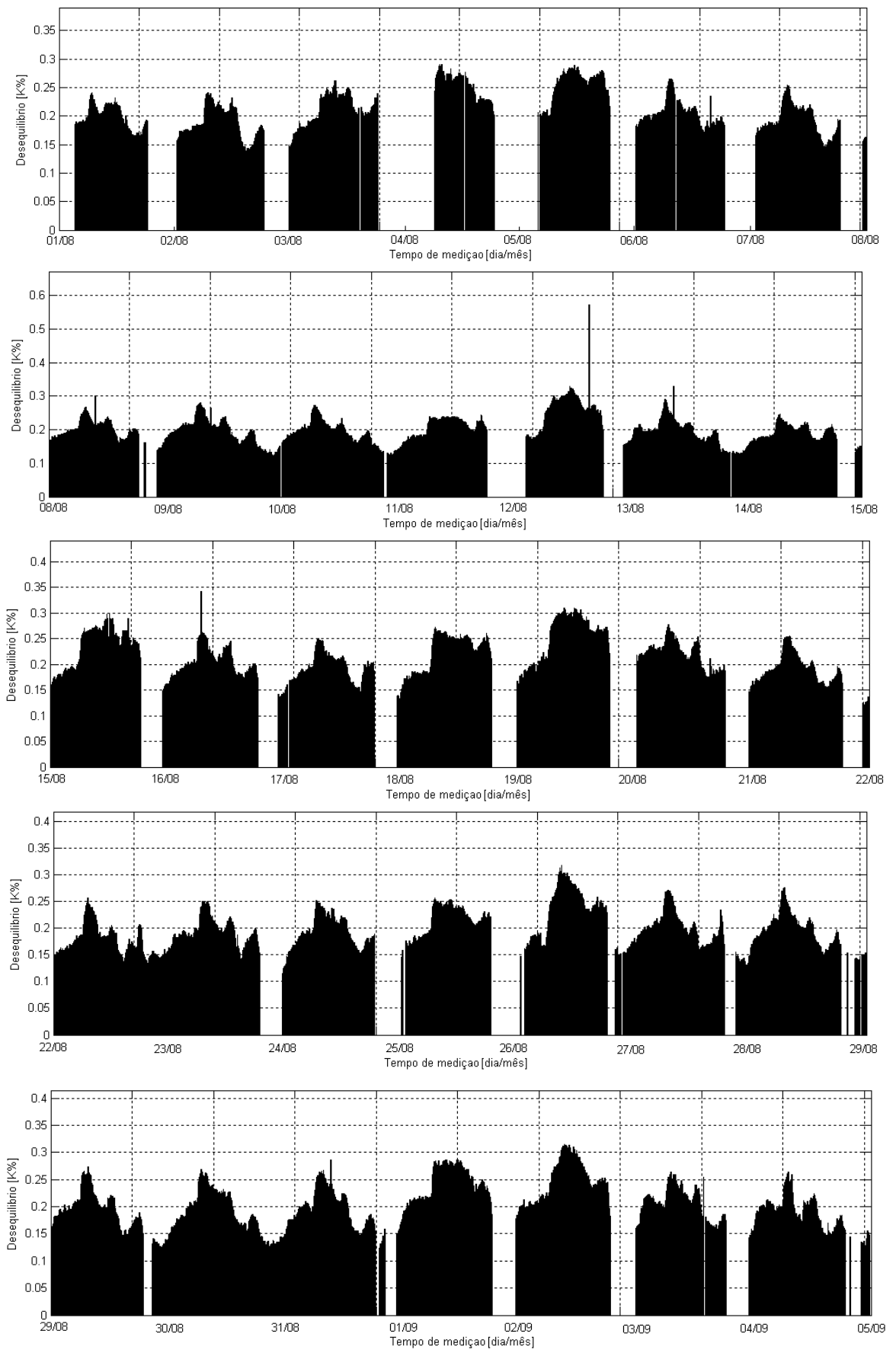


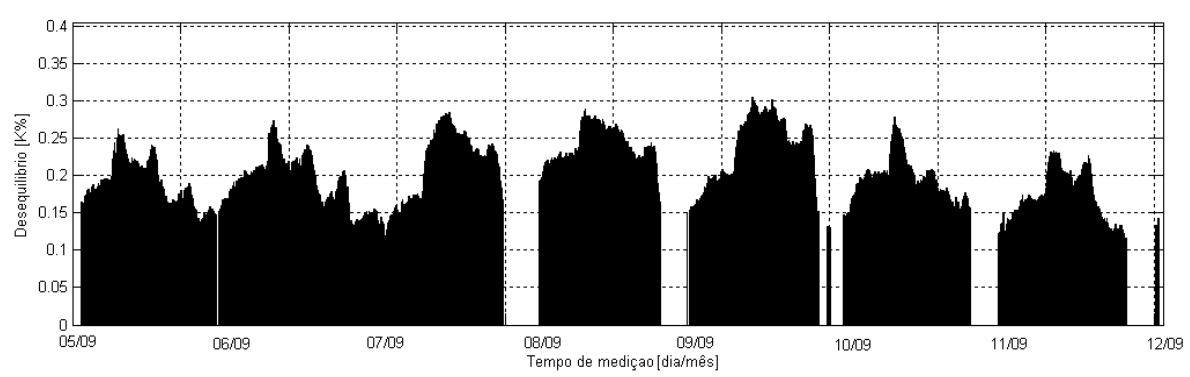

Figura 1 - Distribuição no tempo de 3D-OV na Albrás

\section{2 - DISTRIBUIÇÃO NO TEMPO NA ALUMAR}
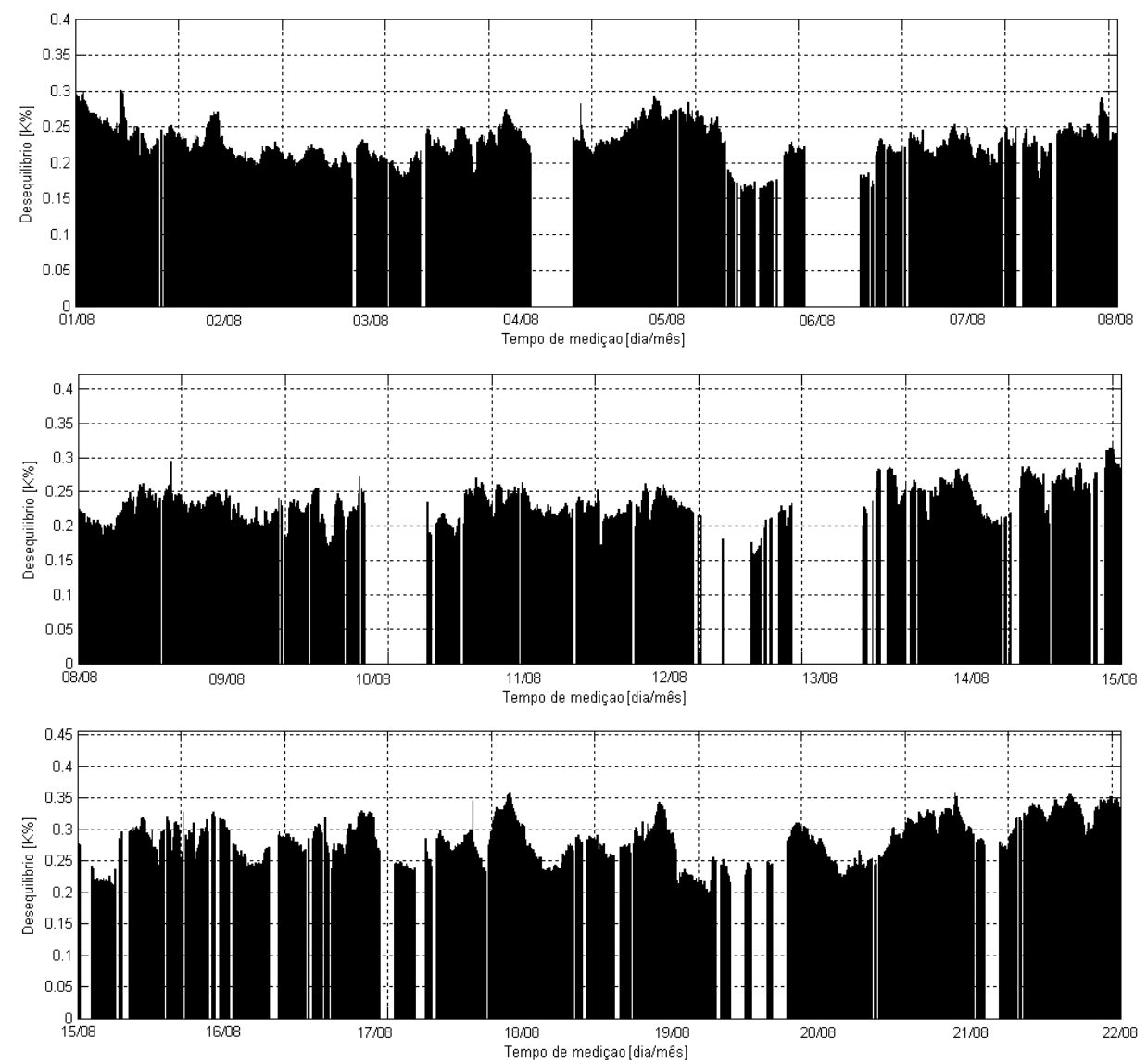

Figura 2 - Distribuição no tempo na Alumar de 3D-OV/1D-OA/1D-UA de 15 a 21/08 de 2007 


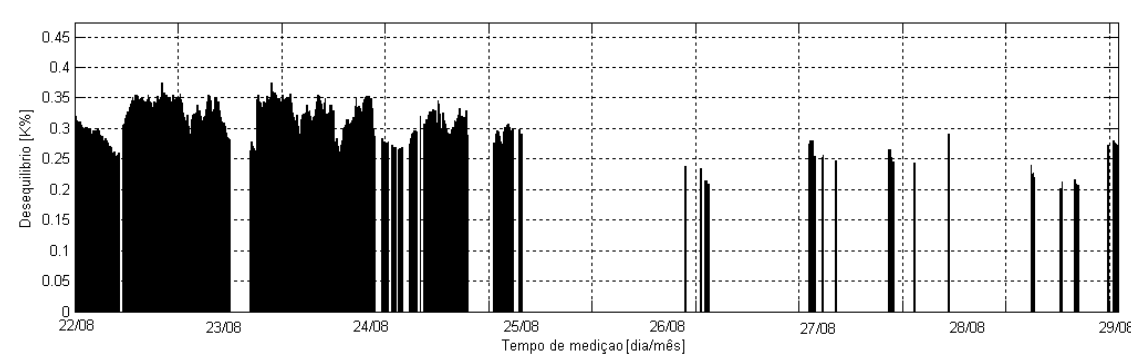

3D-OV/1D-OA/1D-UA

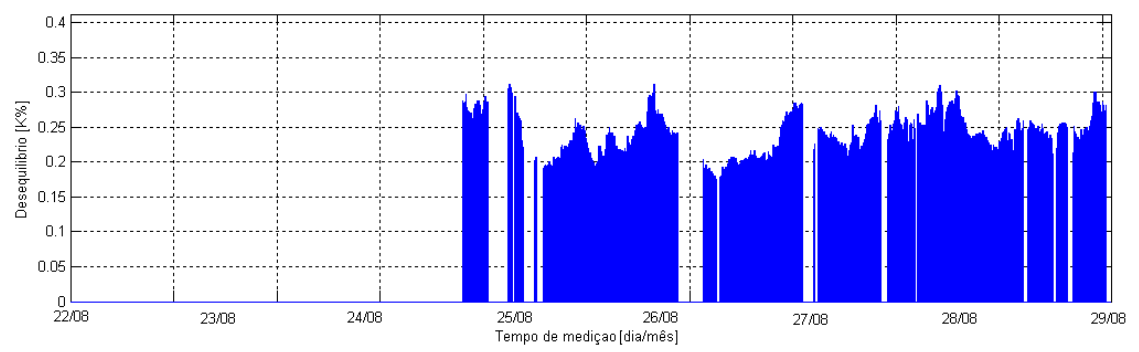

3D-OV / 1D-OA

Figura 3 - Distribuição no tempo na Alumar de 22 a 28/08 de 2007

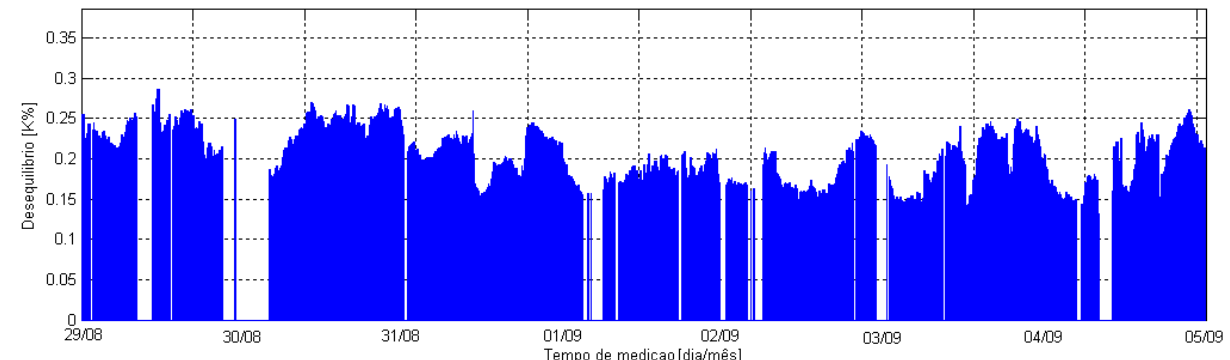

Figura 4 - Distribuição no tempo na Alumar de 3D-OV/1D-OA de 29/08 a 04/09 de 2007

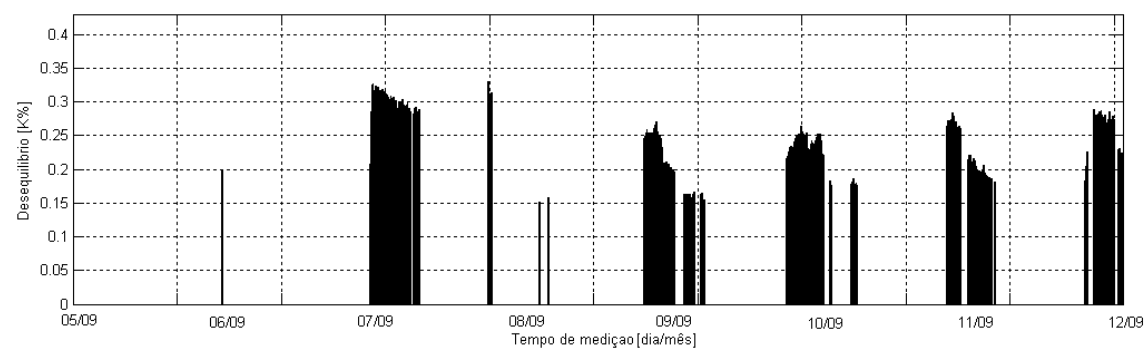

3D-OV/1D-OA/1D-UA

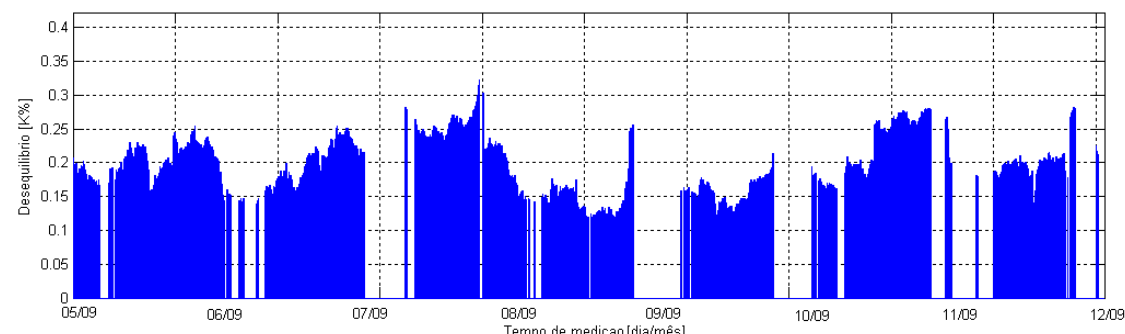

3D-OV / 1D-OA

Figura 5 - Distribuição no tempo em Alumar de 05 a 11/09 de 2007 


\section{3 - DISTRIBUIÇÃO NO TEMPO NA ALUNORTE}
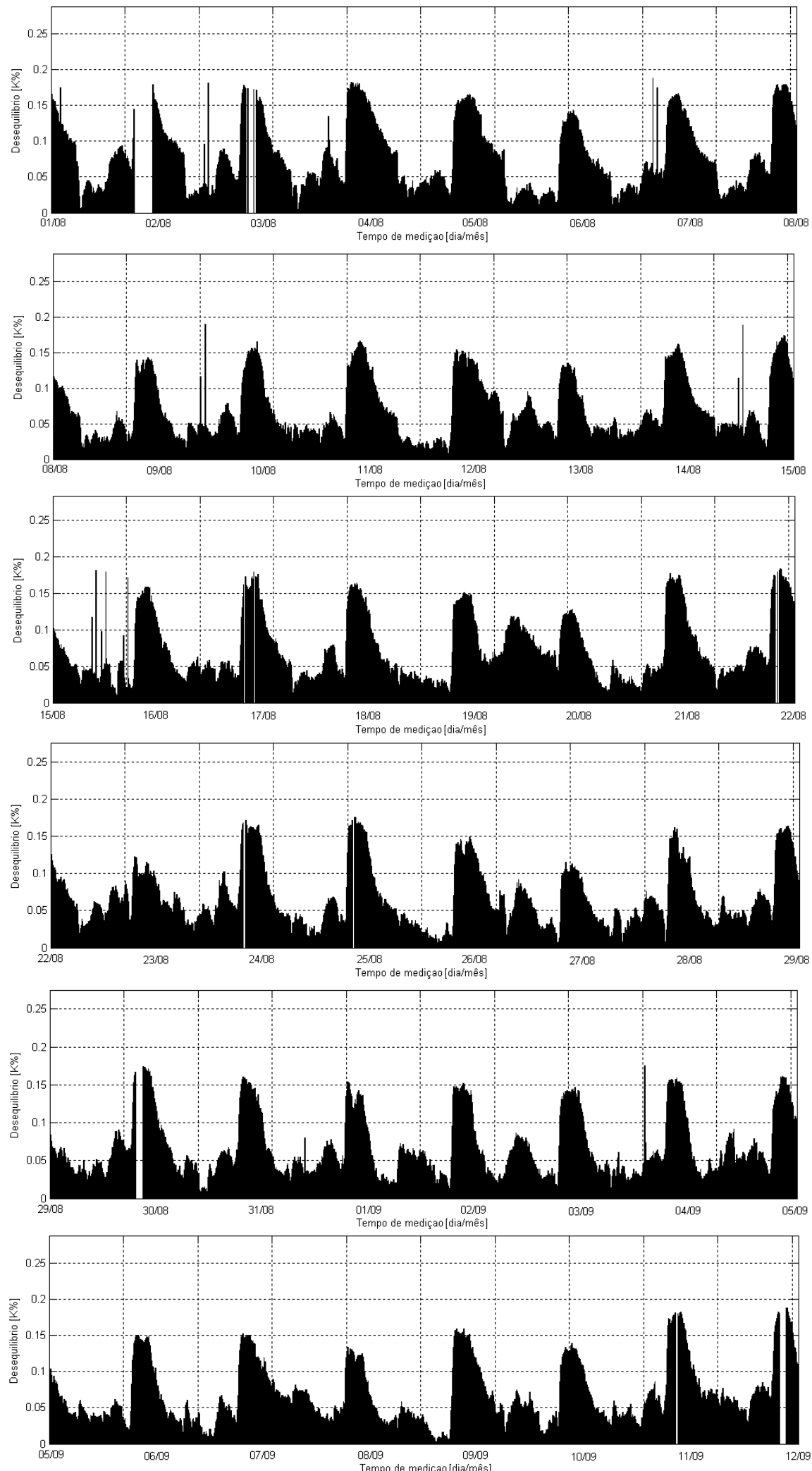

Figura 6 - Distribuição no tempo de 3D-OV em Alunorte 


\section{4 - DISTRIBUIÇÃO NO TEMPO NA CAMARGO CORREA METAIS - CCM}
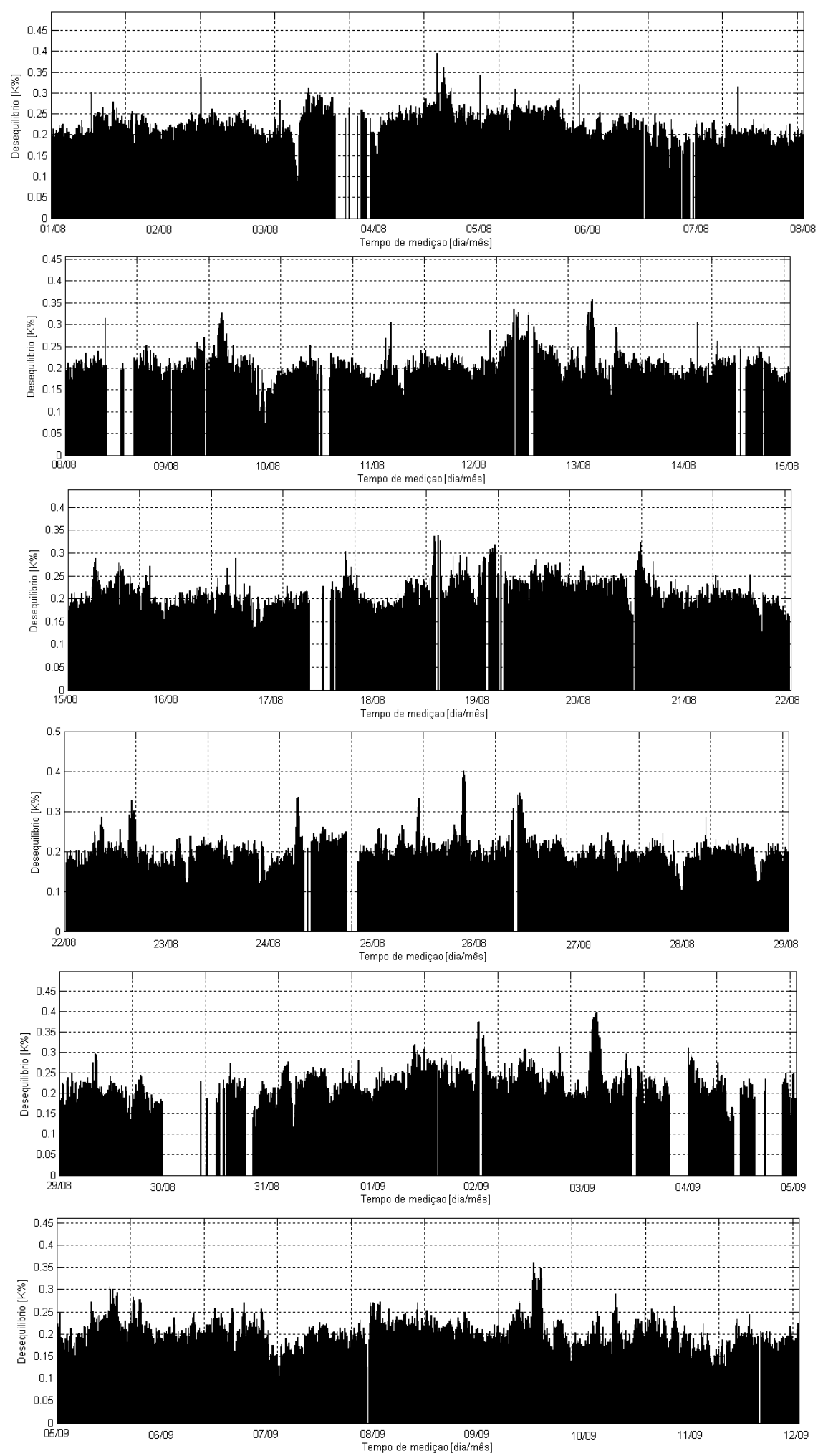

Figura 7 - Distribuição no tempo de 3D-UV na CCM 


\section{5 - DISTRIBUIÇÃO NO TEMPO EM CVRD SÃO LUÍS}
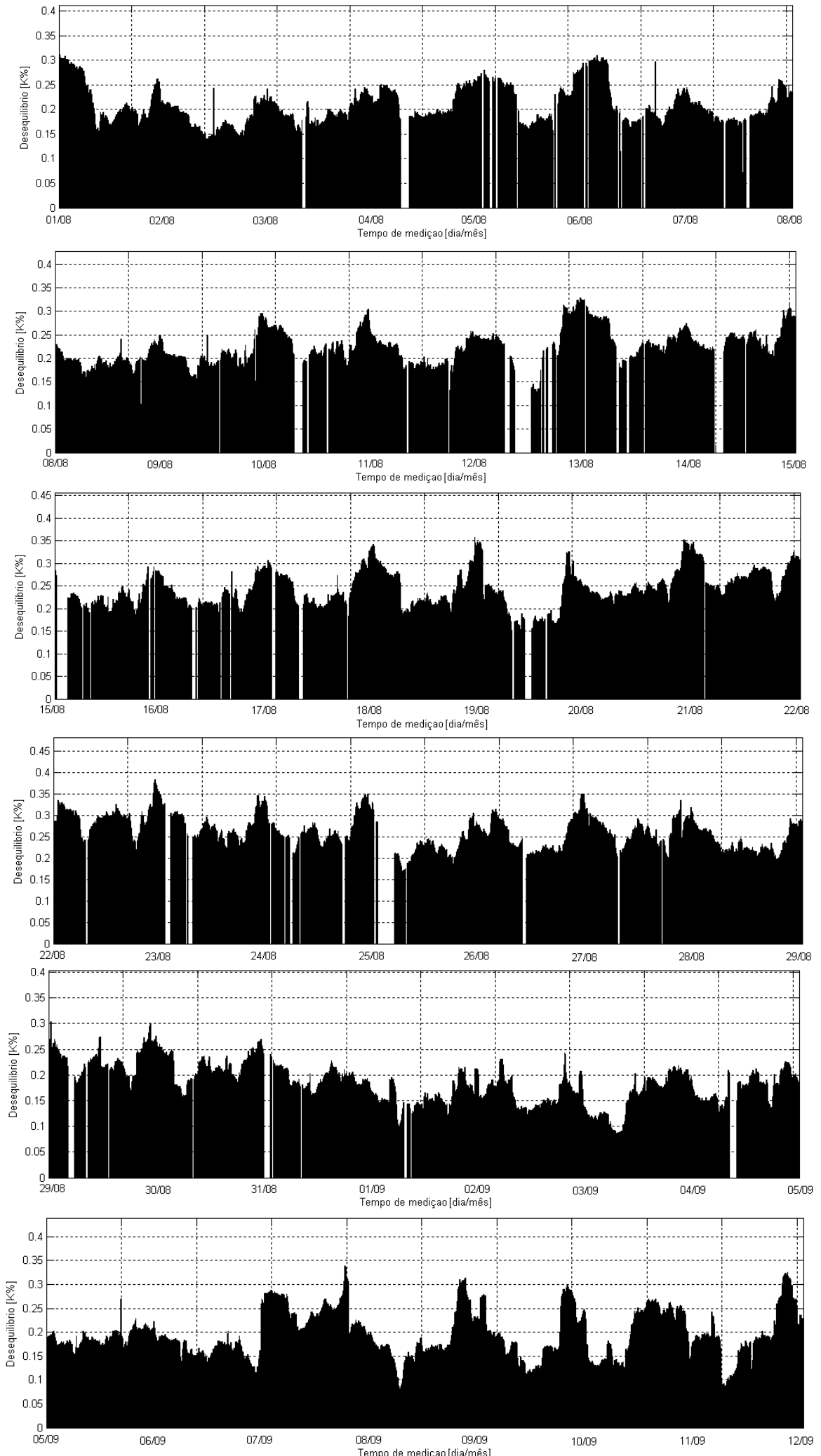

Figura 8 - Distribuição no tempo de 3D-OV em CVRD São Luís 


\section{6 - DISTRIBUIÇÃO NO TEMPO EM MARABÁ}
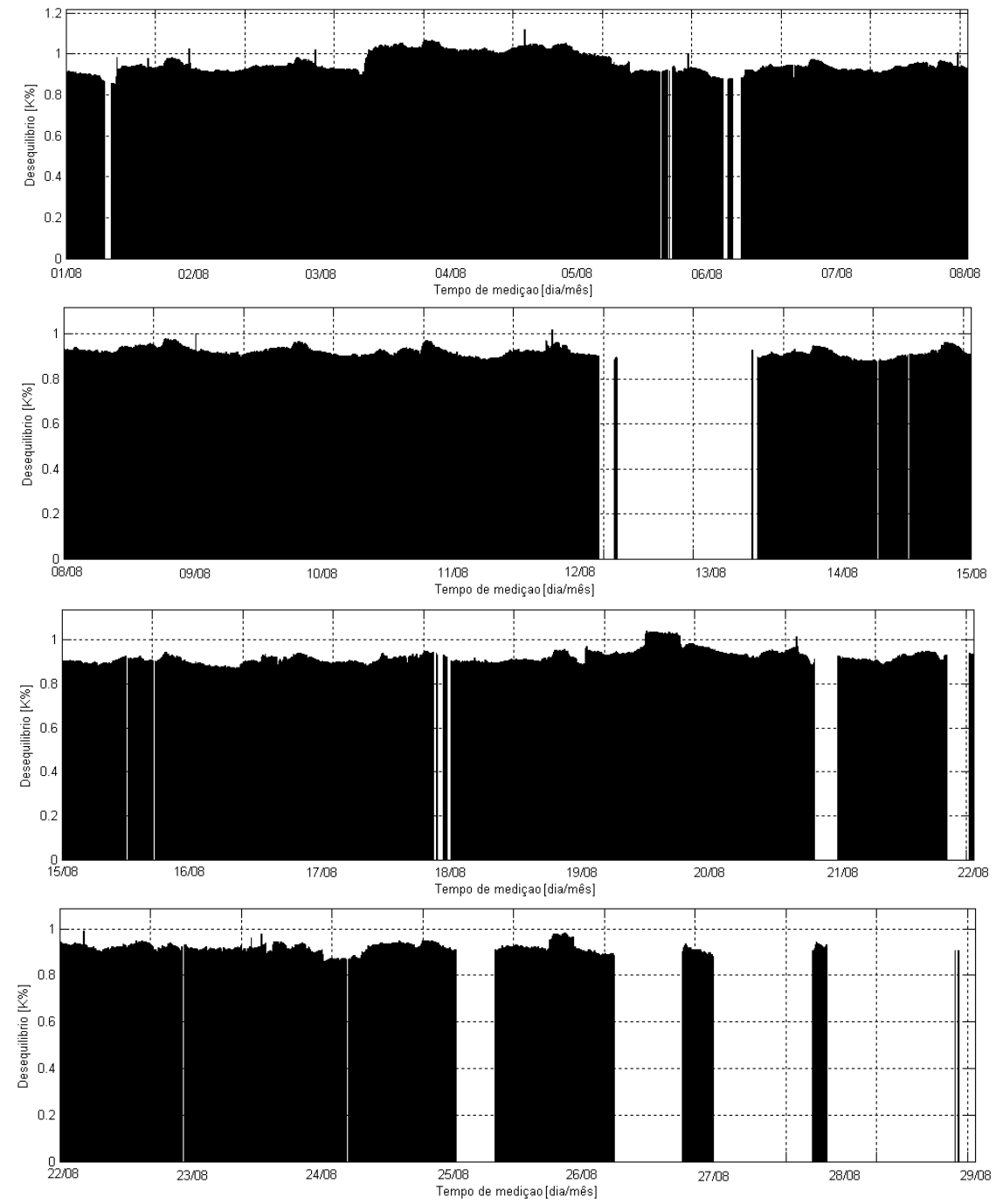

Figura 9 - Distribuição no tempo de 3D-OV/1D-UA em Marabá de 01 a 28/08 de 2007

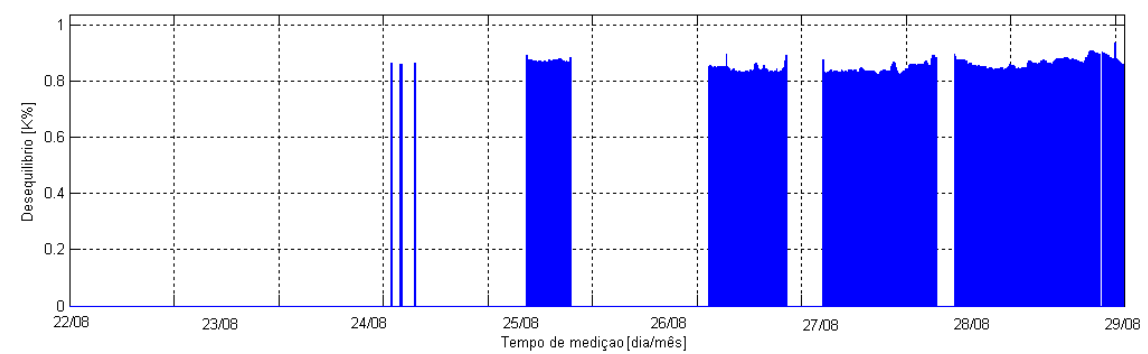

Figura 10 - Distribuição no tempo de 3D-OV/2D-UA em Marabá de 22 a 28/08 de2007 


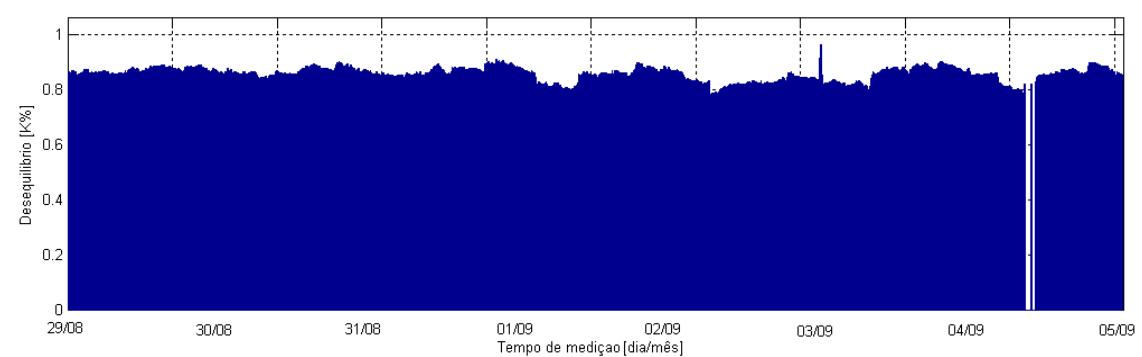

Figura 11 - Distribuição no tempo de 3D-OV/2D-UA em Marabá de 29/08 a 04/09 de 2007

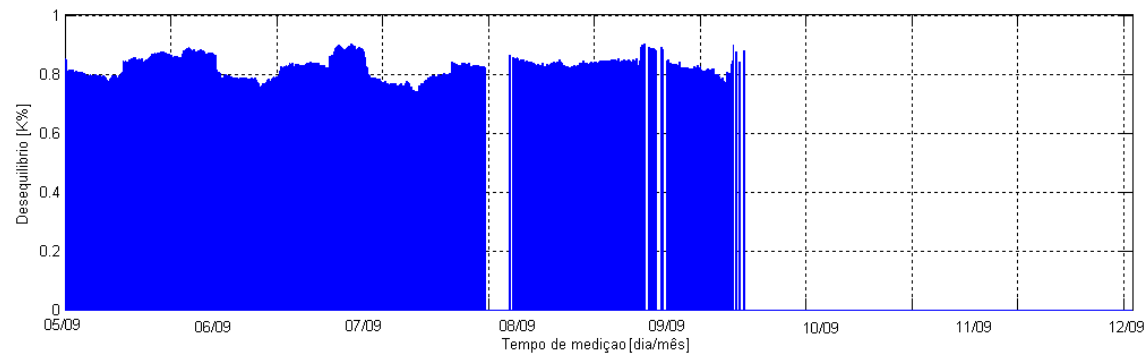

3D-OV/2D-UA

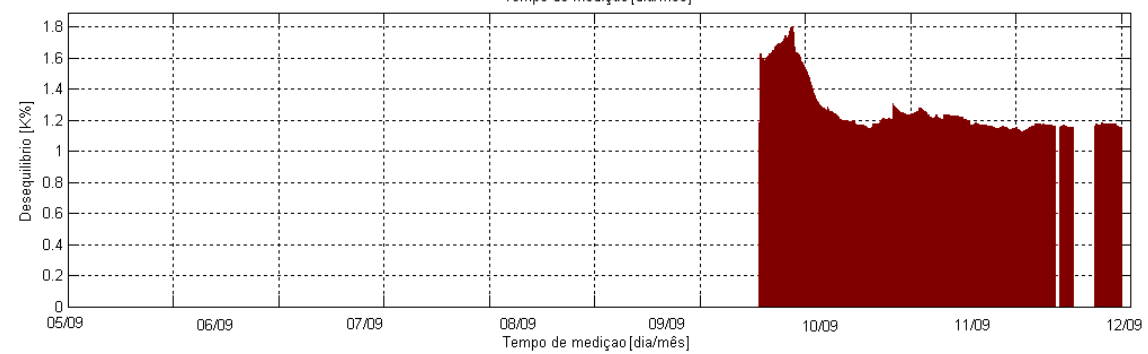

$3 \mathrm{D}-\mathrm{OV} / 2 \mathrm{D}-\mathrm{OA}$

Figura 12 - Distribuição no tempo em Marabá de 5 a 11/09 de 2007

\section{7 - DISTRIBUIÇÃO NO TEMPO EM MIRACEMA}
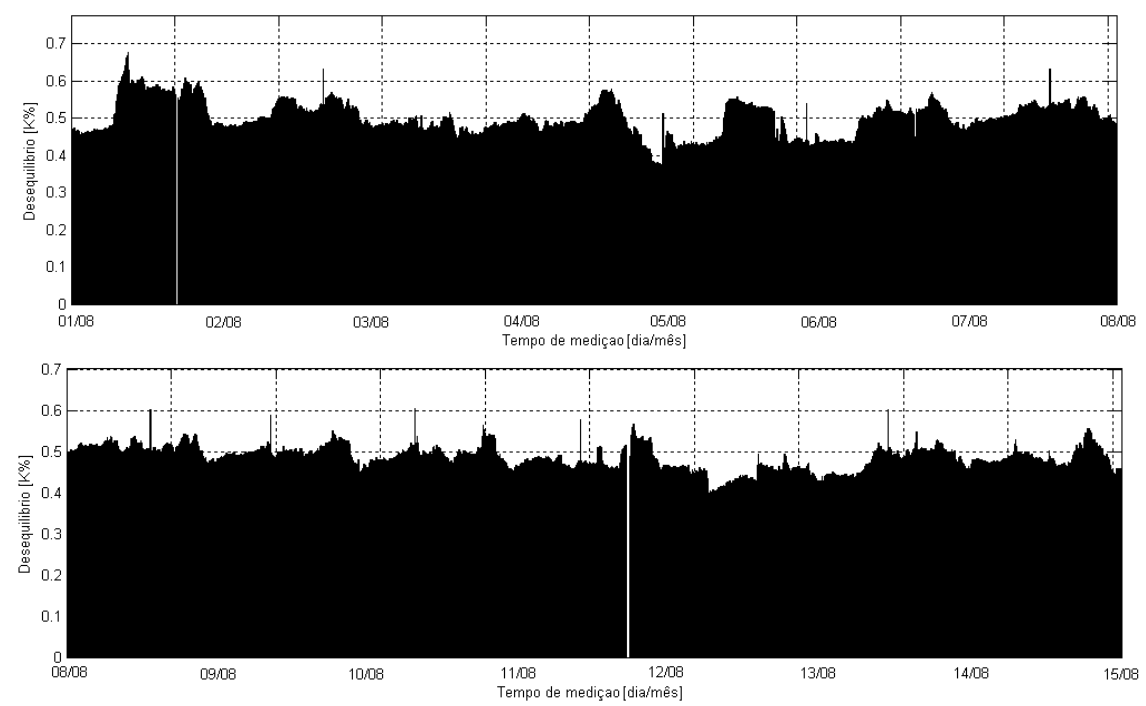

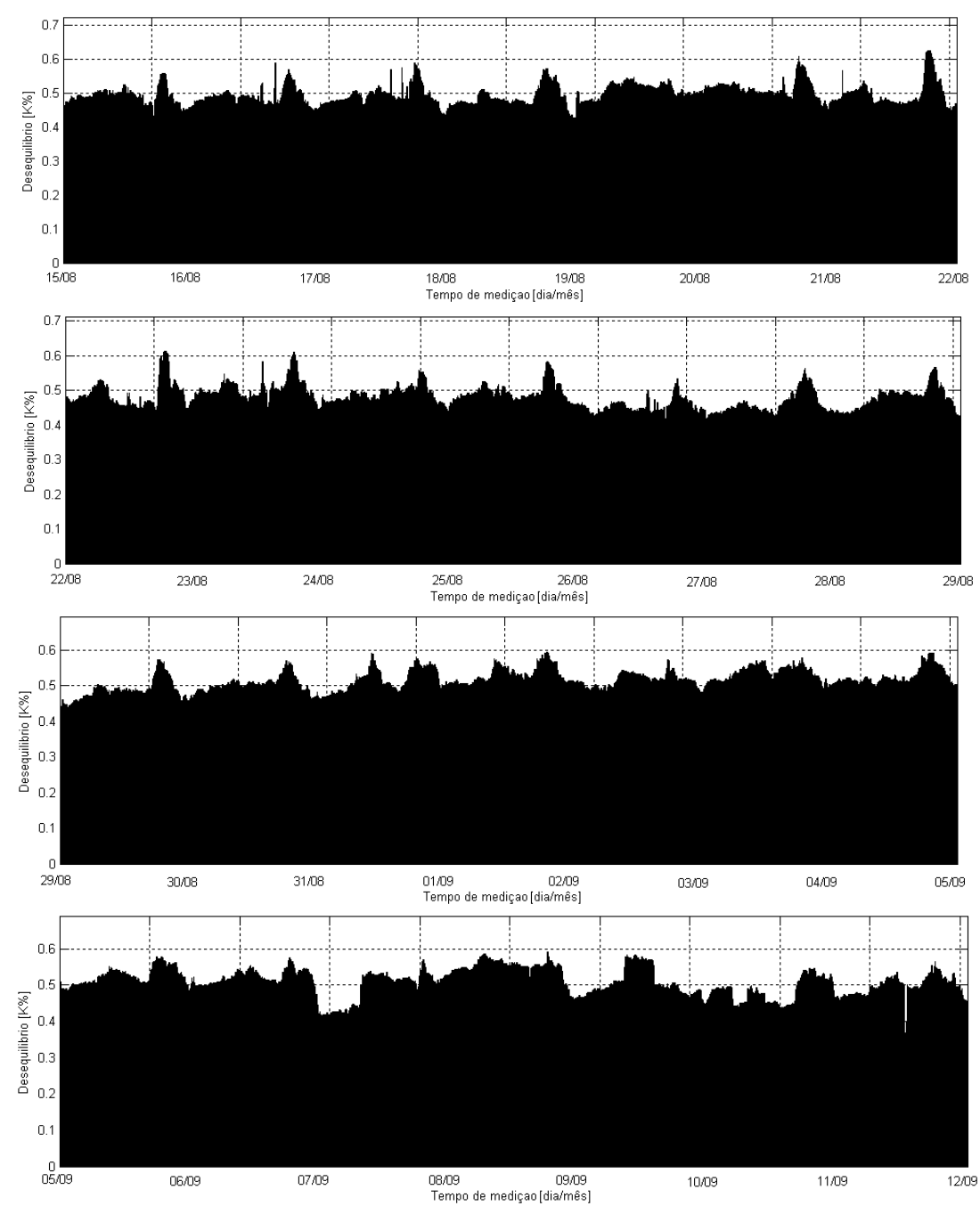

Figura 13 - Distribuição no tempo de 3D-OV/1D-OA em Miracema 
8 - DISTRIBUIÇÃO NO TEMPO EM TSPD - PRESIDENTE DUTRA
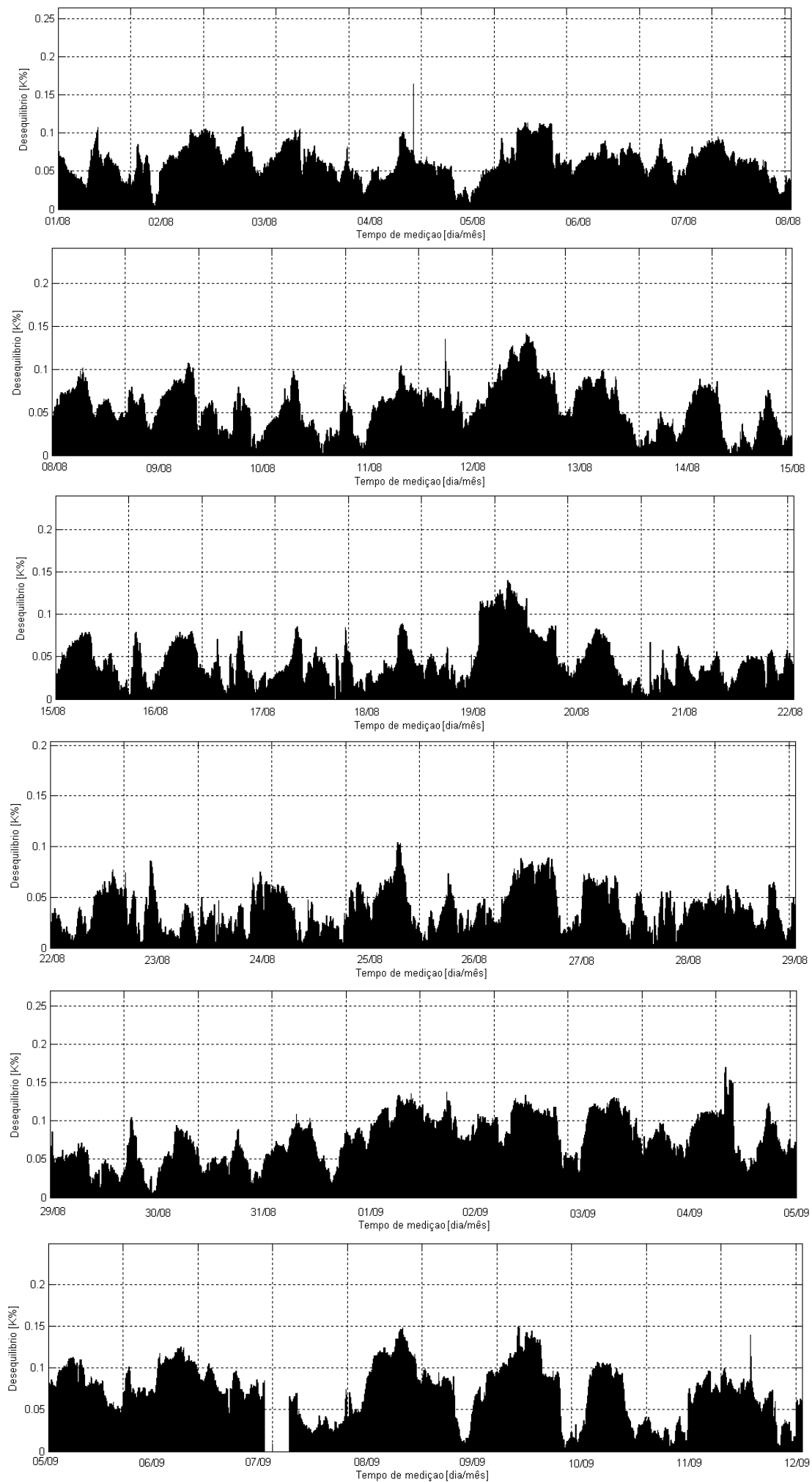

Figura 14 - Distribuição no tempo de 3D-OV em TSPD 